A 3501 - 726 ?

Kelarence

\title{
NBSIR 78-1489
}

\section{Building Regulatory Data Analysis National Solar Heating and Cooling Demonstration Program Progress Report - From Inception through September 30,1977}

Joseph Greenberg

Sandra Berry

lleana Martinez

Building Economics and Regulatory Technology Division

Center for Building Technology

National Engineering Laboratory

National Bureau of Standards

Washington, D.C. 20234

June 1978

Prepared for

Office of Policy Development and Research

Division of Energy, Building Technology and Standards

U.S. Department of Housing and Urban Development

Washington, D.C. 20234

and

Office of the Assistant Secretary

Conservation and Solar Applications

J.S. Department of Energy

Nashington, D.C. 20545 
. 
NBSIR 78-1489

ABs

BUILDING REGULATORY DATA

ANALYSIS NATIONAL SOLAR

HEATING AND COOLING

DEMONSTRATION PROGRAM

PROGRESS REPORT - From

Inception through September

30,1977

Joseph Greenberg

Sandra Berry

lleana Martinez

Building Economics and Regulatory Technology Division

Center for Building Technology

National Engineering Laboratory

National Bureau of Standards

Washington, D. C. 20234

June 1978

Prepared for

Office of Policy Development and Research

Division of Energy, Building Technology and Standards

U.S. Department of Housing and Urban Development

Washington, D.C. 20410

and

Office of the Assistant Secretary

Conservation and Solar Applications

U.S. Department of Energy

Washington, D.C. 20545

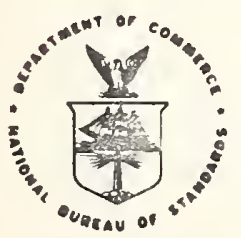

U.S. DEPARTMENT OF COMMERCE, Juanita M. Kreps, Secretary

Dr. Sidney Harman, Under Secretary

Jordan J. Baruch, Assistant Secretary for Science and Technology

NATIONAL BUREAU OF STANDARDS. Ernest Ambler, Director 



\section{BUILDING REGULATORY DATA \\ ANALYSIS NATIONAL SOLAR \\ HEATING AND COOLING \\ DEMONSTRATION PROGRAM \\ PROGRESS REPORT - From \\ Inception through September}

30, 1977

Joseph Greenberg

Sandra Berry

lleana Martinez

Building Economics and Regulatory Technology Division

Center for Building Technology

National Engineering Laboratory

National Bureau of Standards

Washington, D. C. 20234

June 1978

Prepared for

Office of Policy Development and Research

Division of Energy, Building Technology and Standards

U.S. Department of Housing and Urban Development

Washington, D.C. 20410

and

Office of the Assistant Secretary

Conservation and Solar Applications

U.S. Department of Energy

Washington, D.C. 20545

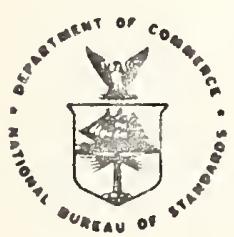

U.S. DEPARTMENT OF COMMERCE, Juanita M. Krops, SOcreqaY

Dr. Sidnoy Harman, Under Secretary

Jordan J. Baruch. Assistant Secretary for Science and Technology

NATIONAL BUREAU OF STANDARDS, Ernest Ambler, Director 
' 
1. Introduction . . . . . . . . . . . . . . . . . . . 1

2. Project Description . . . . . . . . . . . . . . . . 3

3. Yethodology . . . . . . . . . . . . . . . . . . 5

4. Identification of Data Sources and Instruments Applicable to the Solar Regulatory Study . . . . . . . . . . . . . . . 1

4.1 Residential Program . . . . . . . . . . . . . . . . 10

4.2 Commercial Program . . . . . . . . . . . . . . . 15

5. Status of Data . . . . . . . . . . . . . . . 19

5.l Residential Program . . . . . . . . . . . . . . 19

5.2 Commercial Program . . . . . . . . . . . . . . . 27

6. Analysis of Code Data... . . . . . . . . . . . . . 32

6.] Residential Solar Demonstration Sites . . . . . . . . . 32

6.1.1 Distribution of Sites . . . . . . . . . . . . 3-

6.1 .2 Distribution of New and Retrofit Sites . . . . . . 4 42

6.1.3 Conclusion . . . . . . . . . . . . . . 45

6.2 Comercial Solar Demonstration Sites . . . . . . . . . . 45

6.2.1 Distribution of Sites.............. . . 45

6.2.2 Distribution of Building Type . . . . . . . . . 52

6.2.3 Conclusion . . . . . . . . . . . . . 55

7. Preliminary Results and Future Actions . . . . . . . . . . . . 5 n

๕. Summary. . . . . . . . . . . . . . . . . . . . 50

APPENDIX I Data Collection Instruments . . . . . . . . . . . . 59

APPENDIX II Literature Survey . . . . . . . . . . . . . . . $9 \varepsilon$

APPENDIX III Building Regulatory Process . . . . . . . . . . . . 106 
FIGURES

Page

Figure 1. Project Methodology . . . . . . . . . . . . . 6

Figure 2. RERC Data Collection Instruments . . . . . . . . . . . . 11

Figure 3. AIA/RC Data Collection Instruments . . . . . . . . . . . . 14

Figure 4. HUD/Boeing Data Collection Instruments . . . . . . . . . . 16

Figure 5. PRC Data Collection Instruments . . . . . . . . . . . . 18

Figure 6. Statewide and Major Cities Building Codes: Technical Basis

for Regulations in Existence (Map) . . . . . . . . . . . 33

Figure 7. Residential Program Site/Population Distribution in Cycles . . 4 $1,2,3$ (Total New and Retrofit Sites)

Figure 8. Residential Program. Site/Population Distribution in Cyclea . 43 1, 2, 3 (Total New Sites)

Figure 9. Residential Program. Site/Population Distribution in Cycles . A. 1, 2, 3 (Total Retrofit Sites)

Figure 10. Commercial Program. Site/Population Distribution in Cycles . 5 C 1, 2 (Total New and Retrofit Sites)

\section{TABLES}

Table 1. Regulatory Data Summary - Residential Program - Cycle l • . 21

Table 2. Regulatory Data Summary - Residential Program - Cycle 2 • • • 23

Table 3. Regulatory Data Summary - Commercial Program - Cycle 1 . . . 30

Table 4. Residential Program. Sites Per Cycle and Model Code Base • . 35

Table 5. Residential Program. Building Code Distribution . . . . . . 3i

Table 6. Residential Program. Sumary of Code Distribution . . . . . 3o

Table 7. Commercial Program. Sites Per Cycle and Model Code Base . . . 46

Table 8. Commercial Program. Building Code Distribution . . . . . . 48

Table 9. Commercial Program. Summary of Code Distribution . . . . . . 49

Table 10. Commercial Program. Building Types by State in Cycles 1 and 2. 53 


\section{INTRODUCTION}

This report is prepared jointly for the Department of Housing and Urban Development (HLD) and the Department of Energy (DoE) under activities carried out by the National Bureau of Standards (NBS) relative to the National Solar Heating and Cooling Demonstration Programs. The report encompasses botr: the residential and commercial building demonstration programs and covers the period from project inception through september 30, 1977.

The effort expended during the period was in the identification and organization of sources of material, in the establishment of a methodolog: for processing data to be received from the demonstration programs relative to the building regulatory process and in the preliminary analyses of the sites selected for the early phases of the demonstration programs. In tir. context of this report, it is to be understood that the building regulator process excludes zoning questions.

It had been hoped that some analysis regarding problems being encountered in the field with code officials or barriers presented by existing codes and standards would be included in this report. However, due to the scarcity of this information during the time period covered, no analysis is possible. The report, nevertheless, contains several observations relative to the building regulatory process based on informal discussions with individuals collecting questionnaire data during the conduct of the demonstration programs. In addition, the current status regarding the availability of information for both the residential and commercial programs is reported.

This report also contains a preliminary analysis of the geographical and code base distribution of the demonstration sites selected for both the residential and commercial demonstration programs. This initial anal:sis identifies certain inconsistencies in site selection, from a regulator. viewpoint, and recommends adjustments to be considered in subsequent cycles of the programs. 
A brief literature search which addresses the problems of building regulation as related to the installation and use of solar energy systems is included as Appendix II. Although the literature cited points to codes as barriers to solar technology and advocates a performance based solution, the conclusions stated may not be supported by a subsequent analysis of the data gathered under the demonstration programs. However, judgment must be reserved until supporting data are gathered and analyzed. 


\section{PROJECT DESCRIPTION}

The objectives of this project are to work within the data gathering mechanisms established by HUD and DoE for the solar demonstration program: and to analyze this data and identify those aspects of the building regulatory process that needlessly inhibit, impede, or otherwise adversely affect the installation of solar hot water systems and space heating and/or cooling systems. In addition, definitive information will be compiled which will provide useful input to appropriate standards generating committees, building code promulgating organizations, and regulatory jurisdictions. This detailed information will guide the building regulatory community in the United States in creating a regulatory environment which will stimulate the acceptance of the use of solar hot water systems and space heating and/or cooling systems.

In order to accomplish the above objectives, this project is designed to provide:

a. An analysis of the building regulatory waivers granted throughout the demonstration programs to gain an insight into the technical causes for these waivers, and to develop recommended solutions to alleviate these regulatory constraints by identifying those areas where additional study is required.

b. An analysis of the response by the participants in the demonstration programs as to their real or perceived regulatory problems encountered during the conduct of the programs and recommendations for proposed solutions to alleviate these real or perceived regulatory difficulties.

c. An analysis of the adverse impacts, if any, resulting from differences in various regulatory statutes by identifying these difierences and providing recommended solutions. Toward this objective, "A Survey of State Legislation Relating to Solar Energy as of 1975" (NBSIR 76-1082) and "State Solar Energy Legislation of 1976: A Review of Statutes Relating to Building" (NBSIR 77-1297) will be useful in conducting this analysis. 
The demonstration programs are structured in a series of cycles, with various projects being awarded for each cycle. The HuD residential demonstration program is expected to have 5 cycles, while the DoE commercial cycles probably will not exceed 4. The analyses for this study are made on a cycle-by-cycle basis, using site-specific regulatory and other related data collected under both the residential and commercial programs. In addition, the effects of varying time frames for the respective cycles will be considered to determine any regulatory impacts on later installations, if early difficulties with solar hardiare and systems are encountered. Consolidated non-cycle related studies will also .. be prepared if meaningful assessments can be derived by such studies. 


\section{METHODOLOGY}

The methodology for this project is formatted to take full advantage oi the various data bases established by HUD and DoE for the solar demonstr tion programs. These overall data bases, when fully implemented, will contain a large amount of information and care must be taken to identify and capture all pertinent information so that a proper study can be made. Caution must be exercised, however, to establish a retrieval system that does not extract needless or superfluous information - a process that is costly and time consurit. and one which makes the task at hand more difficult. The methodology described in this report is developed for the collection of building regulatory information, but could be used for the study of any other aspect of the solar demonstration programs. The same methodology is used for both the residential and commercial programs.

The specific methodology used is shown in flow chart form in Figure 1. The identifying numbers are keyed to the flow chart in the following description:

(1) Identify Organizations Collecting Data - Each organization collecting data for the demonstration programs is identified. A single organization is performing this function for DoE in the commercial program and several organizations are involved in the HLD residential demonstrations. An understanding of each organization, its data collecting role, and its relationships to the other organizations involved is essential.

(2) Identify Data Collection Instruments - Each data collection instrument is identified. Since each instrument varies in style, format and use, an overall understanding of these instruments is required. Care must be taken to obtain the most current data collection instrument in use and liaison was established with the administering organization so that notification is received if any changes are made to them. The NBS also expects to recommend changes (see step 10), as warranted, to the building regulatory information being collected to assure that the information received is useful to the analysis. 


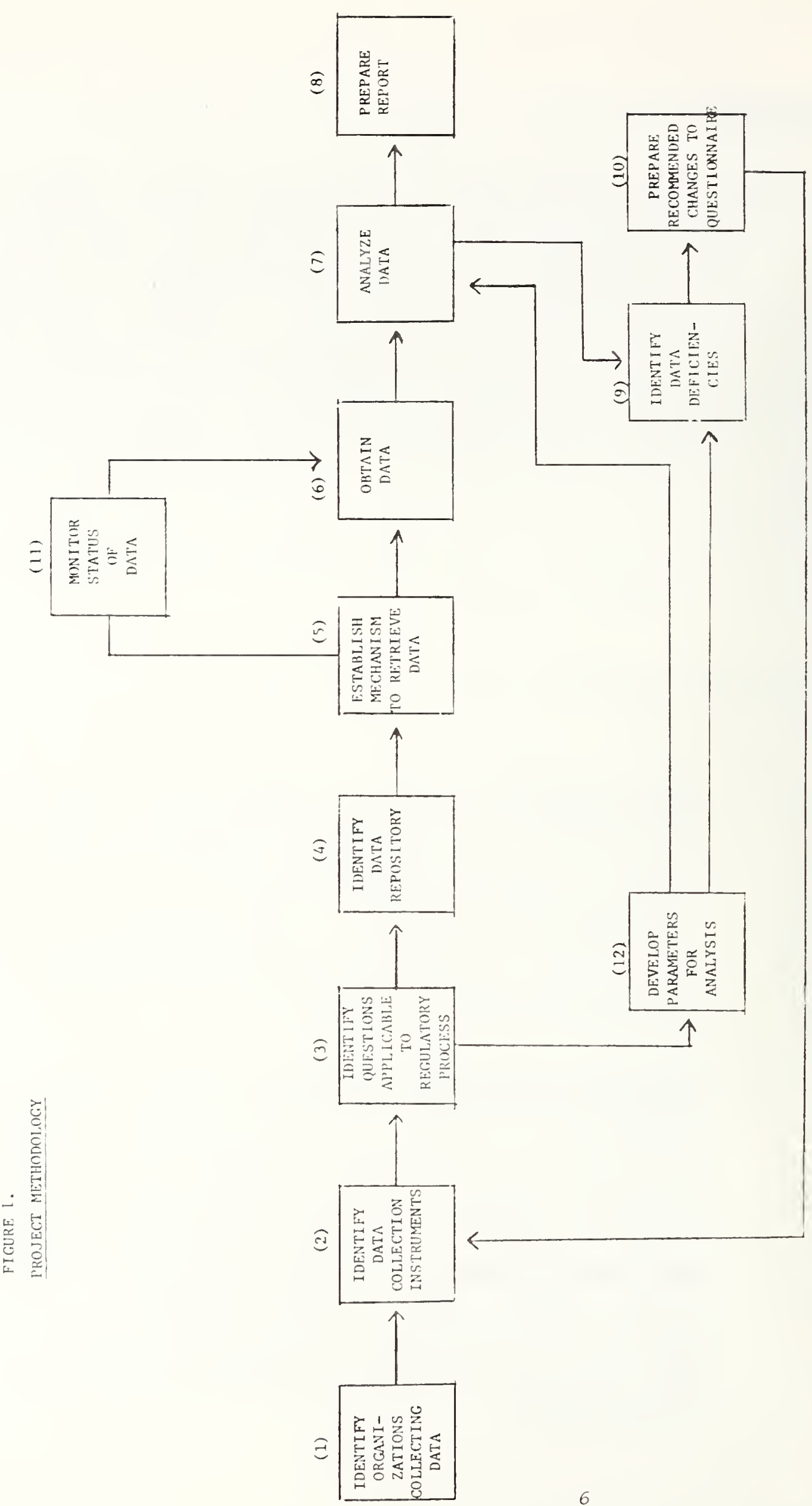


(3) Identify Questions Applicable to the Building Regulatory Process Each data collection instrument identified in step (2) is carefully reviewed and questions pertinent to, the building regulatory process selected as a primary information source for this study. The response to these identified questions represents the limits to any analysis made in the conduct of this study. However, the narrative responses which are, in effect, open ended co:ld contain information which. is not anticipated.

(4) Identify Data Repository - Once the determination is made regarding the questions of interest, the next step is to determine the location of the completed questionnaire. In most cases, the completed questionnaire is computer coded and the information entered into the NBS Solar Data Base. In these cases, printouts prepared for general use are made available for this study or special printouts requested. In some cases where the complete source documents are not forwarded to NBS, arrangements were made to obtain this data directly from the repository custodian.

(5) Establish Mechanism to Retrieve Data - Each source of data needed for this study will have to be available for analysis. As notec in step (4), some data come directly from the NBS Solar Data Base while other data come from different sources. In either case, the frequency for the receipt of these data must be determined and a mechanism developed to obtain the data in suitable format. A balance must be achieved in querying the data source to establish a frequency that is useful to the building regulatory process study, yet not too burdensome and disruptive to the data custodiar.

(6) Obtain Data - Data are received from the sources identified in stef (4) using the mechanism established in step (5) at the predetermined frequency. 
(7) Analyze Data - The data are aggregated and when a meaningful sample is obtained, it is analyzed. The analysis is oriented toward answering the questions addressed in the stated objectives of this project.

(8) Prepare Report - Once enough data are analyzed and meaningful trends determined, appropriate NBS publications are prepared to document these results.

(9) Identify Data Deficiencies - As data are received, deficiencies may be noted and, if not corrected, will preclude the development of reasonably reliable conclusions. Once deficiencies are identified, a feedback mechanism is set in motion to reassess the situation and take corrective action. In addition, potential data deficiencies may be identified through the development of parameters for analyses (see step 12), by reviewing the applicable questionnaires. Corrective action will be taken in this case. However, data may be of insufficient quantity to reach generally. valid conclusions.

(10) Prepare Recommended Changes to Questionnaire - This is accomplished at any point when it is felt the study lacks adequate data, either as a result of an inspection of data received or as a result of data requirements identified through analysis of the source questionnaires. Recommendations are made to the data collecting organizations to modify their data collection instruments, including the rationale behind such requests.

(11) Monitor Status of Data - The collection of data by the appropriatc organization is monitored so that the NBS effort is guided properly during the course of the study. Certain analyses are not started if additional data are forthcoming shortly or, conversely, analytical attempts are accomplished using only the data at hand if no additional data are anticipated. 
(12) Develop Parameters for Analyses - Based on the identification of the applicable questionnaires relative to building regulations, a preliminary attempt is made to determine the most meaningful parameters to be studied and the combinations which might give the best insight into satisfying the objectives of this stud: This parametric overview determines which data are important to the study. Data not identified as being included in the questonnaire are handled as noted in step (9). 
4. IDENTIFICATION OF DATA SOURCES AND INSTRLMENTS APPLICABLE TO THE SOIAR REGLLATORY STUDY

This section addresses the establishment of the baseline sources for this study and covers the first five (5) steps discussed under Section. 3 Methodology, and shown in Figure 1 :

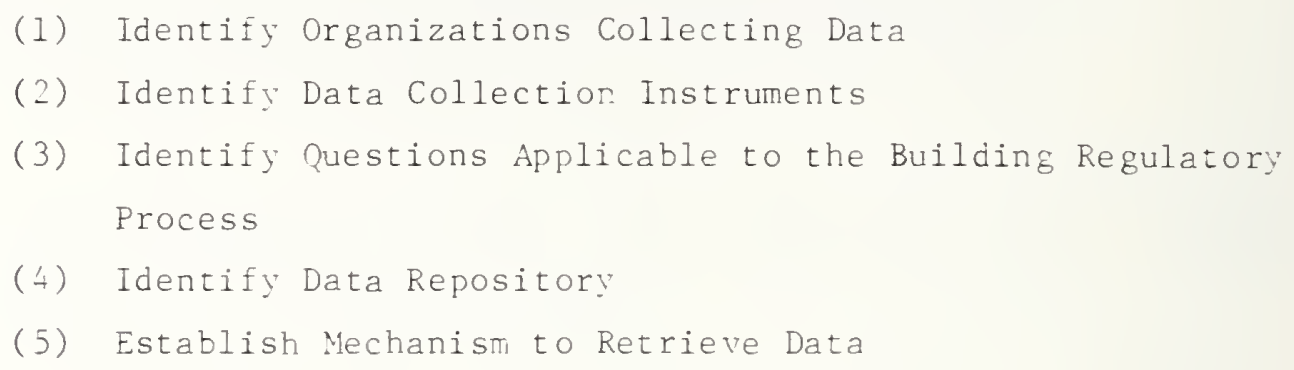

These five steps are documented, based on information available as 0 : September 30, 1977. Any changes in data sources or to the data collectia. instruments that are noted during the conduct of this study will be documented in subsequent reports.

\subsection{RESIDENTIAL PROGRAY}

Each of the organizations involved in collecting data for the Residential Solar Demonstration Program is identified separately. The data collecting instruments are indicated and the specific questions directly applicable to the building regulatory study are identified. Appendixes are included wich exhibit the instruments used and an inspection of these instruments gives ar. idea of the scope and depth of the questions.

\subsubsection{Real Estate Research Corporation (RERC)}

This organization prepared three volumes for use in the Residential Solar Demonstration Program. These volumes, dated January 1977, are all nontechnical in scope and are intended to document responses to questions oriented toward marketing, the consumer, and the institutional sectors. The general layout of these volumes is illustrated in Figure 2. A control mechanism is built into several of the questionnaires in that visits are planned to 


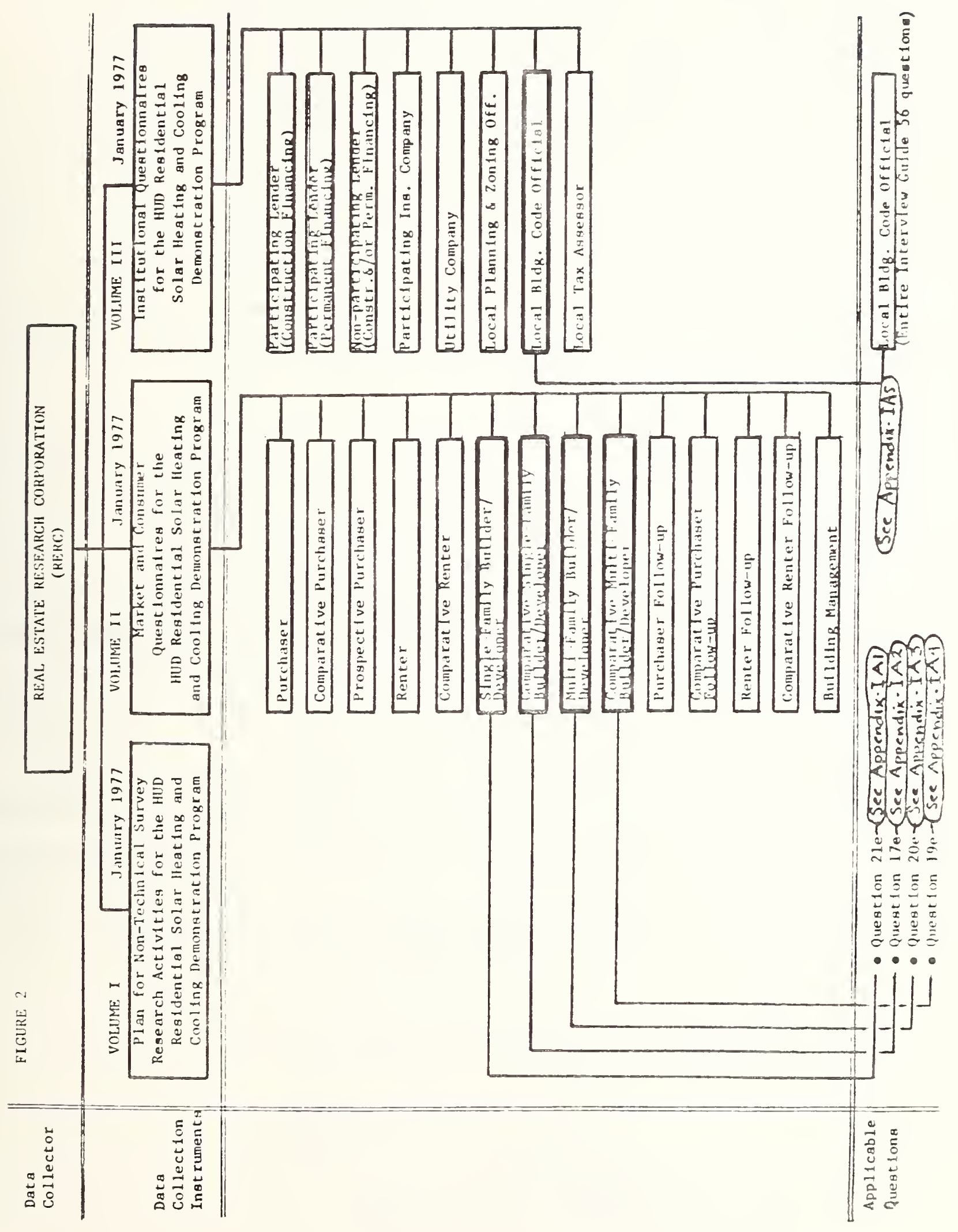


comparative organizations (i.e., organizations that are not directly involved in the Residential Solar Demonstration Program) so that there is the potential to analyze the perceived differences in reactions by the different organizations to a similar situation. For example, a solar demonstration builder is asked if he has had any trouble in processing his plans and specifications through a particular code approval process. The reactions of other builders regarding their experiences with the same code officials on non-solar related actirities are also obtained. Although not all sites are risited, the questionnaires are answered in sets and data are gathered for all information pertinent to a site. To illustrate, if a particular site is to be visited at all, the builder, comparative builder, code official, tax assessor, etc., are all contacted and the respective questionnaires completed.

In addition to showing the three volumes to be used, Figure 2 illustrates the various questionnaires contained in each volume. (V'olume I, incidentally, contains no questions.) There is a separate questionnaire containing numerous questions oriented toward "The Purchaser," "The Comparative Purchaser," "The Prospective Purchaser," etc., and these questionnaires are listed on the chart. Each questionnaire was reviewed to identify those questions containing useful input to this study. The questions of interest are identified in Figure 2 and given in Appendix I-Section A. Of the 14 questionnaires contained in Volume II, only four (4) questionnaries are directly relevant to codes and standards. Furthermore, only one question within each of those four (4) questionnaires relate to regulatory concerns. In Volume III, only one questionnaire of the eight ( 8 ) identified is of interest. However, this questionnaire, "Local Building Code Official," is of interest in its entirety--all 56 questions. Appendix I-Section A consists of the pages of the RERC interview guide which contain all the questions applicable to this study.

To receive the initial input to this study, contact was made with RERC at the following location:

Real Estate Research Corporation

72 West Adams

Chicago, Illinois 60603 
Arrangements were made with RERC to receive the initial data on an ad hoc basis. Subsequent data could be received by tapping the NBS computerized Solar Data Base, but initial efforts indicate some delay may be encountered. This delay is due to the time lag between the period the data are collected and the time required to code, transmit, input, and retrieve the data from the system.

Section 5 of this report discusses the status of the data actually available as of this reporting period.

\subsubsection{American Institute of Architects Research Corporation (AIA/RC)}

This organization developed a Design Integration Monitor's Handbook, dated March 3, 1977. The handbook is divided into four (4) sections (see Figure 3) and is oriented toward collecting a major portion of the technicel data for the Residential Solar Demonstration Program. Information collected by AIA/RC using these forms is limited to those sites which have been fully instrumented to collect detailed technical data. The data collected are coded by AIA/RC and the coded sheets sent for input into the NBS Solar Data Base.

As noted in Figure 3, only tho (2) sections of the four (4) that makt up the Design Integration Monitor's Handbook are applicable to this study and each of the questionnaires contain only one question which provides data. Appendix I-Section B shows these questions.

Contact was made with $\mathrm{AIA} / \mathrm{KC}$ regarding this study. The original completed questionnaires are maintained at:

\footnotetext{
American Institute of Architects Kesearch:

Corporation
}

1735 New York Avenue

Washington, D.C. 20006 


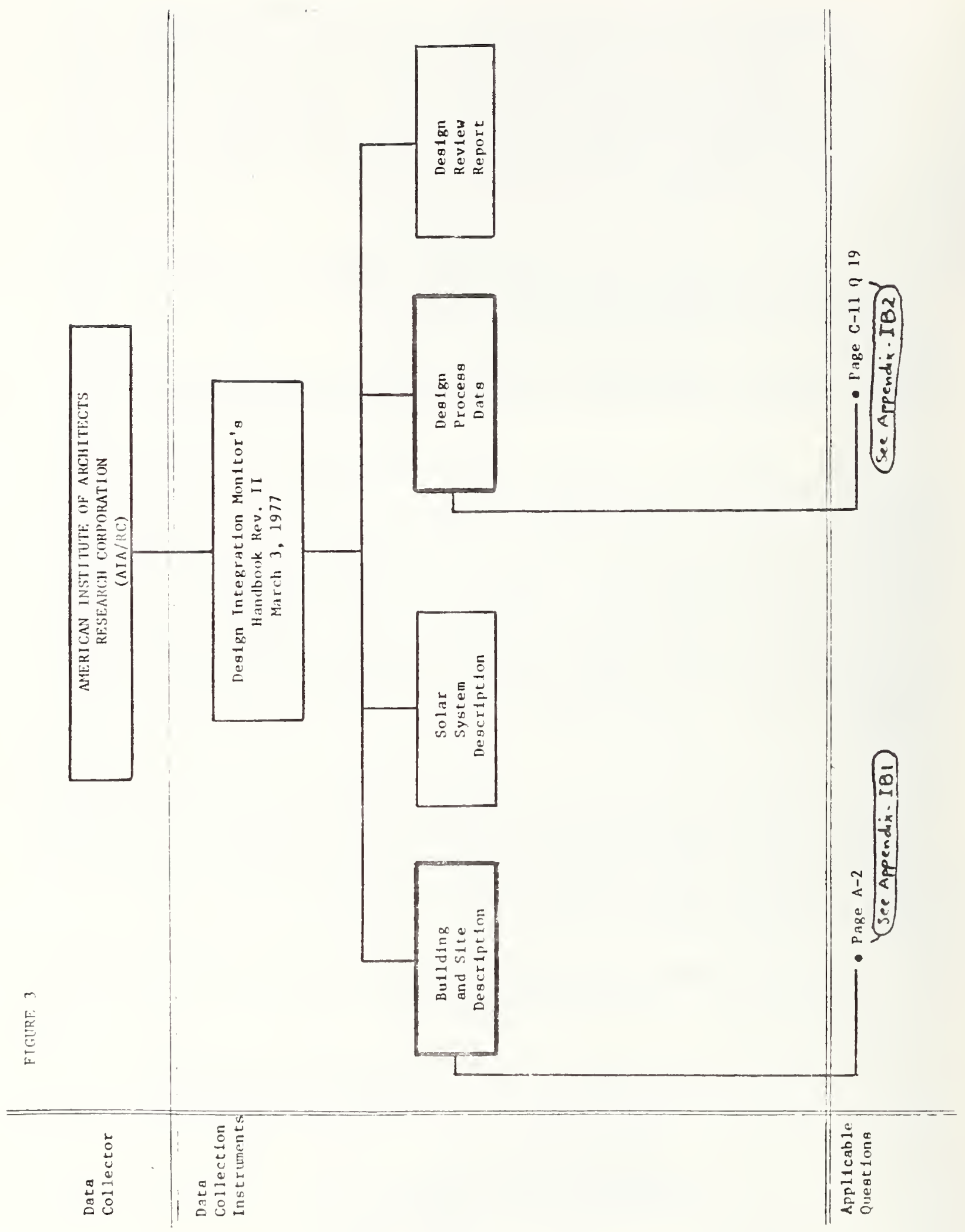


A visit was made to $\mathrm{AIA} / \mathrm{RC}$ and it was determined that data relative to this study can be easily obtained by periodically searching the files where the originals of the completed questionnaires are kept. These data, of course, could be obtained through the NBS Solar Data Base. However, there would be a time lag from the time the data are received until the data are coded and inserted into the NBS Solar Data Base. The file search method for collecting these data from $\mathrm{AIA} / \mathrm{RC}$ is quick, is not sensitive to errors in coding, and requires a minimum of effort by AIA/RC personnel. This method will be tried unless $A I A / R C$ finds that it is interfering with its operations, in which case, the data will be extracted from the NBS Solar Data Base.

Section 5 of this report discusses the status of the data actually available as of this reporting period.

\subsubsection{U.S. Department of Housing and Urban Development/Boeing}

Additional documents identified as containing data pertinent to the Residential Solar Demonstration Program are the Grantee Reports. Inspection of these reports reveals that only one question (in Report No. 3 - Construction Report) is of interest for this study. Figure 4 indicates the four (4) individual reports comprising the Grantee Reports and Appendix I-Section C shows the single question in Report No. 3 - Construction Report - that is directly applicable to this study.

Coding sheets are submitted for inclusion into the NBS Solar Data Base, and are used in obtaining input to this study. The status of these data is discussed in Section 5.

\subsection{COMMERCIAL PROGRAII}

A single organization is collecting data from the Commercial Solar Demonstration Program, namely:

PRC Energy Analysis Company

8130 Boone Boulevard

McLean, Virginia 22101 


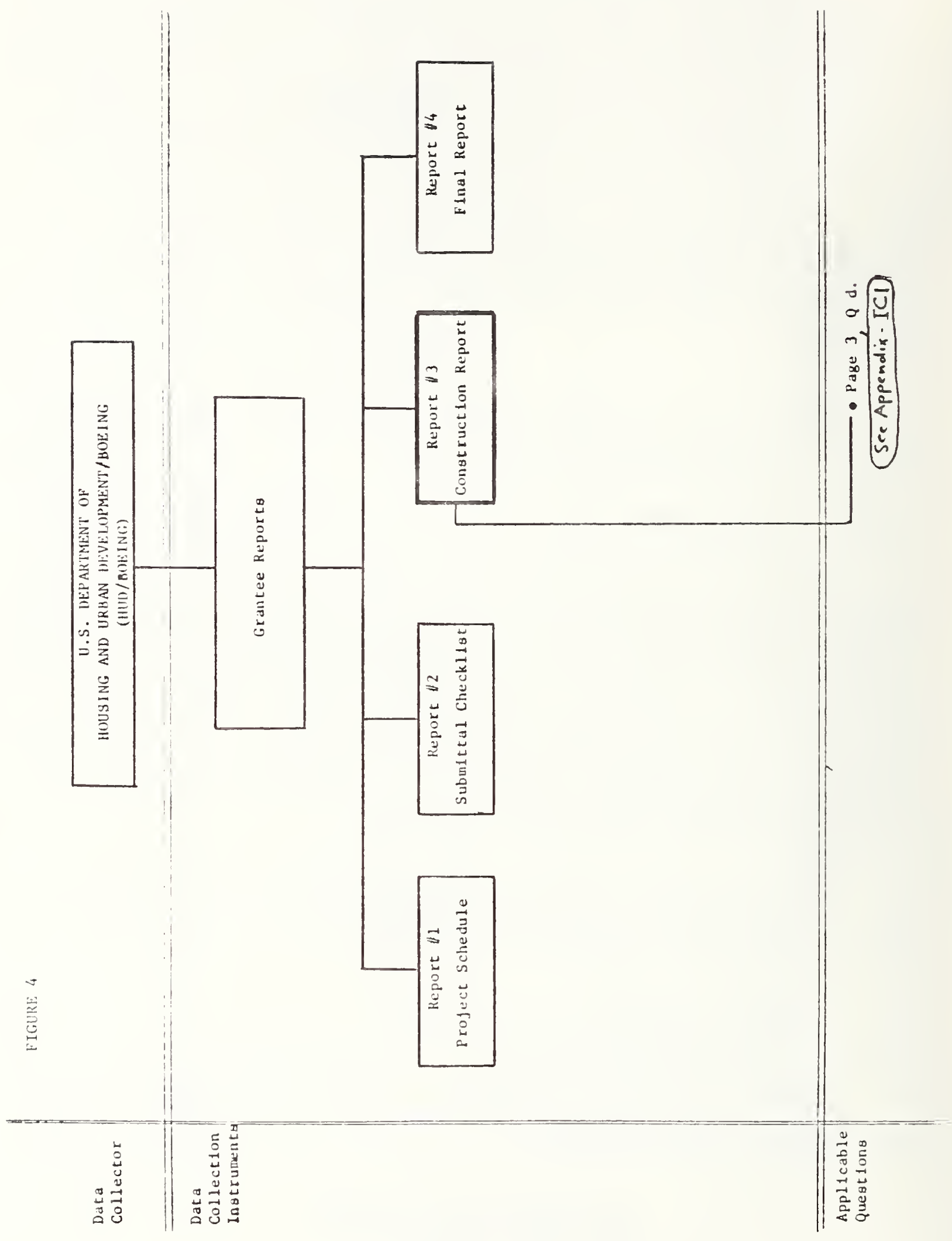


The PRC developed five (5) data collection instruments (dated May 1977) which are packaged as a series of documents. These documents are shown in Figure 5 and the questions applicable to this study are identified. In the various documents, a total of nine (9) questions identified in Appendix ISection $D$ are of interest. Many of these questions are narrative in format and do not lend themselves to computerized tabulation.

The data collected by PRC are not coded for inclusion in the :ibS Solar Data Base, and NBS deals directly with PRC to obtain the data. Contact was made with PRC and arrangements established so that information needed for this study is extracted by PRC onto a format developed by NBS for this purpose. If this mode of operation becomes too burdensome to PRC, alternative means will be developed.

Section 5 of this report discusses the status of the data available regarding building regulations for the commercial demonstration program as oi September $30,1977$. 


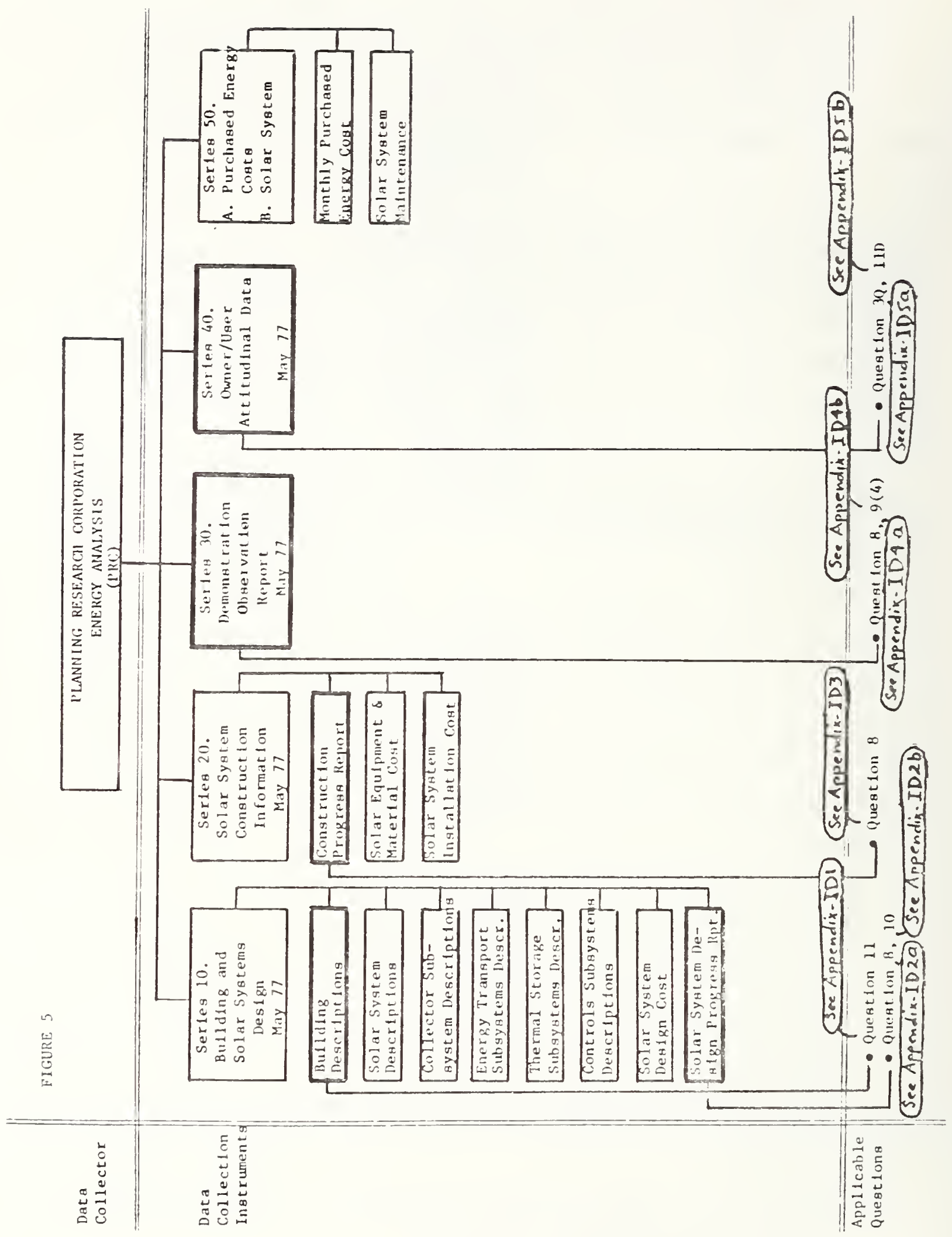




\section{STATUS OF DATA}

This section reports on the status of questionnaire data and corresponds to step (11) on the Project Methodology Chart (Figure 1) as described in Section 3. Each organization identified in Section 4 was contacted and asked to provide the status of responses for the questions identified as pertinent to the building regulatory study. Arrangements were made with these organizations to receive these data on an ad hoc basis with a more formal arrangement to be definitized at a later date.

To organize the data for future analysis and maintain a system which could include studies with time as a variable, information is presented on a cycle-by-cycle basis. This is possible because each demonstration cycle is sequential and falls within a specified time frame. The status of information available is tabulated by cycle. Because of the limited data available, it must be emphasized that this report makes no attempt to analyzt the regulatory environment relative to the demonstration program but rather presents the data base available as of September 30, 197\%. As the data base expands, analyses will be made and as the data gathering is completed, final results will be presented in subsequent reports.

\subsection{RESIDENTIAL PROGRA'}

The information available for the Residential Solar Demonstration Program as of the end of this reporting period is shown in Tables 1 and 2 for Cycles 1 and 2 respectively. The data include some general information (following the Solar Grant Summary format), as well as the status of the availability of completed questionnaires. The general information includes:

1. Project Location

State

City

\section{Grantee}


3. Housing Type

SFD - Single Family Detached

SFA - Single Family Attached

GAL - Garden Apartment and Low Rise

MFM - Multi-family Medium Rise

MFH - Multi-family High Rise

4. Construction

New/Retrofit

5. Number of Units

6. System Type

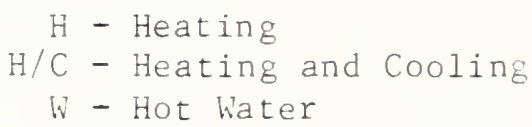

7. Kind of System

A - Active

P - Passive

The specific information shown on the remainder of each chart indicates the organization collecting the data and the exhibit description used throughout this report to identify each solar regulatory related question. Only those sites that are part of the demonstration program as of September 3i, 1977 , are given and subsequent iterations will not include any sites that are eliminated from the demonstration program. Special analyses will be made of situations, if any, where the sites were eliminated because of regulatory issues.

Table 1 illustrates the data available for Cycle 1 of the Residential Solar Demonstration Program. As can be noted, there are 41 grantees identified and most of the available data are from the HLD Grantee Reports (Appendix I-Section C1). This question, in effect, queries the grantee on the code in force by the local jurisdiction. These responses are not of great value in this analysis because the codes applicable to that site can be obtained from other sources, although data from the grantee may give some indication as to the builder's understanding of the local building code. (A preliminary study, using data from non-demonstration sources is included in section 6 of this report.) 


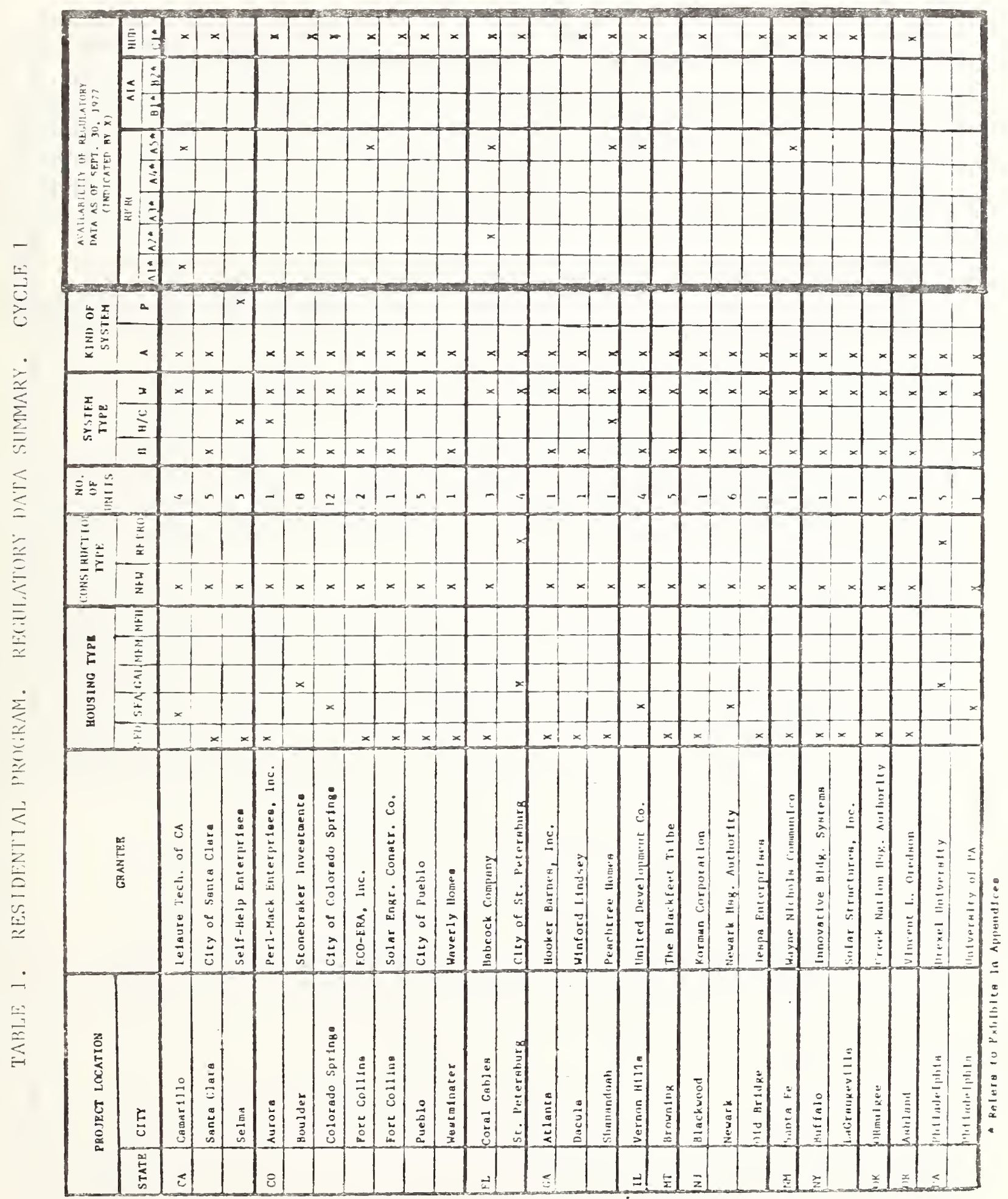




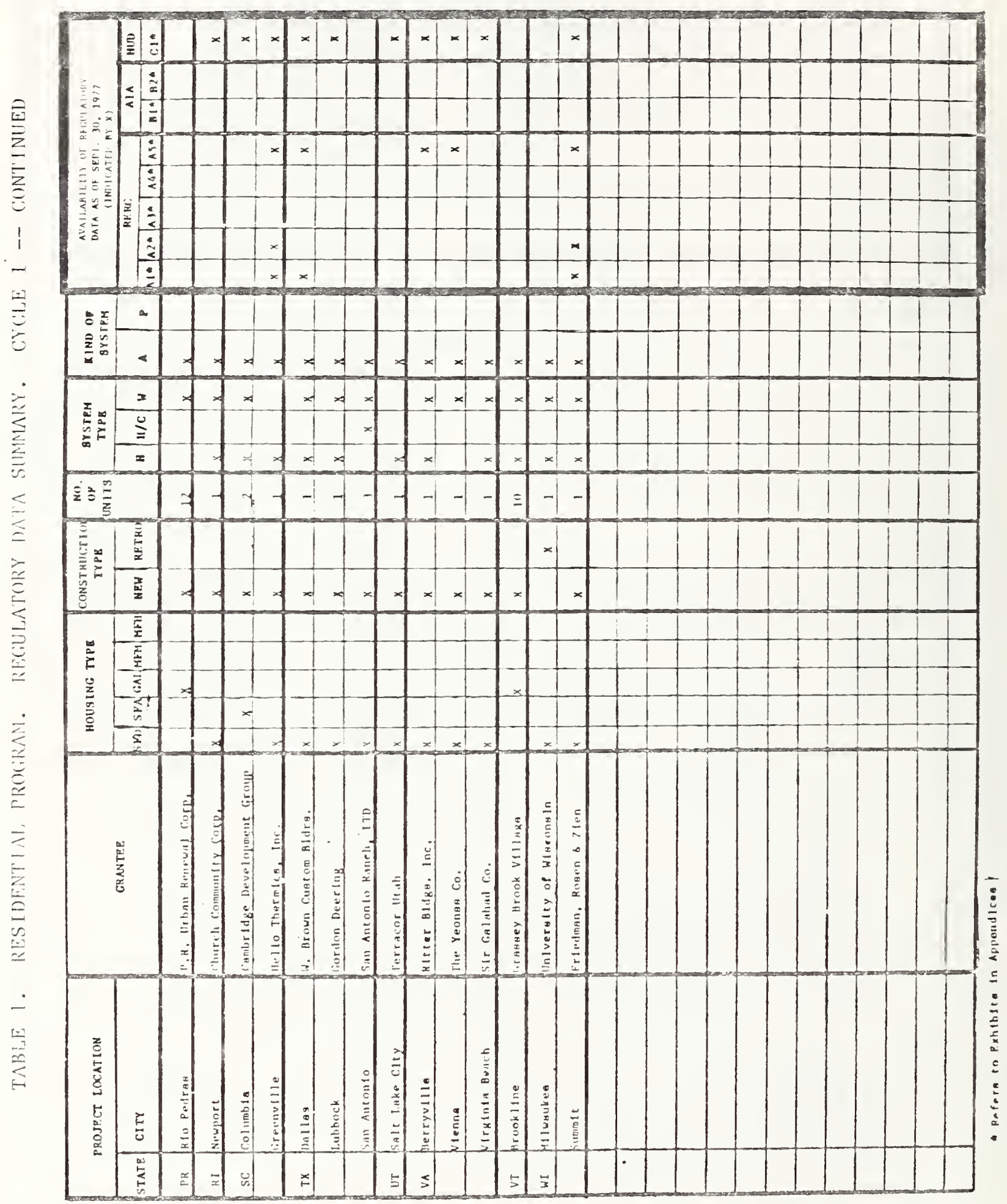




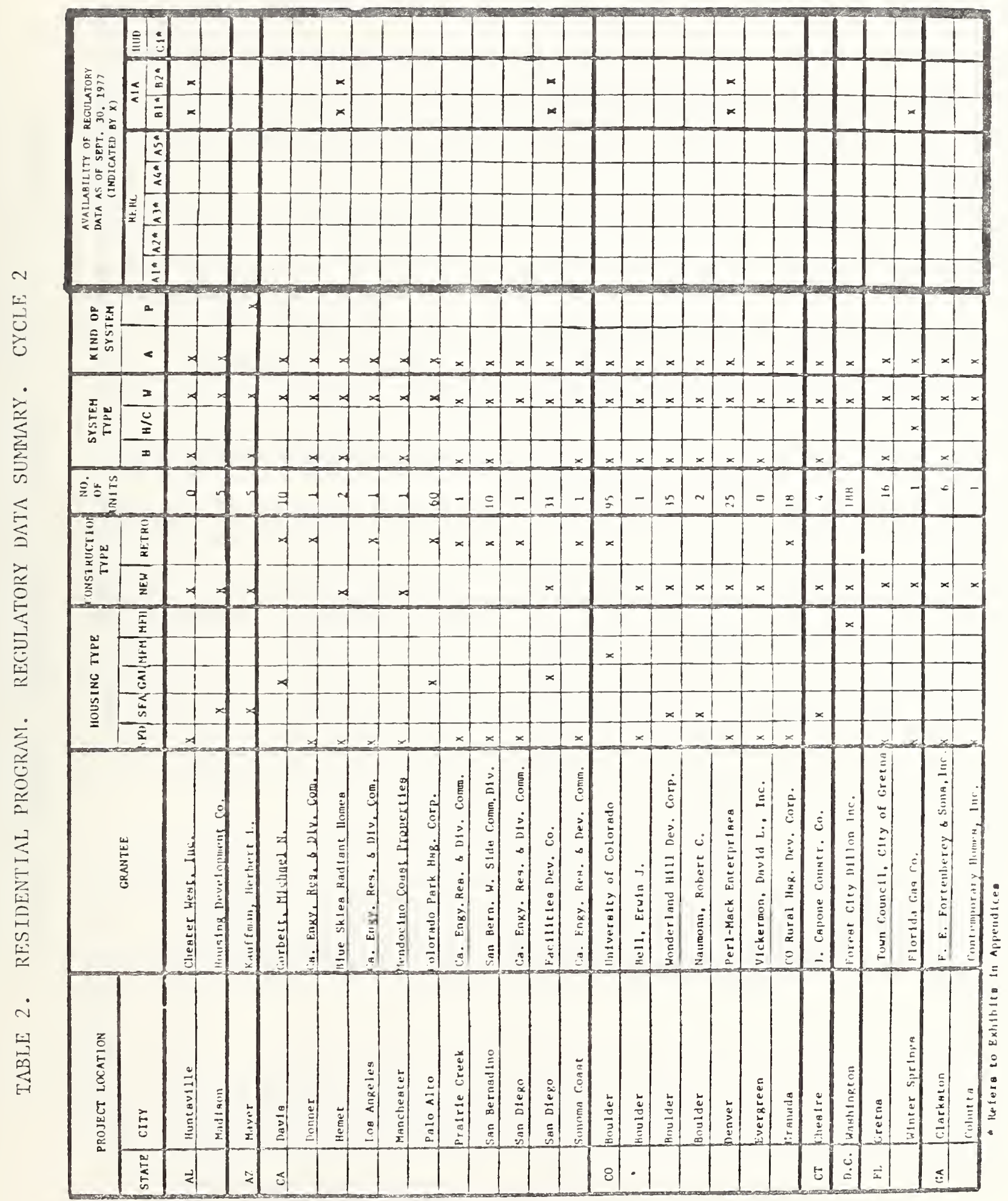




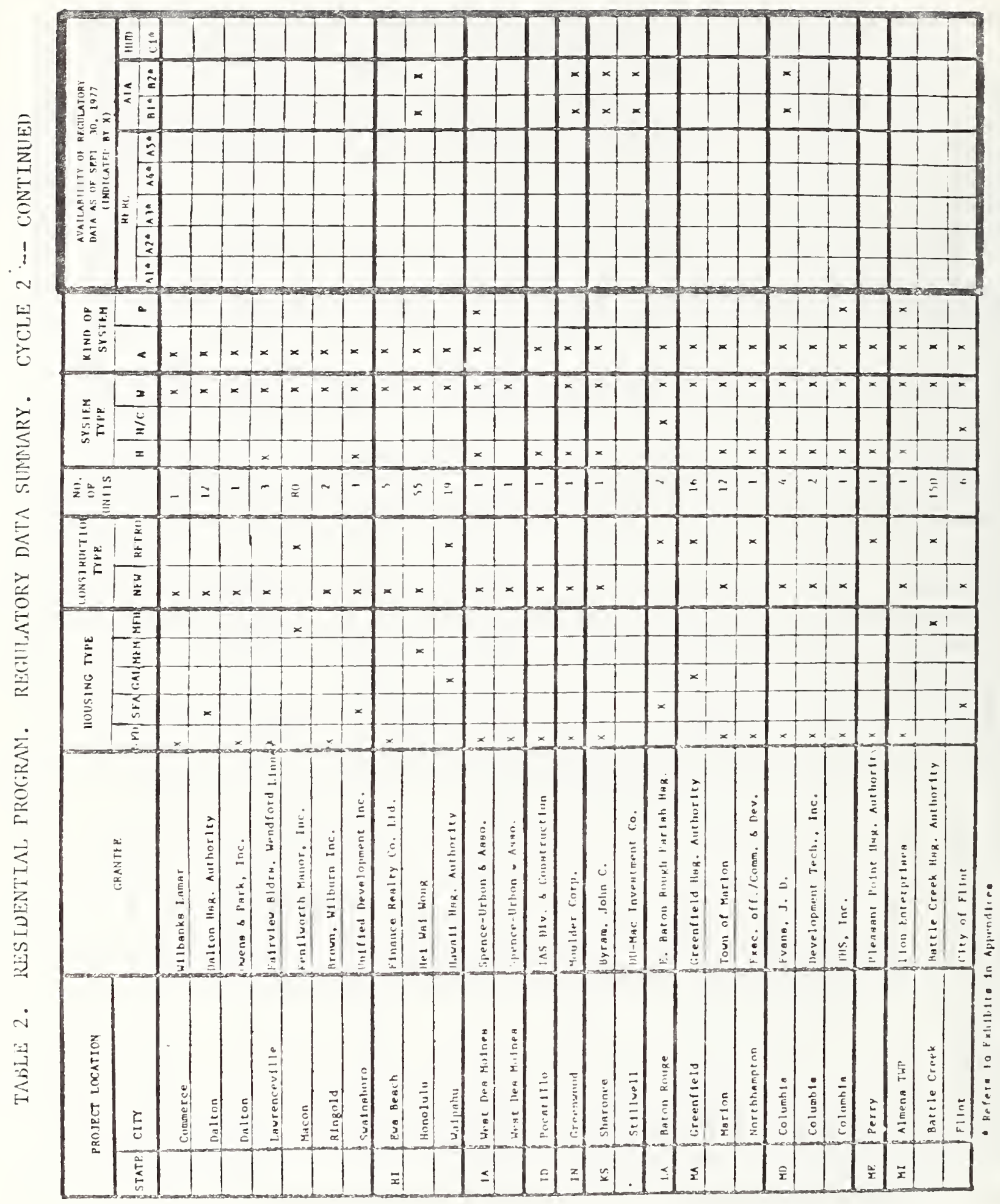




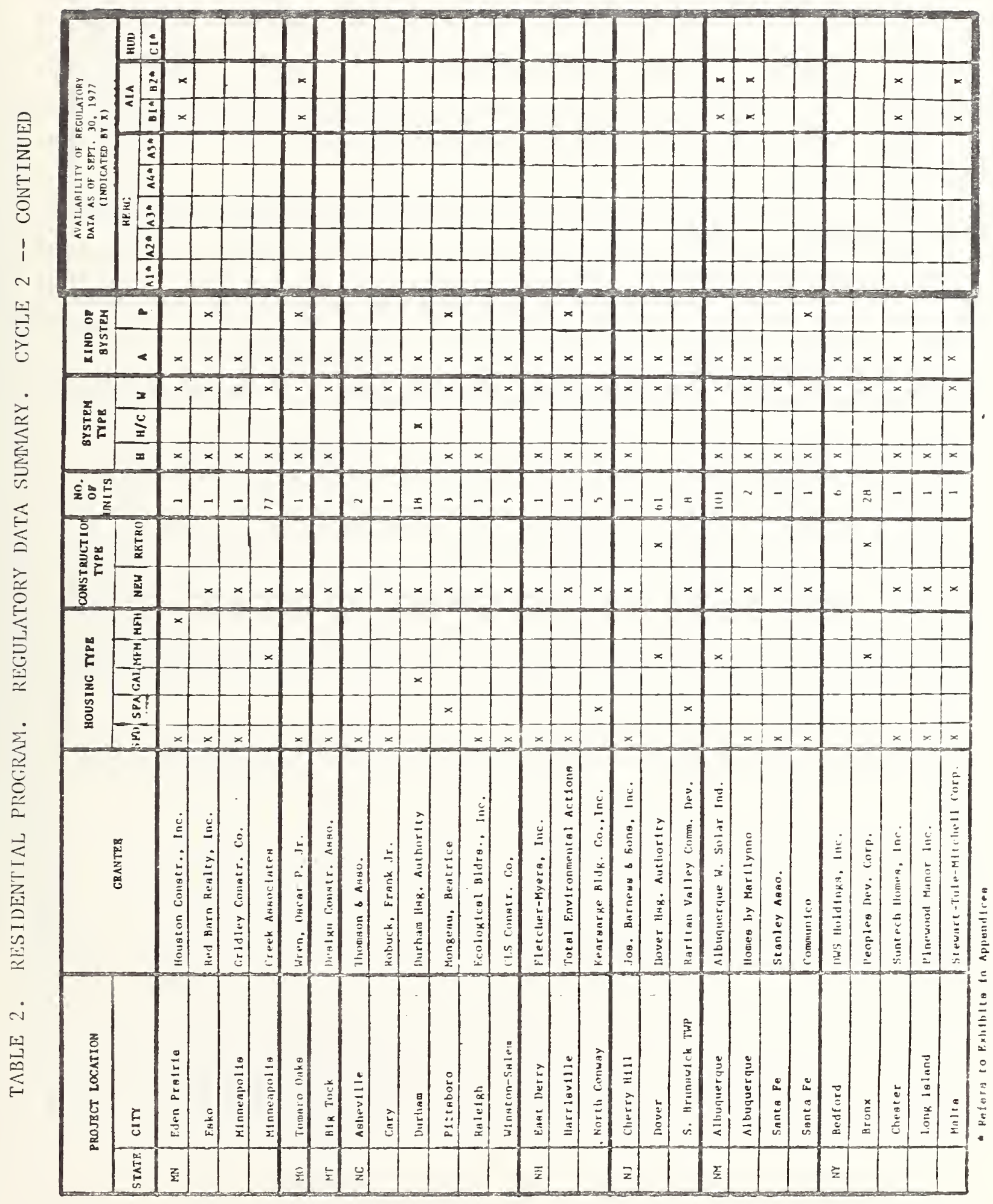




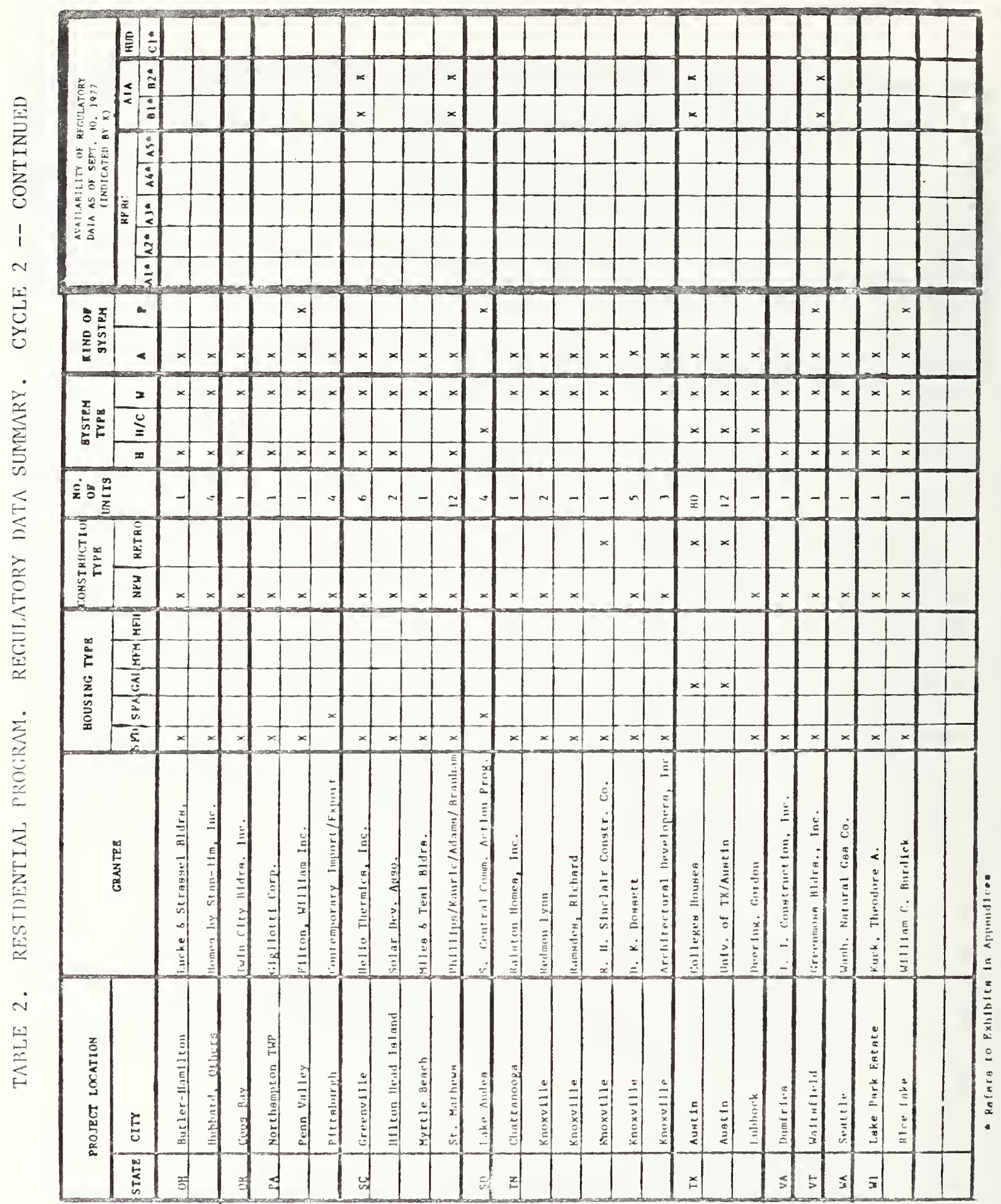


It can also be noted that only four (4) builders' questionnaires (Appendix I-Section AI) and three (3) comparative builders' questionnaires are available, and the two sets do not exactly coincide. There are, however, eleven (II) Local Building Code Official questionnaires (Appendix I-Section A5) available and this is encouraging as these questionnaires will be a major source of input to subsequent studies. No data are identified as being available from AIA/RC (Appendix I-Section B) for Cycle $I$.

With regard to Cycle 2 (Table 2), the only data identified as being available through September 30, 1977 , are twenty (20) sets of AIA/KC data (Appendix I-Section B). No tabulation is presented for Cycle 3 and subsequent cycles as no data are identified. Charts for subsequent cycles indicating available data will be prepared, when appropriate.

\section{5. - COMERCIAL PROGRA:}

The information available for the commercial demonstration program as of the end of this reporting period is shown in Table 3 for cycle 1. These data, following a PRC format, include some general information and the status of the availability of completed questionnaires. The general information includes:

1. Project Location

State

City

2. Collector Manufacturer

3. Building Type

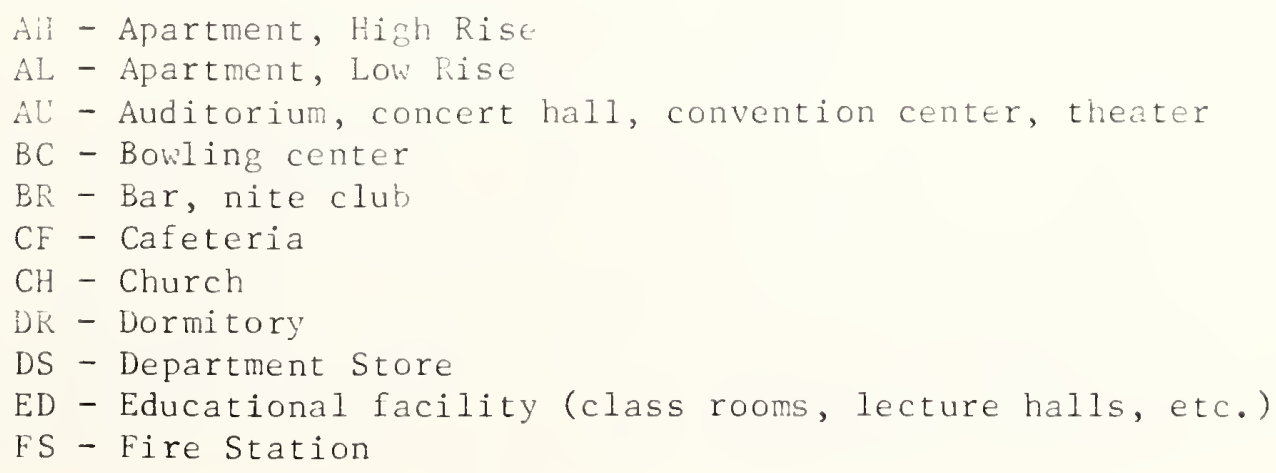




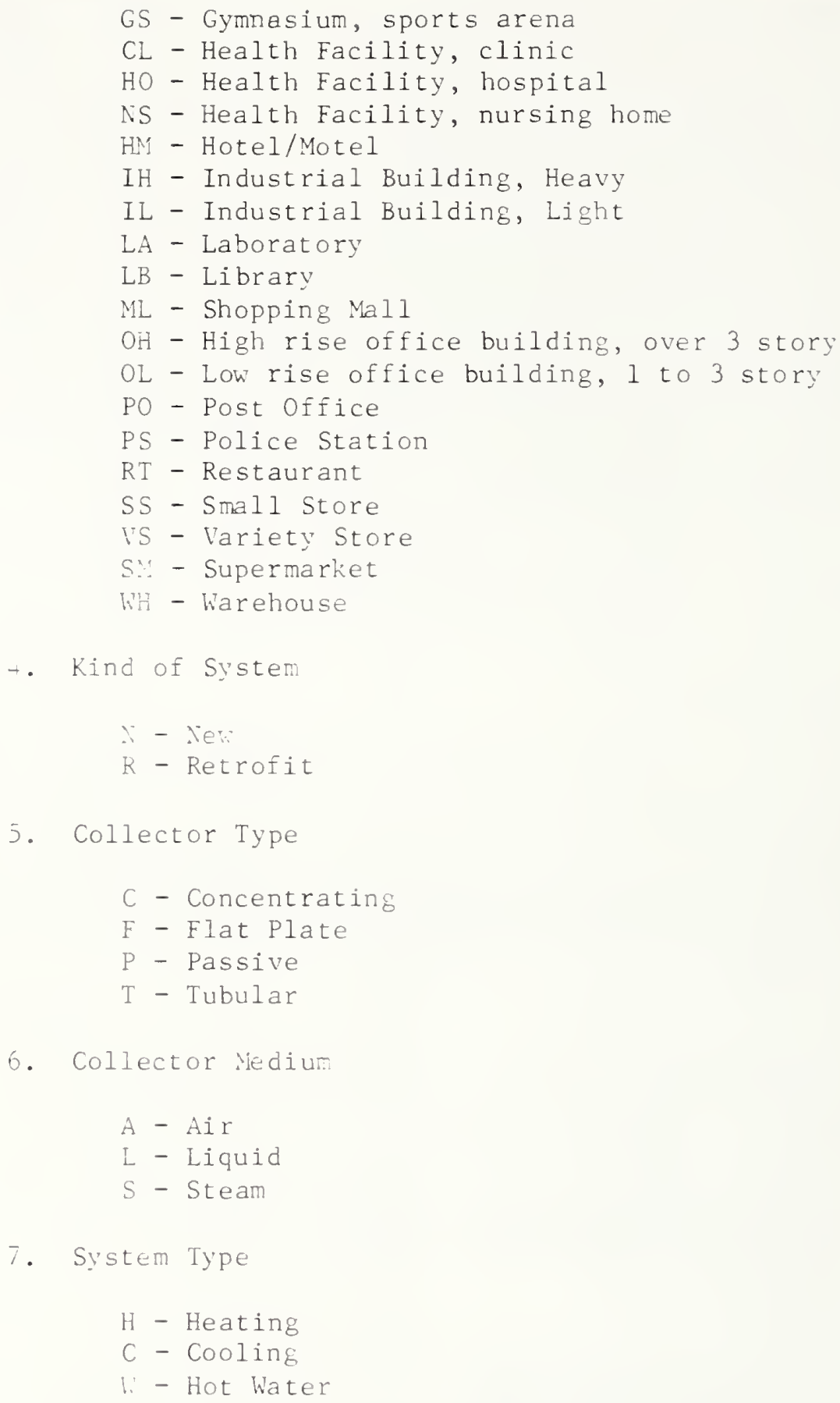

The specific information shown on the remainder of each chart indicates the exhibit description used throughout this report to identify each regulatory related question in the PRC questionnaire package. Again, only current sites are included in each chart and subsequent iterations will eliminate those sites that are no longer a part of the demonstration program. 
Also included are those sites established under National Science Foundation grants, prior to the DoE Commercial Solar Demonstration Program.

As can be noted, there are fifty (50) sites identified with some data available for fourteen (14) of these sites. Analysis of these data will begin once received by NBS. Data are not available for subsequent cycles; charts will be prepared by cycle at the appropriate time. 


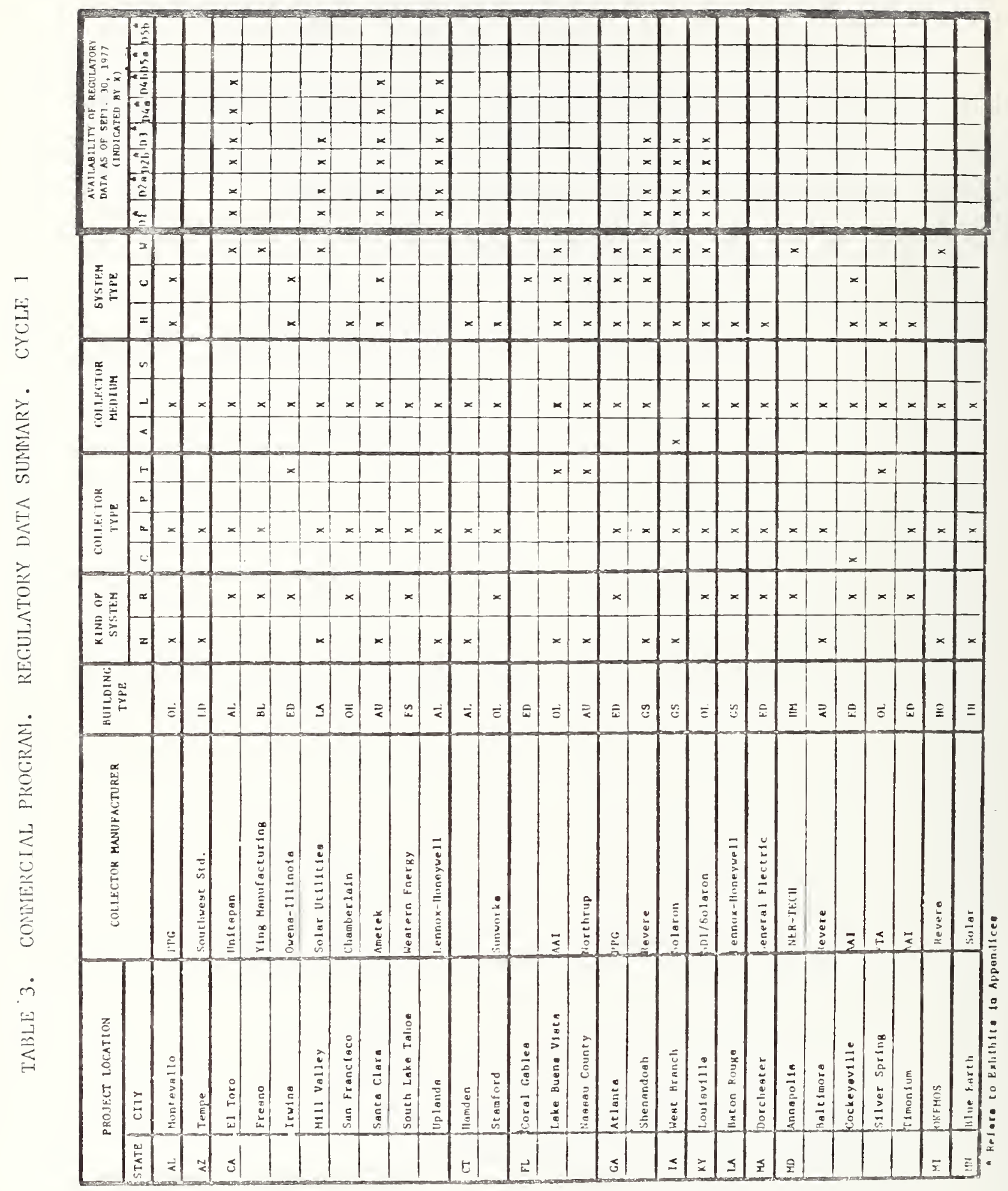




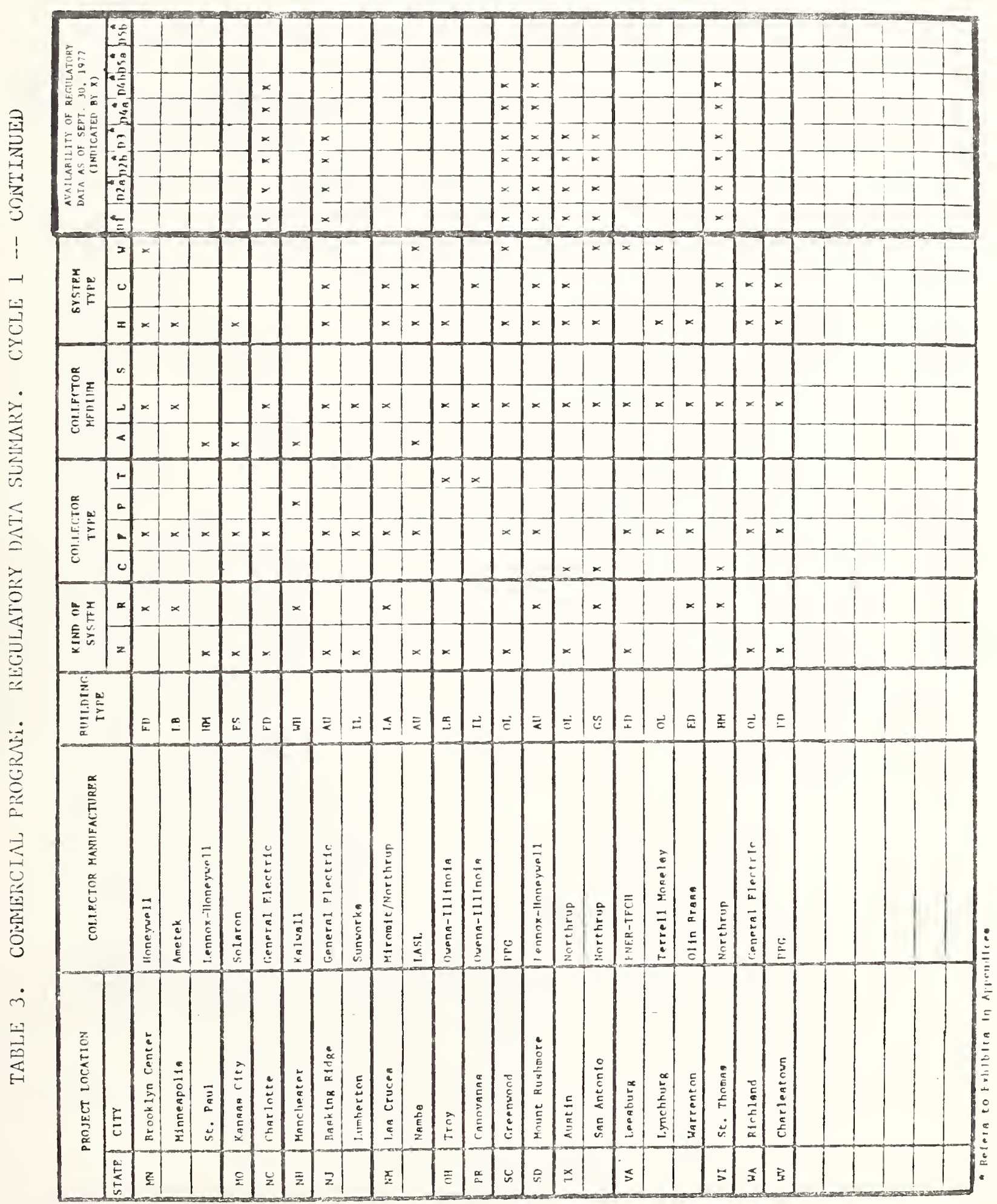




\section{ANALYSIS OF CODE. DAIA}

This preliminary analysis is made to assess the adequacy of the sites selected for the demonstration programs from a building regulatory point of view. Sites can be selected on a technical basis alone to demonstrate various solar systems in different climatic environments, but consideration must also be given to the regulatory thrust of this program. In this regard, the site locations selected for the demonstration program are analyzed for balance from a regulatory perspective and recommendations suggested for future site selection in subsequent demonstration cycles.

Since very little questionnaire data are available, this study is being made independently of the demonstration program data. As the location of the sites are known, code information can be obtained for those locations from sources not dependent on the demonstration program. From one of these sources $^{1}$, an overview of statewide and major city building codes is presented in Figure 6. The map is distorted from the usual geographic presentation to depict the size of the states as determined by population. States with regulatory codes based on the three nationally recognized model codes are shown, as well as states with their own codes and states that have adopted no statewide code. In addition, code information is also shown for major cities. A tabulation is included in the legend to indicate the number of states and major cities in each category.

\subsection{RESIDENTIAL SOLAR DEMONSTRATION SITES}

\subsubsection{Distribution of Sites}

A large number of sites were selected for the Solar Demonstration Program on the basis of various criteria. This section reviews the distribution of the location of these sites from one of these criteria, the building regulatory viewpoint. A non-representative mix of site locations may provide

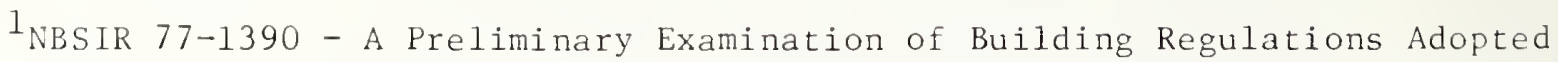
by the States and Major Cities, Patrick W. Cooke and Robert M. Eisenhard. 


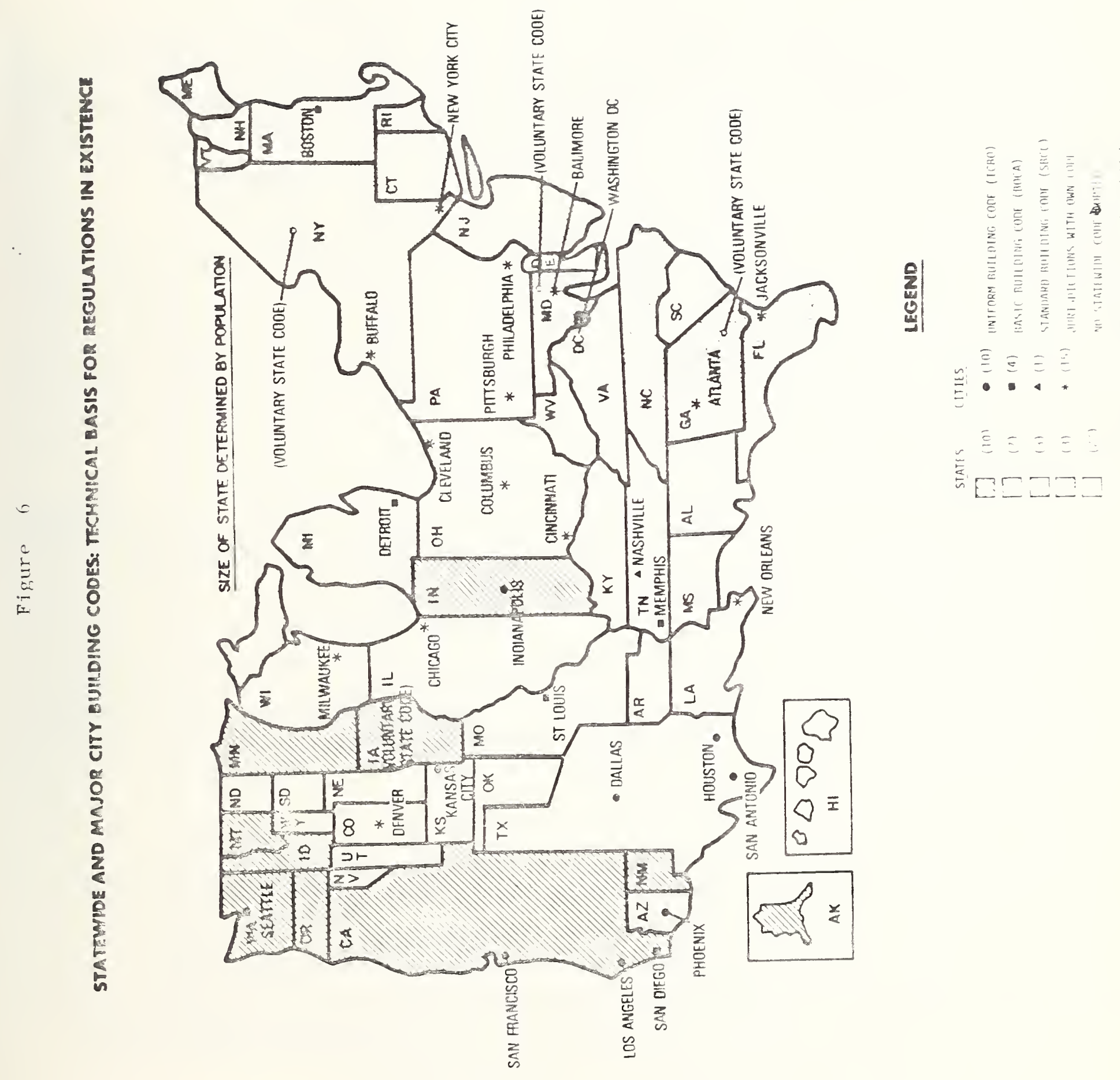


inadequate data to present a total and meaningful comparison. Moreover, the conclusion reached may not be general in nature but biased and misleading.

The overview which follows attempts to provide general information relative to residential site selection for the 3 cycles already awarded. Table 4 is a tabulation of the various sites, by cycle, and state, indicating whether the sites are retrofit sites or new sites. This breakdown is desirable for any future analysis regarding codes as applied to new construction and/or existing building construction.

Using the data shown on the population map (Figure 6), the building code applicable to each state is identified. However, it is recognized that the states listed as having no statewide code may in fact contain jurisdictions which predominantly use a version of one of the nationally recognized model codes. For the purposes of this study, these states are grouped separate 1. .

The data tabulated in Table 5 shows that of the 50 States, ten (20\%) are covered by the Lniform Building Code (UBC); seven (14\%) by the Basic Building Code $(\mathrm{BBC})$; three ( $6 \%$ ) by the Southern Building Code ( $\mathrm{SBC}$ ); three ( $6 \%$ ) by a State building code; and 27 ( $54 \%$ ) by no statewide code.

This type of analysis does not take population into account and since the more densely populated states are better candidates for the exploitation: of solar energy (all other matters being equal), the analysis must somehow be weighted by population.

A tabulation was added to Table 5 to show the various percentages of population affected by the model codes. This indicates that 20 percent of the population is influenced by the Uniform Building Code; 17 percent by the Basic Building Code; 8 percent by the Southern Building Code; 16 percent by a state code; and 39 percent of the population live in states that have not adopted a statewide code. These percentages, summarized in Table 6, are selected as the comparison baseline. 
TABIE 4. RESIDENTIAL PROGRAM

SITES PER CYCLE AND MODEI CODE BASE

\begin{tabular}{|c|c|c|c|c|c|c|c|c|c|c|c|c|c|c|c|c|c|c|}
\hline \multirow{3}{*}{ STATE } & \multirow{3}{*}{$\begin{array}{l}\text { POPUL, } \\
\text { (mill) }\end{array}$} & \multirow{2}{*}{\multicolumn{4}{|c|}{$\begin{array}{c}\text { NUMBEK OF SITES } \\
\text { IN CYCLE }\end{array}$}} & \multirow{2}{*}{\multicolumn{4}{|c|}{$\begin{array}{l}\text { NE' SITES } \\
\text { IN CYCLE }\end{array}$}} & \multirow{2}{*}{\multicolumn{4}{|c|}{$\begin{array}{c}\text { RETROFIT SITES } \\
\text { IN CYCIE }\end{array}$}} & \multicolumn{5}{|c|}{ BLILAN COIE } \\
\hline & & & & & & & & & & & & & & \multicolumn{3}{|c|}{ BASED ON } & \multirow{2}{*}{ SIATE } & \multirow{2}{*}{ No: } \\
\hline & & 1 & 2 & 3 & Tota & 1 & 2 & 3 & To: $:=1$ & 1 & 2 & 3 & $2 c \leq c 2$ & UBC & $\mathrm{BE}^{\prime}$ & 55 & & \\
\hline AL & 3.4 & 0 & 2 & 1 & 3 & 0 & 2 & 1 & 3 & 0 & 0 & 0 & 0 & & & & & $X$ \\
\hline $\mathrm{AK}$ & 0.4 & 0 & 0 & 0 & 0 & 0 & 0 & 0 & 0 & 0 & 0 & 0 & 0 & $x$ & & & & \\
\hline$A R$ & 2.1 & 0 & 0 & 0 & 0 & 0 & 0 & 0 & 0 & 0 & 0 & 0 & 0 & & & & & $\mathrm{x}$ \\
\hline$A Z$ & 1.8 & 0 & 1 & 2 & 3 & 0 & 1 & 2 & 3 & 0 & 0 & 0 & 0 & & & & & $x$ \\
\hline $\mathrm{CA}$ & 19.7 & 3 & 11 & 9 & 23 & 3 & 3 & 8 & 14 & 0 & 8 & 1 & 9 & $x$ & & & & \\
\hline $\mathrm{CO}$ & 2.2 & 7 & 7 & 11 & 25 & 7 & 5 & 10 & 22 & 0 & 2 & 1 & 3 & & & & & $x$ \\
\hline $\mathrm{CT}$ & 3.0 & 0 & 1 & 4 & 5 & 0 & 1 & 3 & 4 & 0 & 0 & $I$ & 1 & & $x$ & & & \\
\hline$D E$ & 0.5 & 0 & 0 & 1 & 1 & 0 & 0 & 1 & 1 & 0 & 0 & 0 & 0 & & & & & $x$ \\
\hline $\bar{F}$ & 6.7 & 2 & 2 & 5 & 9 & 1 & 2 & I & 4 & 1 & 0 & 4 & 5 & & & $x$ & & \\
\hline GA & 4.5 & 3 & 9 & 1 & 13 & 3 & 8 & 0 & 11 & 0 & I & 1 & 2 & & & $x$ & & \\
\hline $\mathrm{HI}$ & 0.7 & 0 & 3 & 1 & 4 & 0 & 2 & 0 & 2 & 0 & I & 1 & 2 & & & & & $x$ \\
\hline If & 2.8 & 0 & 2 & 2 & 4 & 0 & 2 & 2 & 4 & 0 & 0 & 0 & 0 & $x$ & & & & \\
\hline ID & 0.7 & 0 & 1 & 2 & 3 & 0 & 1 & 1 & 2 & 0 & 0 & $I$ & 1 & $x$ & & & & \\
\hline II & 11.0 & 1 & 0 & 3 & 4 & 1 & 0 & 3 & 4 & 0 & 0 & 0 & 0 & & & & & $x$ \\
\hline IN & 5.1 & 0 & 1 & 10 & 11 & 0 & 1 & 9 & 10 & 0 & 0 & $I$ & 1 & $x$ & & & & \\
\hline KS & 2.2 & 0 & 2 & 2 & 4 & 0 & 2 & 2 & 4 & 0 & 0 & 0 & 0 & & & & & $x$ \\
\hline $\mathrm{KY}$ & 3.1 & 0 & 0 & 2 & 2 & 0 & 0 & 2 & 2 & 0 & 0 & 0 & 0 & & & & & $x$ \\
\hline LA. & 3.6 & 0 & 1 & 0 & 1 & 0 & 0 & 0 & 0 & 0 & 1 & 0 & 1 & & & & & $\mathrm{X}$ \\
\hline$M A$ & 5.6 & 0 & 3 & 15 & 18 & 0 & 1 & 12 & 13 & 0 & 2 & 3 & 5 & & $\mathrm{x}$ & & & \\
\hline$M$ & 3.9 & 0 & 3 & 3 & 6 & 0 & 3 & 3 & 6 & 0 & 0 & 0 & 0 & & $\mathrm{x}$ & & & \\
\hline ME & 1.0 & 0 & 1 & 3 & 4 & 0 & 0 & 1 & 1 & 0 & 1 & 2 & 3 & & & & & $x$ \\
\hline$M i$ & 8.8 & 0 & 3 & 4 & 7 & 0 & 2 & 4 & 6 & 0 & 11 & 0 & 1 & & $x$ & & & \\
\hline 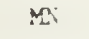 & $3 . \varepsilon$ & 1 & 4 & 3 & 8 & 1 & 4 & 3 & 8 & 0 & 0 & 0 & 0 & $\mathrm{x}$ & & & & \\
\hline MO & 4.6 & 0 & 1 & 6 & 7 & 0 & 1 & 5 & 6 & 0 & 0 & 0 & 0 & & & & & $x$ \\
\hline $\mathrm{MS}$ & 2.3 & 0 & 0 & 0 & 0 & 0 & 0 & 0 & 0 & 0 & 0 & 0 & 0 & & & & & $x$ \\
\hline$m$ & 0.7 & 1 & 1 & 4 & 6 & 1 & 1 & 4 & 6 & 0 & 0 & 0 & 0 & $x$ & & & & \\
\hline NC & 5.6 & 0 & 6 & 4 & 10 & 0 & 6 & 4 & 10 & 0 & 0 & 0 & 0 & & & $x$ & & \\
\hline ND & 0.6 & 0 & 0 & 1 & 1 & 0 & 0 & 1 & 1 & 0 & 0 & 0 & 0 & & & & & $x$ \\
\hline$N E$ & 1.5 & 0 & 0 & 3 & 3 & 0 & 0 & 3 & 3 & 0 & 0 & 0 & 0 & & & & & $x$ \\
\hline $\mathrm{NH}$ & 0.7 & 0 & 3 & 4 & 7 & 0 & 3 & 4 & 7 & 0 & 0 & 0 & 0 & & & & & $x$ \\
\hline $\mathrm{NJ}$ & 7.1 & 3 & 3 & 2 & 8 & 3 & 2 & 0 & 5 & 0 & 1 & 2 & 3 & & $x$ & & & \\
\hline NM & 1.0 & 1 & 4 & 5 & 10 & 1 & 4 & 5 & 10 & 0 & 0 & 0 & 0 & $x$ & & & & \\
\hline $\mathrm{NV}$ & 0.5 & 0 & 0 & 1 & 1 & 0 & 0 & 1 & 1 & 0 & 0 & 0 & 0 & & & & & $x$ \\
\hline $\mathrm{NI}$ & 18.0 & 2 & 5 & 8 & 15 & 2 & 4 & 2 & 8 & 0 & 1 & 6 & 7 & & & & $x$ & \\
\hline $\mathrm{OH}$ & 10.5 & 0 & 2 & 8 & 10 & 0 & 2 & $\varepsilon$ & 10 & 0 & 0 & 0 & 0 & & & & $x$ & \\
\hline
\end{tabular}

* These states may contain jurisdictions which predominantly use a version of one of the nationally recognized model codes. 
IABLE 4. RESIDENTIAL PROGRAY

SITES PER CYCLE AND MODEL CODE BASE - - CONIINUED

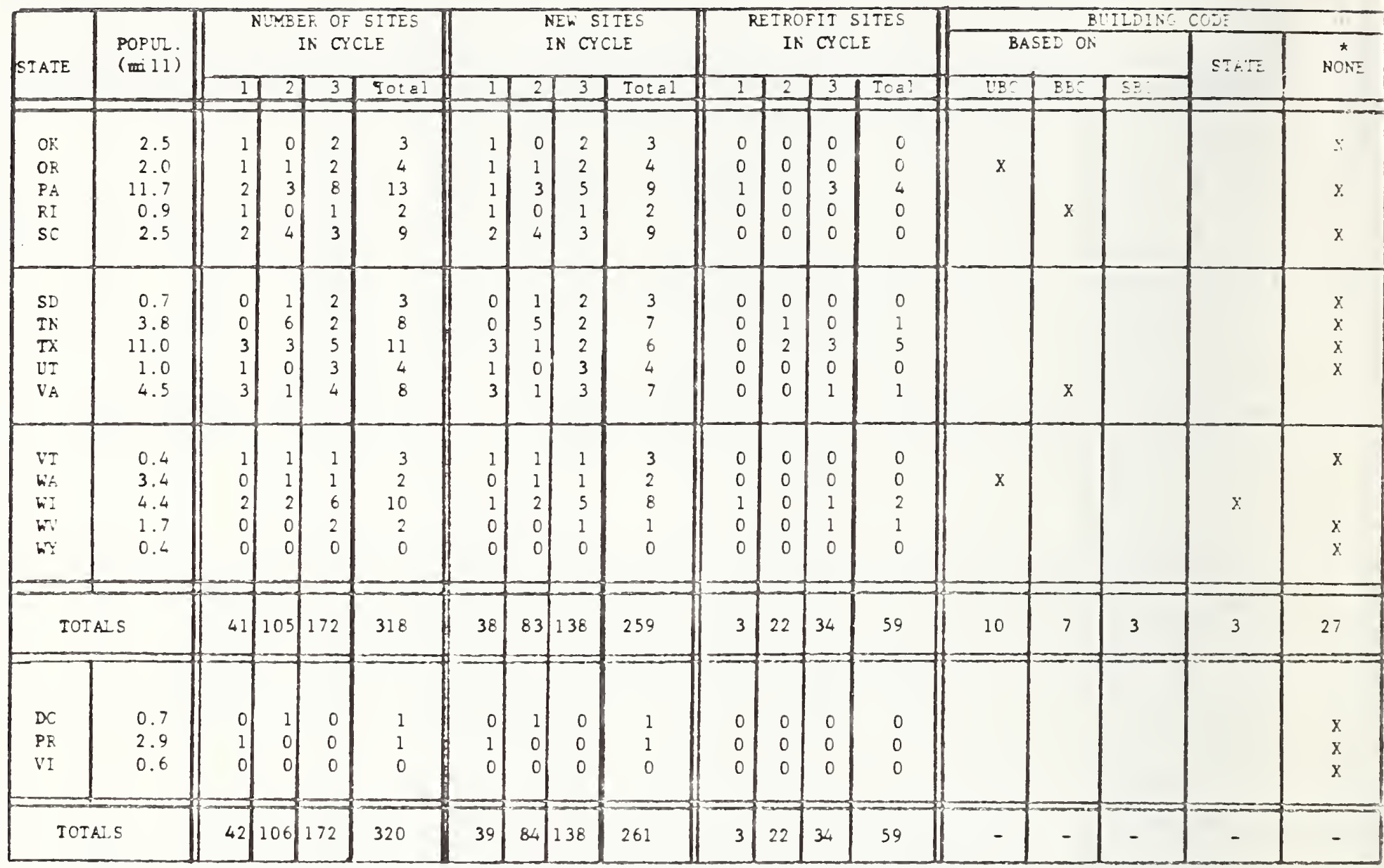

* These states may contain jurisdictions which predominantly use a version of one of the nationally recognized model codes. 
TABLE 5. RESIDENTIAL PROGFAM. BLILDING CODE DISTRIBLTION

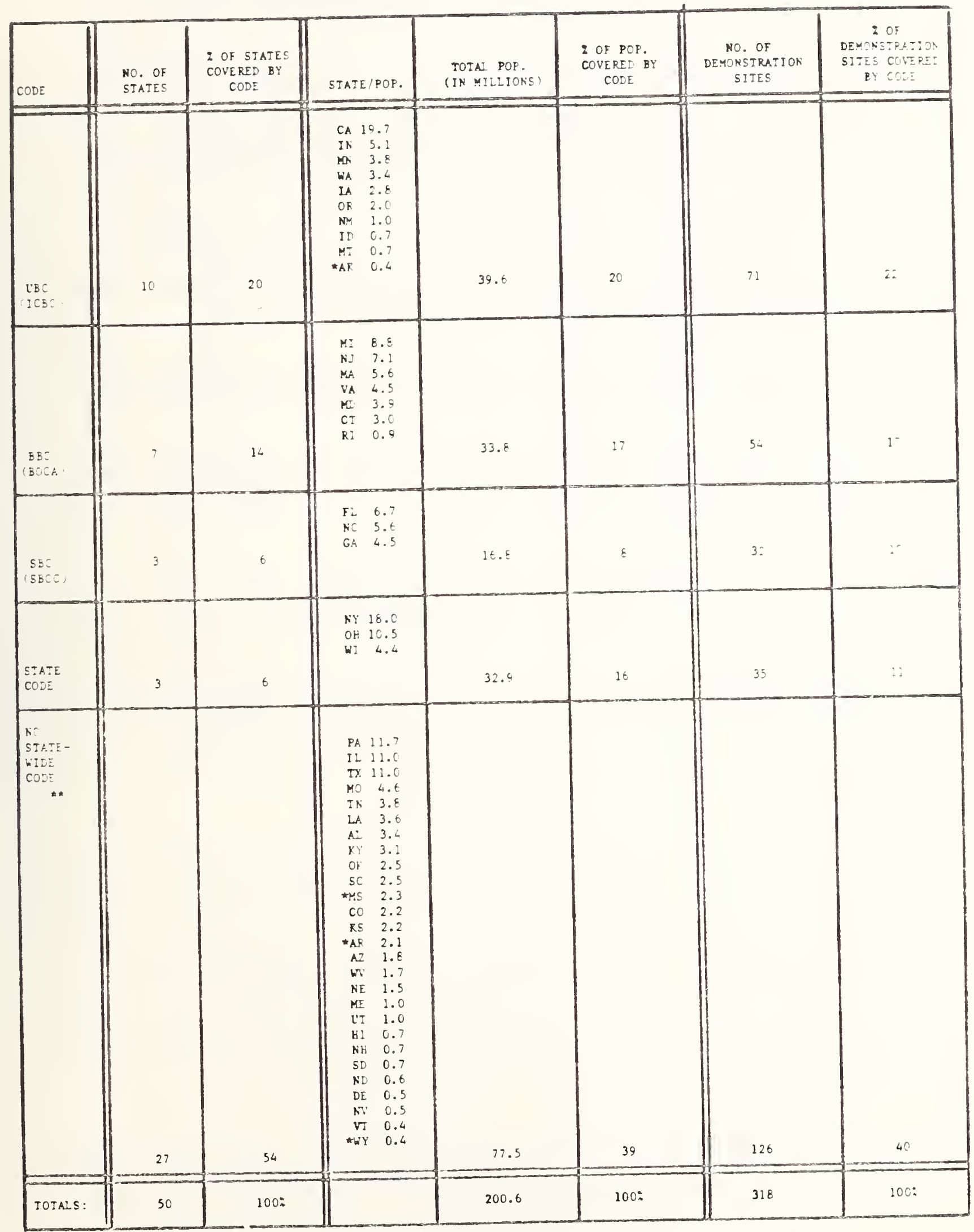

Rore: This informstion does not include Puerto Rico (one site). District of Columbia (one site), Virgin Is lands (no bite).

- These states do not have reaidential aites.

* These atates may contsin juriadictiona which predominantiy uae veraion of one of the nationally recognized model codes. 


\begin{tabular}{|l|c|c|}
\hline & $\begin{array}{c}\text { \% Population } \\
\text { Covered by } \\
\text { Code }\end{array}$ & $\begin{array}{c}\text { of } \\
\text { Demonstration } \\
\text { Site Covered } \\
\text { by Code }\end{array}$ \\
\hline UBC & 20 & 22 \\
\hline BBC & 17 & 17 \\
\hline SBC & 8 & 10 \\
\hline State Code & 16 & 11 \\
\hline $\begin{array}{l}\text { No State- } \\
\text { wide Code* }\end{array}$ & 39 & 40 \\
\hline Total & 100 & 100 \\
\hline
\end{tabular}

* These states may contain jurisdictions which predominantely use a version of one of the nationally recognized model codes.

Table 6. Residential Program Summary of Code Distribution

It appears, from Table 6, that a reasonable overall selection of sites was made for the residential demonstration program, although more sites wert chosen from UBC, SBC, and states that have no statewide code at the expense of states that have written their own state codes.

The distribution of the number of sites by state population is charted in Figure 7 , where the number of sites for a particular location is plotted against the population of the state. In Figure 7 , the states are identified by a code-related symbol. However, the site/population distribution is code-independent. As such, this graph serves the dual purpose of showing the overall distribution and, upon closer scrutiny, identifies the code used in the state.

The general premise postulated is that, from a regulatory viewpoint, more demonstration sites should be selected from the most populated states. 
To facilitate this analysis, a diagonal line was initally added to the chart with a slope representing the number of sites to be included in the demonstration based on the population percentage and the total number of sites in the demonstration program to date. Since California has approximately $9.8 \%$ of the national population, it is reasoned that 9.8\% of the sites should be in California or a total of 31 of the 317 sites currently comprising cycles 1, 2, and 3. The line was drawn from the origin through the coordinates representing 31 sites and a population. of 19.7 million. (Although the coordinates are off-scale in Figure 7 to give greater detail to the actual sites plotted, the slope indicated uses the methodology described above.)

The resulting slope, however, is not unique to California, but in effect is a constant slope for all states for the total number of sites in the cycles plottec. However, since each state cannot have a fractiona. number of sites, it is more appropriate to have a band-width (represented by the shaded portion of the graph) than a single line which would in mos: cases represent fractional sites for a particular state. This wholeinteger band-width turns out to be 2 sites wide. For this study, howerer. the band-width was doubled to a 4 site-wide dimension as representing a more reasonable area for analysis purposes, although any reasonable bancwidth would be appropriate and offer similar conclusions.

By viewing this presentation, and also referring back to the percentage summary shown in Table 6 , the following recommendations are offered with regard to site selection for the remaining cycles.

Uniform Building Code Sites - Table 6 indicates a slightly higher number of UBC sites than desirable. In attempting to approach 20 percent of the sites, in total, emphasis could be placed on selectin: some sites in Washington and more in California (because these States fall below the band-width shown in Figure 7) and conversely, few sites, if any, should be selected in New Mexico and Montana. The selection of sites in Arkansas (no sites identified in the first three residential demonstration cycles) could also be considered. 
Basic Building Code Sites - Table 6 indicates a good balance of the Basic Building Code sites in relation to the overall number of sites, but within that number the distribution could be adjusted slightly to provide better coverage. For example, a heavier selection of sites could be considered for Michigan and perhaps New Jersey for subsequent cycles. while Massachusetts with its 18 sites appears to have a sufficient number of sites for the overall demonstration program.

Standard Building Code Sites - The number of Standard Building Code sites is greater than desired, as indicated in Table 6, and adjustments could be made in site selection. In reducing the number of sites selected for the next cycles, fewer sites could be selected in Georgia, wille the number of sites in Florida and North Carolina seem adequate for the first three cycles.

State Code Sites - The sites using state codes are the least represented from an overall point of view. A heavier selection of sites irom New York would be in order, and some consideration should be given to increasing the number of sites in Ohio, while, of course, increasing the overall number of these sites from this group of states.

No Statewide Code Sites - Although the twenty-seven (27) no code states seem to be represented adequately as a group, as indicated in Table 6 , a study of Figure 7 indicates an inconsistent distribution as witnessed by the number of states falling outside the band-nidth established. obviously, Colorado, with its 25 sites should not be a candidate for additional installations. New Hampshire and South Carolina fall outside of the band-width and could not be assigned too many additional sites. On the other hand, Kentucky, Puerto Rico, Louisiana, Texas, Pennsylvania, and certainly Illinois are site shy in relation to the overall population scheme. Mississippi, Arkansas, and Wyoming have no sites at al1-a situation which could be considered in the next demonstration cycle. 


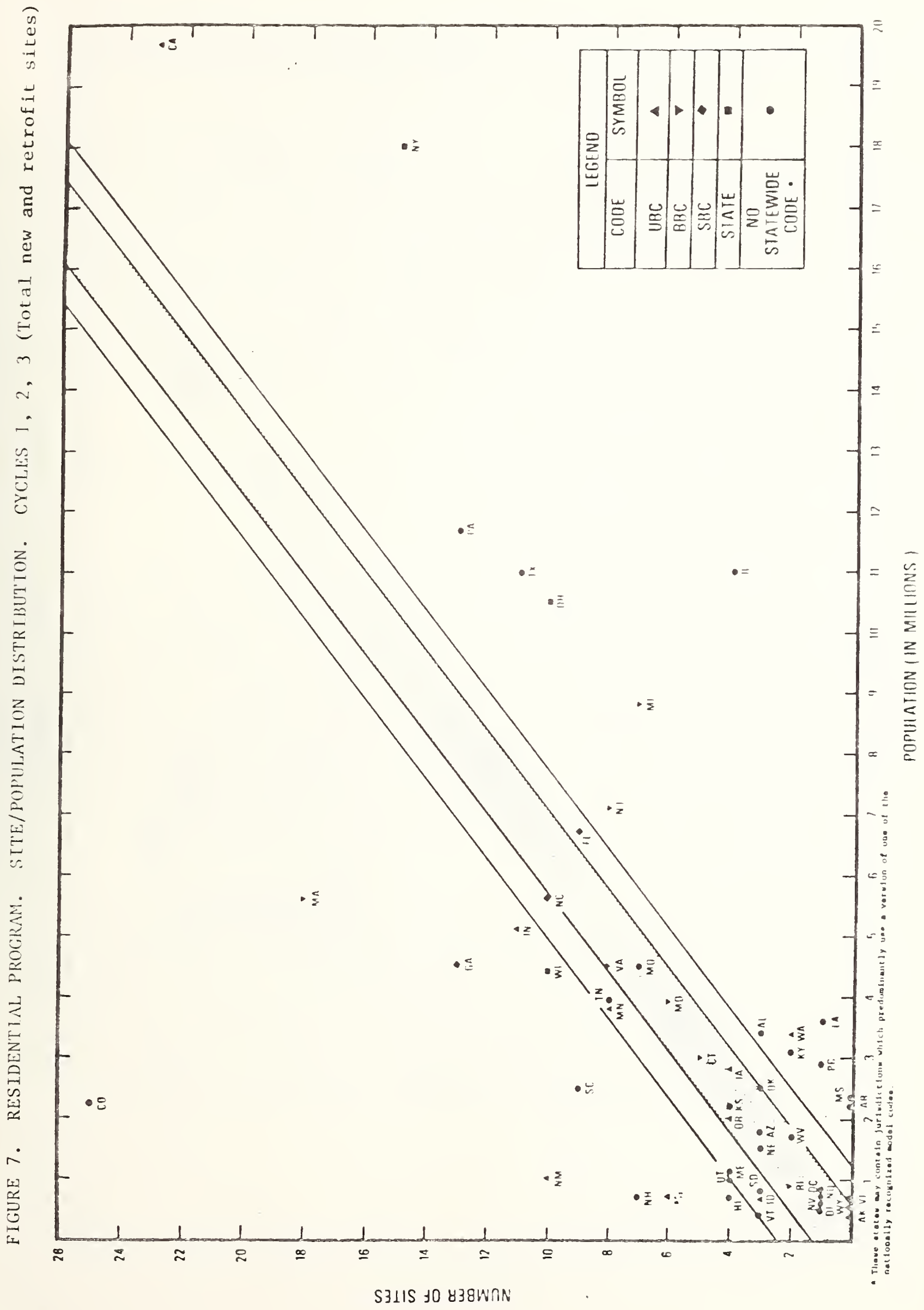




\subsubsection{Distribution of New and Retrofit Sites (Residential Program)}

Since building regulations present different problems to the builders of new buildings as compared to the builder who must retrofit an existing building, it is also important to determine a proper mix of these units if any meaningful conclusions are to be reached. There are five states which have no new solar sites; however, there are a disproportionate twenty-nine states that have no retrofit solar sites. Based on these figures, it is recommended that greater emphasis be placed on the selection of retrofit units and that the demonstration be conducted in states that have no sites presently assigned.

Figures 8 and 9 indicate the distribution of sites on a population basis for new and retrofit sites.

The ne: site distribution chart (Figure 8) includes a band-width constructed as previously described. The basis for this slope, however, is the premise that new sites should constitute $50 \%$ of the demonstration program and retrofit sites the other $50 \%$. From Figure 8 , it appears that Colorado, Massachusetts, New Mexico, South Carolina, New Hampshire, Montana, Tennessee, Minnesota, Wisconsin, l'irginia, Indiana, North Carolina, and Georgia perhaps contain too many new sites while Texas, Illinois, and certainly new lork could be said to be low on new demonstration sites.

A plot of retrofit sites compared to population is also made and included in Figure 9 and a band-width added using the slope as described previously under new sites. It is recommended that retrofit demonstratior. sites be selected in at least some states that presently contain nont and perhaps additional retrofit demonstration sites be assigned to Indiana, New Jersey, Michigan, Texas, Pennsylvania, New York and California. 


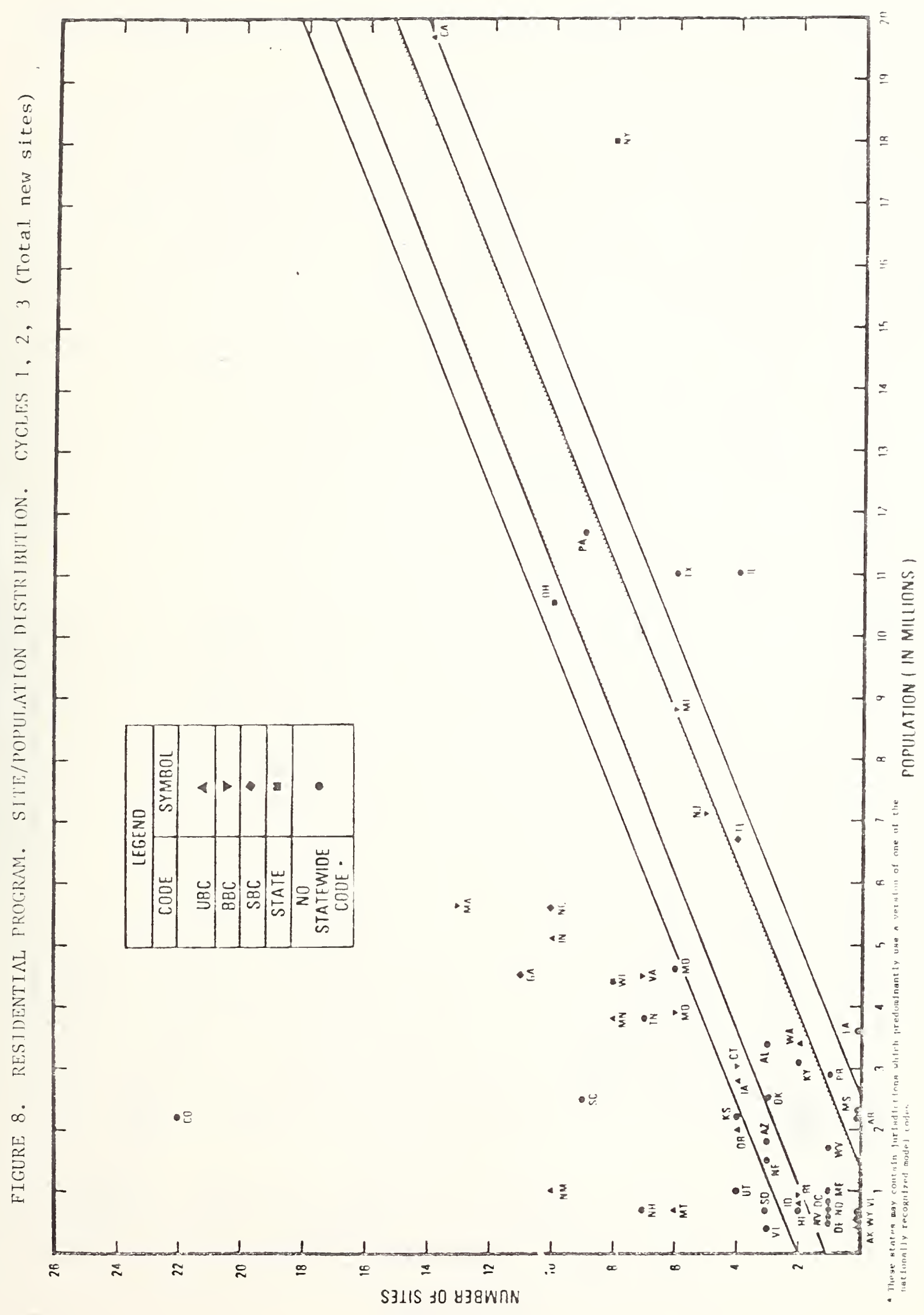




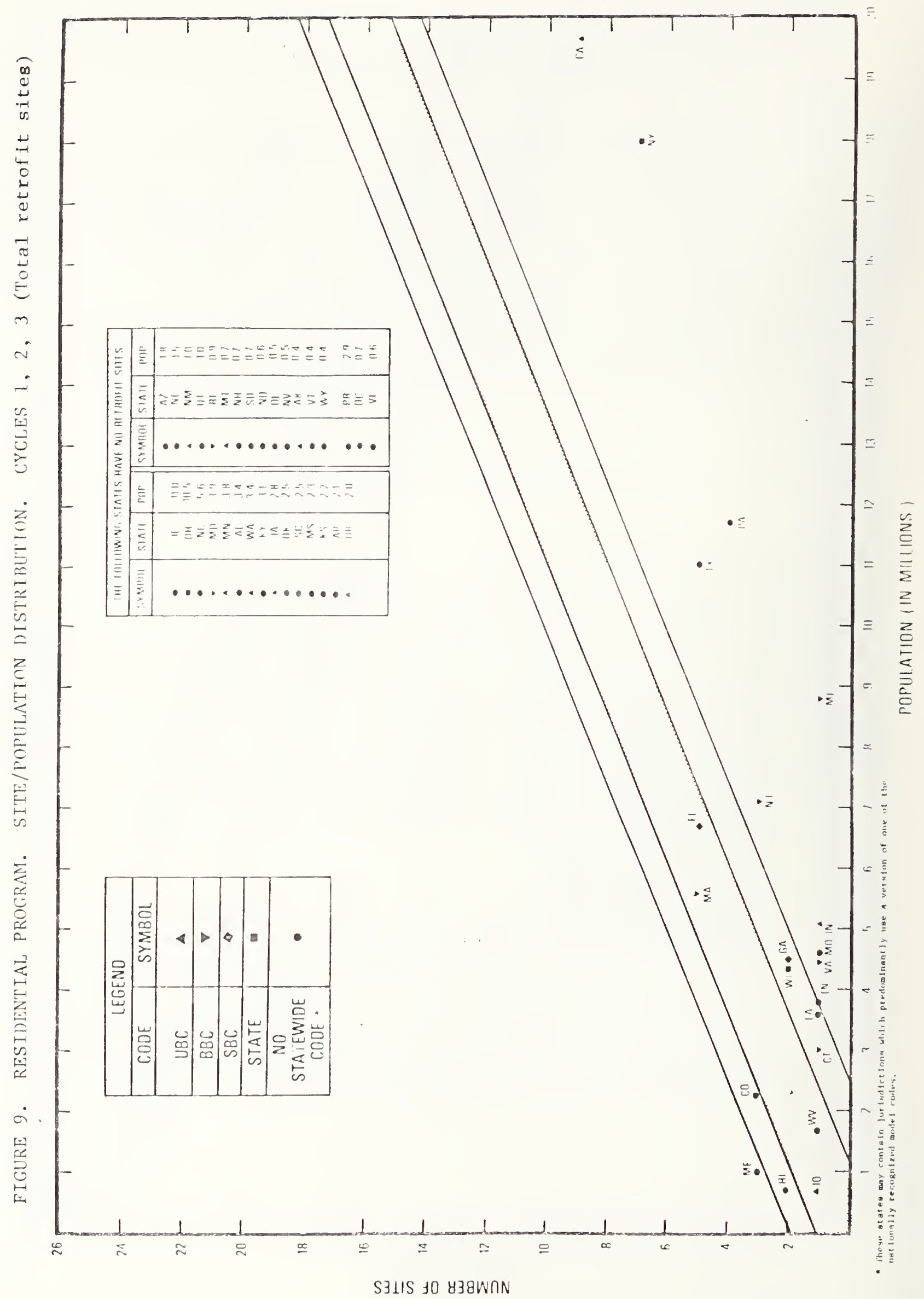


Although a reasonable overall distribution of demonstration sites presently exists, it is recommended that subsequent cycles be used to adjust demonstration site locations, as indicated, to more closely approa.t the population distribution of the United States. It is recognized that the above recommendations are offered to provide the baseline for subsecuent definitive regulatory studies and that other conditions, such as technical, climatological, geographical, political, and operational concerns may override the recommendations offered. However, the regulatory component of this project should be considered, and given appropriate priority.

\subsection{COMMERIAL SOLAR DEMONSTRAIION SITES}

\subsubsection{Distribution of Sites}

This part of the report review's the distribution of the solar energ: commercial sites selected for the demonstration program and the adequacy of the distribution for subsequent analyses of regulatory problems. The methodology used is similar to that described under the residential demonstration program with some changes in approach, as appropriate, as it is recognized that the commercial program differs from the residential program. with respect to types of installations, numbers of units, and variety of applications.

The basis for this analysis is a tabulation in Table 7 of the various states showing the distribution of the units per cycle for both cycles 1 and .. As is done for the residential study, the applicable codes are indicated from data contained in NBSIR 77-1390. Again, it is recognized that the states listed as having no statewide code may in fact contain jurisdictions which predominantly use a version of one of the nationally recognized model codes. However, for the purposes of this study, these states are grouped separately.

The data tabulated in Table 8 are developed using the same methodolog: as described in the residential section. It shows the number of states 
TABLE 7. COMERCIAL PROGRAY

SIIES PER CYCLE AND MODEL CODE BASE

\begin{tabular}{|c|c|c|c|c|c|c|c|c|c|c|c|c|c|c|c|}
\hline \multirow{3}{*}{ STATE } & \multirow{3}{*}{$\begin{array}{l}\text { POPUI. } \\
\text { (will) }\end{array}$} & \multirow{2}{*}{\multicolumn{3}{|c|}{$\begin{array}{l}\text { NUMBER OF SIIES } \\
\text { IN CYCLE }\end{array}$}} & \multirow{2}{*}{\multicolumn{3}{|c|}{$\begin{array}{l}\text { NEW SITES } \\
\text { IN CYCLE }\end{array}$}} & \multirow{2}{*}{\multicolumn{3}{|c|}{$\begin{array}{c}\text { RETROFII SIIES } \\
\text { IN CYCLE }\end{array}$}} & \multicolumn{5}{|c|}{ BUILDING COIE } \\
\hline & & & & & & & & & & & & $S E D$ & & & $\star$ \\
\hline & & 1 & 2 & $10: 81$ & 1 & 2 & Iot: & 1 & 2 & Io: 8 : & UBC & BE & SE: & & \\
\hline AL & 3.4 & 1 & 2 & 3 & 1 & 1 & 2 & 0 & 1 & 1 & & & & & $x$ \\
\hline $\mathrm{AR}$ & 0.4 & 0 & 0 & 0 & 0 & 0 & 0 & 0 & 0 & 0 & $x$ & & & & \\
\hline$A R$ & 2.1 & 0 & 0 & 0 & 0 & 0 & 0 & 0 & 0 & 0 & & & & & $x$ \\
\hline $\mathrm{AZ}$ & 1.8 & 1 & 0 & 1 & 1 & 0 & 1 & 0 & 0 & 0 & & & & & $x$ \\
\hline $\mathrm{CA}$ & 19.7 & 8 & 11 & 19 & 3 & 8 & 11 & 5 & 3 & 8 & $\mathrm{x}$ & & & & \\
\hline $\mathrm{CO}$ & 2.2 & 0 & 4 & 4 & 0 & 3 & 3 & 0 & 1 & 1 & & & & & $x$ \\
\hline CI & 3.0 & 2 & 4 & 6 & 1 & 3 & 4 & 1 & 1 & 2 & & $x$ & & & \\
\hline$D E$ & 0.5 & 0 & 0 & 0 & 0 & 0 & 0 & 0 & 0 & 0 & & & & & $\mathrm{X}$ \\
\hline F2 & 6.7 & 3 & 3 & 6 & 3 & 1 & 4 & 0 & 2 & 2 & & & $x$ & & \\
\hline$G_{A}$ & 4.5 & 2 & 1 & 3 & 1 & 1 & 2 & 1 & 0 & 1 & & & $\mathrm{x}$ & & \\
\hline $\mathrm{HI}$ & 0.7 & 0 & 1 & 1 & 0 & 0 & 0 & 0 & 1 & 1 & & & & & $x$ \\
\hline IA & 2.8 & 2 & 1 & 2 & 1 & 0 & 1 & 0 & 1 & 1 & $x$ & & & & \\
\hline ID & 0.7 & 0 & 0 & 0 & 0 & 0 & 0 & 0 & 0 & 0 & $\mathbb{X}$ & & & & \\
\hline II & 11.0 & 0 & 2 & 2 & 0 & 1 & 1 & 0 & 1 & 1 & & & & & $\mathrm{x}$ \\
\hline If & 5.1 & 0 & 2 & 2 & 0 & 1 & 1 & 0 & 1 & 1 & $\mathrm{X}$ & & & & \\
\hline RS & 2.2 & 0 & 4 & 4 & 0 & 4 & 4 & 0 & 0 & 0 & & & & & $x$ \\
\hline KY & 3.1 & 1 & 0 & 1 & 0 & 0 & 0 & 1 & 0 & 1 & & & & & $x$ \\
\hline LA & 3.6 & 1 & 0 & 1 & 0 & 0 & 0 & 1 & 0 & 1 & & & & & $x$ \\
\hline MA & 5.6 & 1 & 4 & 5 & 0 & 2 & 2 & 1 & 2 & 3 & & $\mathrm{x}$ & & & \\
\hline$M D$ & 3.9 & 5 & 3 & 8 & 1 & 3 & 4 & 4 & 0 & 4 & & $x$ & & & \\
\hline ME & 1.0 & 0 & 0 & 0 & 0 & 0 & 0 & 0 & 0 & 0 & & & & & $x$ \\
\hline$M I$ & 8.8 & 1 & 3 & 4 & 1 & 2 & 3 & 0 & 1 & 1 & & $x$ & & & \\
\hline$m$ & 3.8 & 4 & 2 & 6 & 3 & 2 & 5 & 1 & 0 & 1 & $x$ & & & & \\
\hline MO & 4.6 & 1 & 2 & 3 & 1 & 2 & 3 & 0 & 0 & 0 & & & & & $x$ \\
\hline MS & 2.3 & 0 & 0 & 0 & 0 & 0 & 0 & 0 & 0 & 0 & & & & & $\mathrm{X}$ \\
\hline $\mathrm{mt}$ & 0.7 & 0 & 1 & 1 & 0 & 1 & 1 & 0 & 0 & 0 & $x$ & & & & \\
\hline NC & 5.6 & 1 & 1 & 2 & 1 & 1 & 2 & 0 & 0 & 0 & & & $x$ & & \\
\hline ND & 0.6 & 0 & 0 & 0 & 0 & 0 & 0 & 0 & 0 & 0 & & & & & $x$ \\
\hline NE & 1.5 & 0 & 1 & 1 & 0 & 1 & 1 & 0 & 0 & 0 & & & & & $x$ \\
\hline $\mathrm{NH}$ & 0.7 & 1 & 2 & 3 & 0 & 1 & 1 & 1 & 1 & 2 & & & & & $\mathrm{X}$ \\
\hline $\mathrm{NJ}$ & 7.1 & 2 & 2 & 4 & 2 & 1 & 3 & 0 & 1 & 1 & & $x$ & & & \\
\hline NM & 1.0 & 2 & 3 & 5 & 1 & 2 & 3 & 1 & 1 & 2 & $x$ & & & & \\
\hline$N$ & 0.5 & 0 & 0 & 0 & 0 & 0 & 0 & 0 & 0 & 0 & & & & & $x$ \\
\hline$N Y$ & 18.0 & 0 & 5 & 5 & 0 & 3 & 3 & 0 & 2 & 2 & & & & $x$ & \\
\hline $\mathrm{OH}$ & 10.5 & 1 & 2 & 3 & 1 & 1 & 2 & 0 & 1 & 1 & & & & $\ddot{x}$ & \\
\hline
\end{tabular}

* These states may contain jurisdictions which predominantly use a version of one of the nationally recognized model codes. 
TAELE 7. COMERCIAI PROGRAM

SITES PER CYCLE AND MODEL CODE BASE - CONIINTED

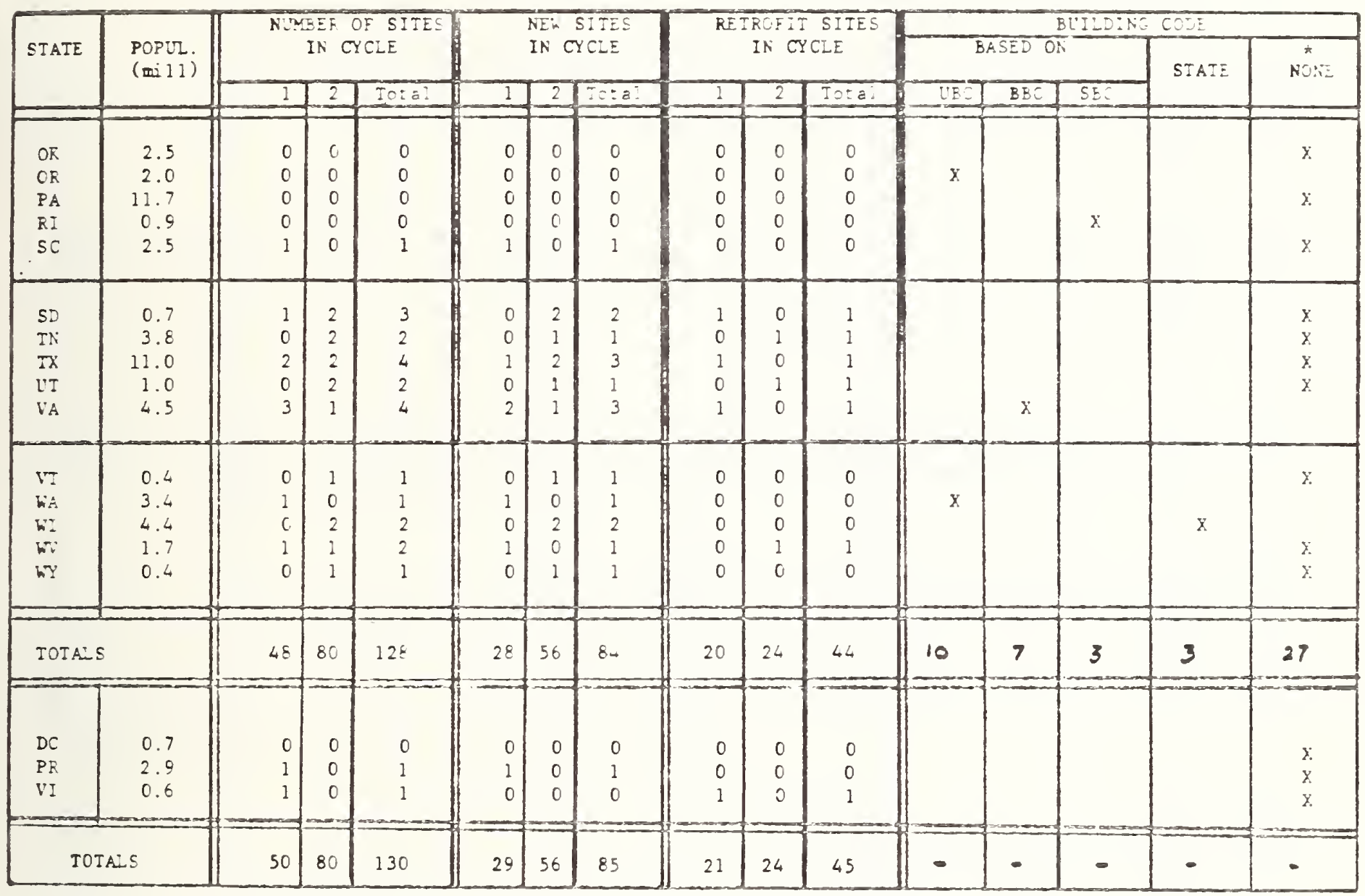

* These states may contain jurisdictions which predominantly use a version of one of the nationally recognized model codes. 
IABLE B. COMERCIAL PROGRA. BLILDINC CODE DISTRIBLTION

\begin{tabular}{|c|c|c|c|c|c|c|c|}
\hline $\operatorname{CODE}$ & $\begin{array}{l}\text { NC. OF } \\
\text { ETATES }\end{array}$ & $\begin{array}{l}2 \text { OF STATES } \\
\text { COVEPED BY } \\
\text { CODE }\end{array}$ & STATE/POP. & $\begin{array}{l}\text { TOTAL POP. } \\
\text { (IN MULLOOSS) }\end{array}$ & $\begin{array}{l}2 \text { OF POF } \\
\text { COYERED } \\
\text { CODE }\end{array}$ & $\begin{array}{l}\text { MO. OF } \\
\text { DEMONSIRATIOK } \\
\text { EITES }\end{array}$ & 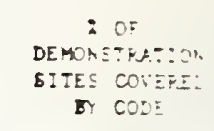 \\
\hline ICB: & 10 & 20 & $\begin{array}{cc}\text { CA } & 19.7 \\
\text { IN } & 5.1 \\
\text { MA } & 3.8 \\
\text { HA } & 3.4 \\
\text { IA } & 2.8 \\
\text { OF } & 2.0 \\
\text { NW } & 1.0 \\
\text { ID } & 0.7 \\
\text { W } & 0.7 \\
\text { W } & 0.4\end{array}$ & 35.6 & 20 & 35 & $\Omega^{-}$ \\
\hline $\begin{array}{l}E B: \\
B O C A:\end{array}$ & 7 & 3 & 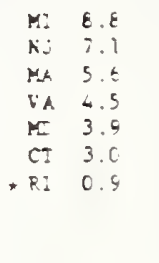 & $33 . \varepsilon$ & 17 & 31 & 2. \\
\hline $\begin{array}{l}55= \\
55:=\end{array}$ & 3 & 6 & $\begin{array}{ll}F_{2} & t .7 \\
N= & 5.6 \\
G= & 4.5\end{array}$ & $16 . \varepsilon$ & $\varepsilon$ & 1: & $\oiiint$ \\
\hline $\begin{array}{l}\text { ETREE } \\
\text { COEE }\end{array}$ & 3 & t & $\begin{array}{l}\text { Ne } 1 E .6 \\
\text { of: } 10.5 \\
\text { w: } \quad 4.4\end{array}$ & 32.9 & dt & ac & $\varepsilon$ \\
\hline 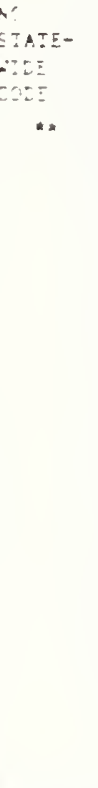 & 27 & 54 & 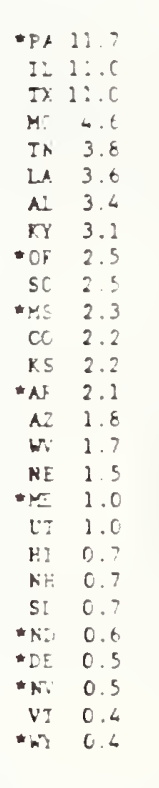 & 77.5 & 39 & 41 & 3: \\
\hline IOTALS: & so & $100:$ & & 200.6 & 100: & 128 & 100: \\
\hline
\end{tabular}

NOTE: This information deses not include Pueren fico (one site), Djstrict of Cojumbia (no site). V⿺rgan Islands (one site).

- These states do not have comerclal slies.

- These otates ma contain juriadictions utich predocinarity uae a version of one of the nationally recognized model cades. 
covered by each code, the corresponding population and the number of sites. The information is summarized in Table 9.

\begin{tabular}{|l||c|c|}
\hline Code & $\begin{array}{c}\% \text { Population } \\
\text { Covered by } \\
\text { Code }\end{array}$ & $\begin{array}{c}\% \text { of Demonstration } \\
\text { Sites Covered by } \\
\text { Codt }\end{array}$ \\
\hline UBC & 20 & 27 \\
\hline BBC & 17 & 24 \\
\hline SBC & 16 & 8 \\
\hline State Code \\
\hline $\begin{array}{l}\text { No State- } \\
\text { wide Code* }\end{array}$
\end{tabular}

Table 9. Commercial Program

Summary of Code Distribution

This comparison reveals a disproportionate mix of commercial sites, as compared to the percentage of population covered by each code with the exception of the Standard Building Code sites. The Uniform Building Code states seer: to have too many sites, while the states with no statewide code and states that have their own code are site deficient, from a codes and standards viewpoint. Subsequent site selection could, of course, alleviate this situation.

To further analyze the distribution of the commercial demonstration sites, a site/population distribution (Figure 10) is made as described in the residential section of this report. Again, a band-width of four sites is 


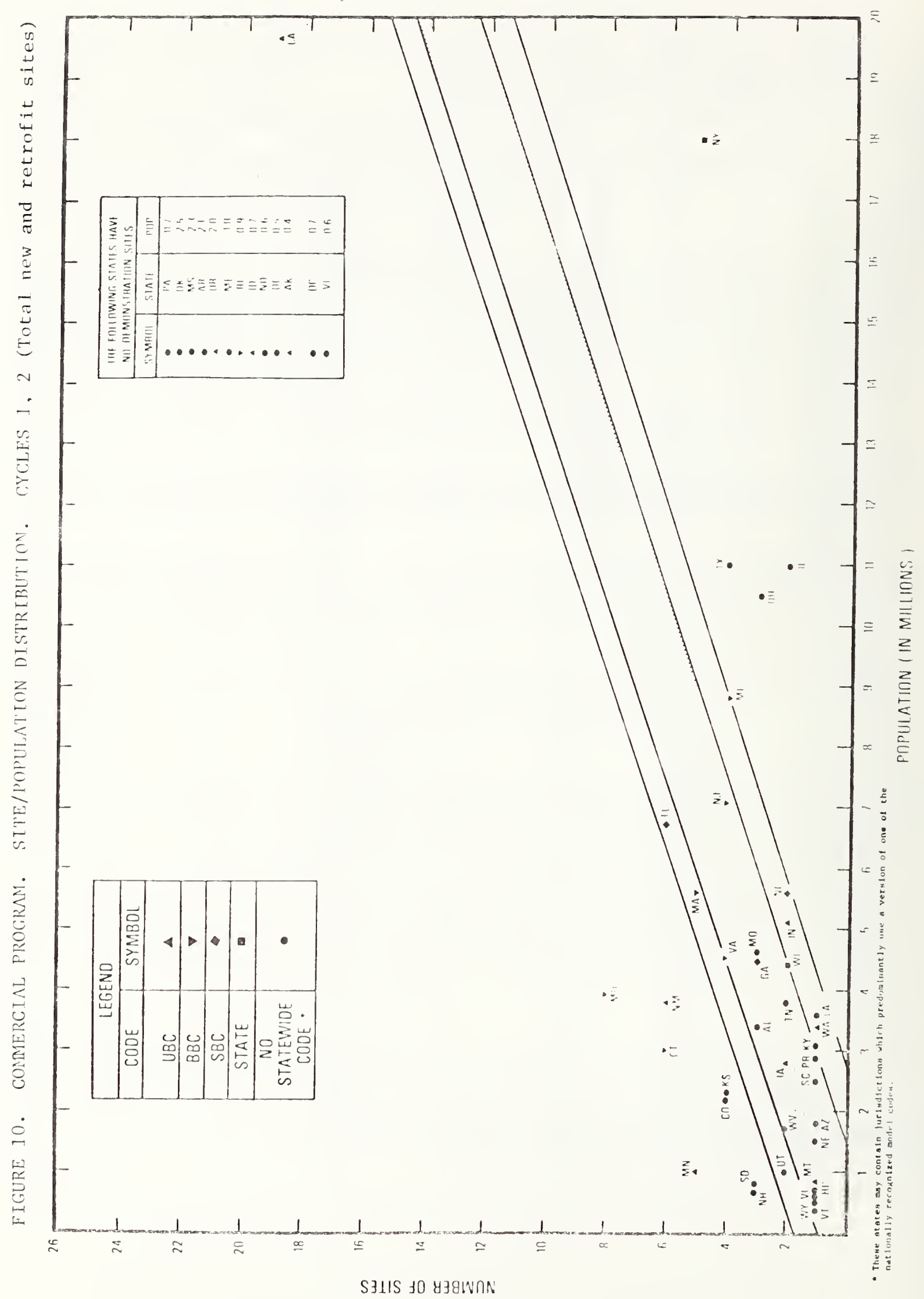


constructed using a șlope appropriate for the total number of sites in the commercial program to indicate a reasonable tolerance for site distribution, but as indicated previously, any reasonable band-width will give basically the same results. Comments and recommendations concerning the commercial sites are given by applicable codes:

Uniform Building Code Sites - A disproportionate number of sites fall into this category. Sites selected for subsequent cycles could be proportionately fewer than selected for the first two cycles. New Mexico, Minnesota and California may also contain a sufficient number of sites for the entire demonstration and a more desirable choice would be to select sites in Oregon, Indiana, and Arkansas, which contain no commercial sites.

Basic Building Code Sites - The number of Basic Building Code sites is also excessive when compared to the percentage of the population covered by the Basic Building Code. Figure 10 leads to the recommendation of not selecting Maryland or Connecticut for additional sites, as well as reducing the total number of sites to be selected for subsequent demonstration cycles.

Standard Building Code Sites - The total percentage and the distribution of sites basing their regulations on the Southern Building Code seems reasonable, and no changes are recommended.

State Code Sites - The selection of sites within these states should be emphasized during subsequent cycles if a good mix of code data is to be obtained. Additional sites could be chosen in ohio and certainly New York.

No Statewide Code Sites - These states also need emphasis for site selection during the remainder of the commercial demonstration program. From an inspection of the site/population distribution (Figure 10), the states with no commercial sites should be prime candidates; namely Arizona, Delaware, Maine, Mississippi, North 
Dakota, Oklahoma, the District of Columbia, the Virgin Islands and certainly Pennsylvania. Additional sites in Illinois and Texas are also recommended.

Again, it must be stated that these suggestions are made with regard to developing an adequate distribution for regulatory analysis purposes. Compelling reasons could change this distribution if technical, climatological, geographical, political, or operational concerns are warranted. In addition, it is recognized that commercial solar demonstration sites may be difficult to establish in certain states.

No analysis is made regarding the mix of new and retrofit sites. Such: an analysis is meaningless at this time, because of the relatively small number of sites in the commercial demonstration program; however, for subsequent site selection, an attempt to achieve a proper balance of new and retrofit sites could be considered.

\subsubsection{Distribution of Building Type}

Another parameter examined is the distribution of building types (occupancy) within the commercial solar demonstration program. A larger variety of building types over a wide distribution of locations is desirable. These could demonstrate various technologies and applications and lay the groundwork to assess any regulatory difficulties encountered because of building usage.

The sites selected for demonstration cycles 1 and 2 are tabulated alons with building type (see Table 10). From this tabulation it appears that educational facilities (ED) and low rise office buildings, one to three stories (OL), are more than adequately represented. It would, of course, be impossible (or perhaps even undesirable) to demonstrate each building type in each state; however, a more homogeneous matrix should be developed through subsequent site/building selection. Perhaps dormitories (DR), department stores (DS), shopping malls (ML), post offices (PO), and supermarkets (SM) can be represented if the other parameters affecting site selection can also be satisfied. 


\begin{tabular}{|c|c|c|c|c|c|c|c|c|c|}
\hline 童 & & - & & & - & & & & \\
\hline$\overline{3}$ & & & & & & & - & & \\
\hline$\frac{I}{6}$ & & & & & & & & & \\
\hline$\stackrel{\infty}{>}$ & & - & & - & & & & & - \\
\hline$\infty$ & & & & & & & & - & \\
\hline ta & & & & & & & & - & \\
\hline 2 & & & & & & & & & \\
\hline$\therefore$ & & & & & & & & & \\
\hline$\vec{c}$ & $-\quad-$ & $-m \quad-$ & & $r--$ & - & -- & -- & $\sim$ & $r-$ \\
\hline $\bar{z}$ & $\sim$ & - & & & & & & & \\
\hline $\overrightarrow{\underline{x}}$ & & & & & & & & & \\
\hline$\stackrel{x}{=}$ & $\sim$ & & & & - & & & & -- \\
\hline \pm & - & & & & & & & - & \\
\hline$\doteq$ & $\begin{array}{ll}- & -\end{array}$ & - & & & & & & - & \\
\hline$\Xi$ & - & & & & - & & & & \\
\hline$\underline{\underline{\underline{I}}}$ & & & & - & - & & & - & \\
\hline$\underline{z}$ & - & & & - & & & & & \\
\hline$\cong$ & & - & & - & - & & & & \\
\hline $\overrightarrow{0}$ & & & & & & & & & \\
\hline : & - & - & - & - & & & & & \\
\hline 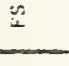 & $\sim$ & & & - & - & & 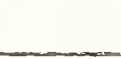 & & \\
\hline$\overline{1}$ & -9 & $\sim \quad-$ & $--\quad \sim-$ & $\begin{array}{l}-40 \\
\end{array}$ & --- & - & - & & -- \\
\hline$\cong$ & & & & & & & & & \\
\hline$\underline{x}$ & & & & & & & & & \\
\hline $\bar{z}$ & & & & & & & & & \\
\hline ث & - & & & & & & & & \\
\hline$\stackrel{x}{ \pm}$ & & & & & & & & & \\
\hline 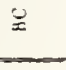 & & & & & & & & & \\
\hline $\bar{z}$ & - & -- & - & -- & - & & & -- & \\
\hline $\overrightarrow{2}$ & 2 & - & & & & & & & \\
\hline$\frac{\pi}{4}$ & & & 20 & & & $x=0$ & $=$ & & \\
\hline 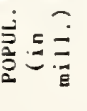 & 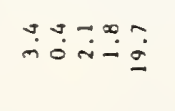 & 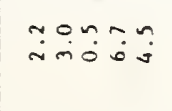 & $\ddot{\circ} \dot{\sim}: \stackrel{0}{=} \dot{\sim}$ & îmiñ & $\begin{array}{l}0 x x \leq ? \\
-\infty \\
-\infty\end{array}$ & $\ddot{i n}$ & $\because \dddot{0}$ & $\because$ & 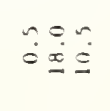 \\
\hline 尝 & 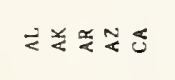 & 8 与岂豞 & $\Xi \leq \Omega \Xi z$ & 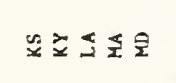 & 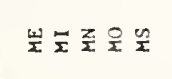 & $\xi \stackrel{0}{\Sigma}$ & 呈势焉 & $\sum \frac{\pi}{2}$ & 引立巨 \\
\hline
\end{tabular}




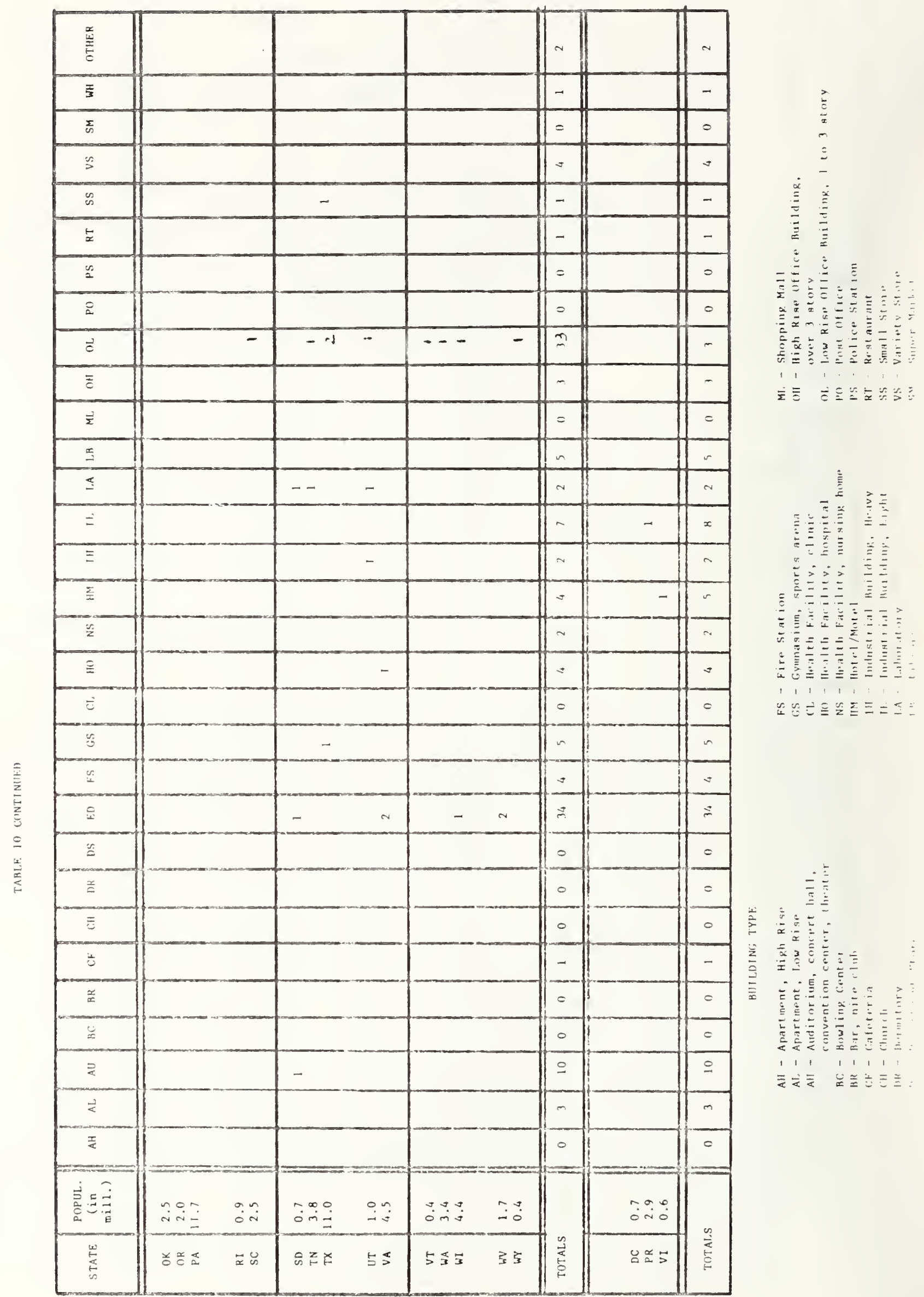




\subsubsection{Conclusion}

The distribution of sites for the first two cycles of the commercial demonstration program with respect to codes and standards is not generally in accord with the population distribution of the lnited States. Moreover, consideration should be given to diversifying the selection of buildins type to demonstrate a broader mix of application. It is, therefore, recommended that subsequent commercial demonstration sites be selected to bring greater balance, if the technical, climatological, geographical, political, and operational concerns can also be satisfied. 


\section{PRELIMINARY RESULTS AND FUTURE ACTIONS}

Most of the data identified in Section 5 were not received as of the closing date of this report. As indicated, contacts were made with all appropriate data collecting organizations and arrangements were mads to receive these data. Upon receipt, data will be reviewed and the rest oi the methodology shown in Figure 1 implemented, including the analysis (step 7 ), the identification of data deficiencies (step 9), the preparation of changes $t$ questionnaires (step 10), and the preparation of reports (step 8). The development of parameters for analysis (step 12) is, of course, not dependent upon the receipt of data and can progress incependently.

Although very limited data have been received, informal discussions initi. individuals in the field indicate that very few problems are perceived in the regulatory area. If these perceptions are correct, does this mean thet:

(1) There are no problems with existing regulations and they are not, and will not be a barrier to the development of solar applications as a viable source of non-depletable energy?

$$
\text { or, }
$$

(2) Problems do not exist because the indiridual jurisdictions have conidence in the system being installed because they have the endorsement and are under the sponsorship of the Federal Government.

or,

(3) The local jurisdictions are not perceptive enough to know they might have problems because they do not really understand the solar systema being installed (and there is a 100 percent auxiliary backup)? lili they over-react, in a regulatory sense, in subsequent installations if presenty installed systems start to fail and complaints are received?

It is anticipated that as this program develops and hard data are receivec, an insight into the solar regulatory system will be achieved and enlightened answers to the above questions forthcoming. On the other hand, attempting to 
develop meaningful conclusions in the field of codes and standards from data based on a Federally-funded demonstration program may be futile or not effective. It might be more productive to collect data from a more "real world situation" by not relying on demonstration data at all, but rather on collecting data from independent builders of solar installations and analyzing their regulatory difficulties. An attempt will be made to address these issues in subsequent reports. 


\section{SUMMARY}

As noted, the reporting period covered by this document is dominated by initial planning and preparation to receive and analyze building regulatcr: data. The time frame covered is such that the data collection effort expended by the various organizations was just starting to become effective as the initial ilow of data appeared. The next thrust in this program, as the data flow increases and the data base broadens, is the effective gathering of these data and the initiation of preliminary analyses with feedback to the data collection system, as required, to assure a meaningful overall assessment. 
APPENDIX I

SECTIONS A, B, C, D 
APPENDIX I

\section{SECTION A}

Selected Questions from RERC Data Collection Instruments Relative to Codes and Standards

Appendix

Reference

\section{Volume II}

I. AI

Single Family Builder/Developer

Question 2le

I. A2

Comparative Single Family Builder/Developer

Question $17 e$

I. A3

Multifamily Builder/Developer

Question $20 e$

I. $A 4$

Comparative Multifamily Builder/Developer

Question IgE

\section{Volume III}

I. A5 Local Building Code Official

Entire Questionnaire

(56 Questions) 
21. Did you hove ony problems with the following during the plonning and construction phase of the project?

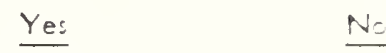

o. Getting construction loons

for development

for solor houses

If yes, please exploin

1
1
2

b. Getting permanent finaneing

for development

for solor houses

If yes, please exploin

for development

for solor houses

12

If yes, please exploin

d. Getting site plans approved

for development

for solar houses

If yes, pleose exploin.

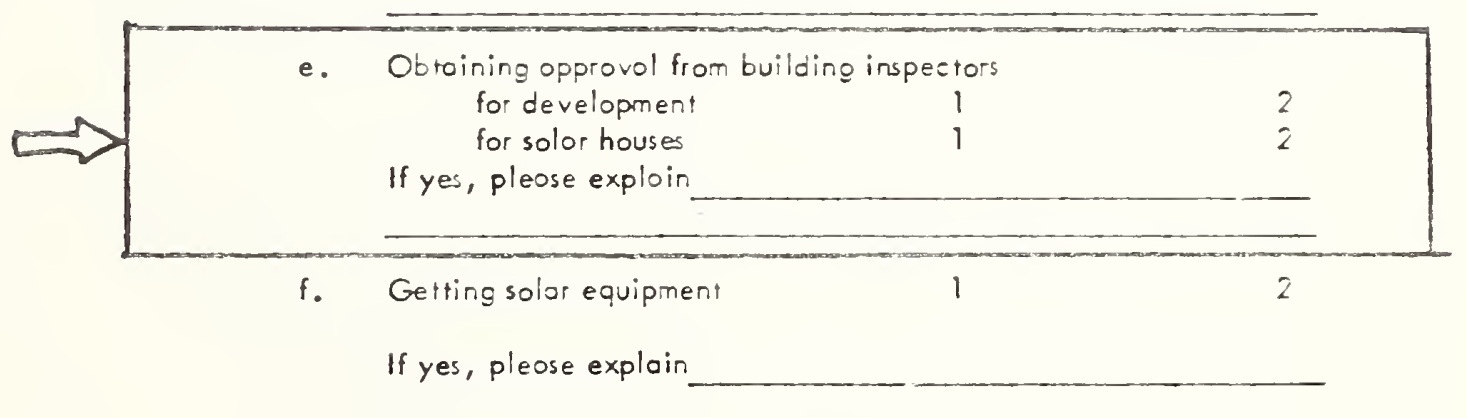

\section{AppendixIA1 - Single Family Builder/Developer}




\section{PHASE OF DEVELOPMENT}

\section{A. Construction Phase}

Now, l'd like to ask you ofew questions obout the construction phase of the development and the houses:

17. Dio you have any problems with the following during the planning ord construction phose of the project?

o. Getting construetion loses

for developmen:

1

If yes, ploose explois

b. Getting permanent financing

for o'evelopmen:

If yes, pleose exploin

=. Gelling zaning opprova!

for óvelopmen:

1

If yes, please exploin

d. Getting site plons approved for development

If yes, pleose exploin

e. Obtoining opproval from building inspectars for development

If yes, please explain

\section{AppendixIA2 - Comparative Single Fomily Builder/Develope}


20.

b. Getting permanent finoncing

for development

for solor op".

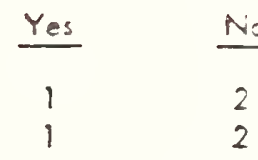

If yes, pleose exploin

c. Getting zoning opprovel

for development

for solar opt.

If yes, please exploin

d. Getting site pions approved

for development

for solar opt.

If yes, piesse exploin.

e. Obtaining opproval from builaing inspesiors

for development

for solor opt.

2

If yes, please exploin

$\begin{array}{ll}1 & 2 \\ i & 2\end{array}$

Gething soior equipment

f. Getting soior equipment

1

2

If yes, pleose exploin

9. Securing servicing for the solar units

1

If yes, plèse exploin

h. Securing worrantees for the solar systems

If yes, pleose exploin

\section{AppendixIA3 - Multi-Family Builder Developer}




\section{PHASE OF DEVELOPMENT \\ A. Construction Phase}

Now, I'd like to ask you c few questions cbout the construction phase of the development and the rental units:

19. Did you have ony problems with the following during the pienning and co-struction phese of the projes:?

c. Gelting consiruction loans

for developmen!

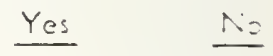

1

2

If yes, pluose explain

b. Getting permanes, fincncing

for cevelopment

?

If yes, plecse explain

c. Gelting zoning approvol

for developner:

1

2

If yes, plecse explain

d. Gelting sire plons opproved

for development

1

2

If yes, pleose explain

e. Obloining approval from builoing inspectors for development

$i$

If yes, pleose explain

\section{Appendix IA4 - Comparative Multi-Family Builder/Developer}




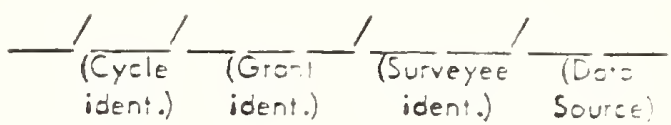

Respondent 10 (Circle one)

Porticipoting Construstion Lender Porticipoting Permonent Lender Non-Forticipoting Lende:

ES

Porticiparing Insurance Co/Agensy

Auxition Uitity

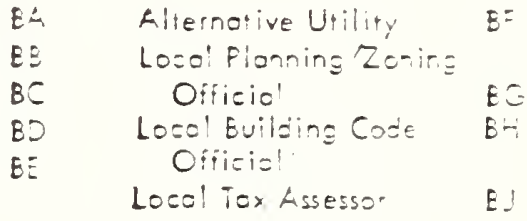

HUD GRANT NO.

LOCA! BUILDING CODE OFFICIAL INTEPVIEW GUIDE

NAME OF RESPONDENT

TITLE

NAME OF AGENCY/DEPARTMENT

JURISDICTION

ADDRESS

TELEPHONE

DATE OF INTERVIEW'

NAME OF INTERVIEVVER

(Detoch ofter completing Interview)

\section{Appendix IA5}



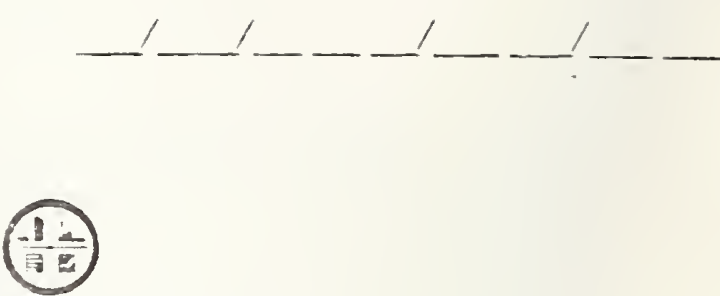

Real Estate Research Corporation

no MT STRET AH - Wasmincton oC $200 x$

\section{LOCAL BUILDING CODE OFFICIAL INTERVIEW GUIDE}

\section{INTRODUCTORY STATEMENT}

Real Estare Research Corporation is conducting a study of marke accepiance of solar energy in residential dwelling units for the U.S. Deportment of housing and Urbon Development. This research effort is port of a national demonstration program fo: resiaential soiar heating and cooling. Part of our research is focusec on the role of institutions whict, may or may not be involved in the development of solar energy in residential construction. In order to assess instifutional response po solar energy we ore tolking to representatives of banks, sovings and loans, planning and zoning officials, tax assessors, utility companies, and others. Essentially, we are interested in finding out what these institutions think about solar, what impast, if any, sola: develosmen: would have on the institution, and whether the ir existing or projested policies would hove o maierial impact on the development of solar. 


\section{LOCAL BUILDING CODE OFFICIAL INTEPVIEW GUIDE}

1. PROFILE OF BUILDING CODE ADMINISTRLTION

1. Where is your deportment lacated within the government's orgarizationa siructure?

2. This deportment is port of what level of govemment?

$\begin{array}{ll}\text { City' } & 1 \\ \text { City/County } & 2 \\ \text { Regiona! } & 3 \\ \text { Other; specify } & \end{array}$

3. How many inspectors do you hove in the deportment?

4. Does your deportment hove (on) establishec building codels?

$\begin{array}{ll}\text { Yes } & 1 \\ \text { No } & 2 \text { (skip to } Q .8 \\ \text { Don't know/not opplicable } & 3 \text { (skip to } Q .8 \\ \text { Did not onswer } & 4 \text { (skip to Q.8 }\end{array}$

5. What is (are) the name (s) of the cade(s)? 
6. On what codefs) is (are) it (they) modeled?

$\begin{array}{ll}\text { BOCA -- Bosic } & 1 \\ \text { AIA - Notional } & 2 \\ \text { SBCC -- Southern } & 3 \\ \text { ICBO -- Uniform } & 4 \\ \text { IAPMO - - Uniform Plumbing } & 5 \\ \text { NFPA - NEC and life sofety } & 6 \\ \text { ANSI } & 7\end{array}$

FHA-MPS

8

Other; specify

Dor'l'know/not applicode

7. Hon closely does (do) your code (s) conform to the model code(s'?

Moceled with some voriation

1 (skif 10 Q.9)

Mienóatory minimum

Mandotory

Don'i know

2 (skip to Q.9)

Does not opply

3 (skip to Q.9

Other, specify

4 (skip to Q.9)

5 (skip 10Q.9)

8. If not, how are buildings and struetures evaluated with regard to putlic health and sofety? 


\section{EXPERIENCE WITH DENONSTRATIONPROGRAM}

Recently, the U.S. Deportment of Housing and Urbar Development pravised o local builde: with o grant to install o sala: system in one (or morel of this resioential units.

9. Are yau familia with the sala house (s)/apartment(s) that was (were, tuil an o federal grant in your jurisoliction?
Yes
1
No
2 (skip to 0.21)

10. Wiere ony waivers requested to occommoozie the solar syster?

$\begin{array}{ll}\text { Yes } & \text { ) } \\ \text { No } & 2 \text { (skip } t=0.12) \\ \text { Dan't know/nat applicable } & 3 \text { (skip } t 0.12 \\ \text { Did no: answer } & 4 \text { (skip to } 0.12\end{array}$

Oine:; specify

If yes, piease explain

11. Wiere these woivers granted?

$\begin{array}{ll}\text { Yes } & 1 \\ \text { No } & 2 \\ \text { Don't know/no applizabie } & 3 \\ \text { Did not onswer } & 4 \\ \text { Other: specity } & \end{array}$

Please explain

12. Viere any design changes required prior to oppraval?

$\begin{array}{ll}\text { Yes } & 1 \\ \text { No } & 2 \\ \text { Don't know/not applicable } & 3 \\ \text { Didnat answer } & 4\end{array}$

Other; specify

If "yes", please explain 
13. Were syster opprovals handled in the normal monner by regulatory personnel or dic' special considerations prevail? Plecse explain.

14. Vras special troining needed for regulatory staff or field inspectors?

$\begin{array}{ll}\text { Yes } & 1 \\ \text { No } & 2 \\ \text { Don't know/not applicable } & 3 \\ \text { Dio not answer } & 4\end{array}$

Oiner; specify

If "yes", please exploin

15. Viere job site inspestions handled in o normal way or by special personnel? Piesse exploin.

16. Viere ony odditional jot site inspections necessory?

Yes

No

Don't know/not opplicable

Did not answer

1

Other; specify

If "yes", please explain 
17. Did it take longe: to process the sola application than it would hove for conventional pioperty?

Yes

No

Don't know/no! applicable

Did not answer

Other, specify

If "yes", please exploin
1

2 skip to 0.19

3 skip to Q.19

4 (skip to 0.19

18. If the time factor was increased, would this hold true for future residemit opplications using solar energy systems?

Yes

1

No

2

Dar'iknow/no: applicable

Dic no: answer

3

Other; spezify

Please exploin

19. Did the foet that the solar unit (s! was (were funded by a federal gran. impost the approval process?

$\begin{array}{ll}\text { Yes } & 1 \\ \text { No } & 2 \\ \text { Don"know/not applicable } & 3 \\ \text { Did not answe- } & 4\end{array}$

Did nol answe

4

Other; specify

If "yes", please explain 
20. Would the process hove differed for a solor unit built outside of the demonstration project?

$\begin{array}{ll}\text { Yes } & 1 \\ \text { No } & 2 \\ \text { Don't know/not opplicable } & 3 \\ \text { Did' not answe: } & 4 \\ \text { Other; specify } \\ \text { If "yes", please exploin }\end{array}$


III. BUILDING CODEAND SOLAF EYSTENSAPPLICATIONIN GENEFLL

21. Hos your office /agency reviewed or piosessez any applico ions fo builum permits for other solor units ir inis jurisoiction?

Yes

No

Don't know/not opplicable

Dic not onswer

1

2 (skif 100.31 )

3 (skip to 0.31 )

4 (skip to O.3!)

If "yes", how many and whe" type of units were the;?

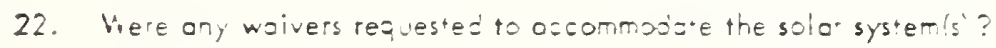

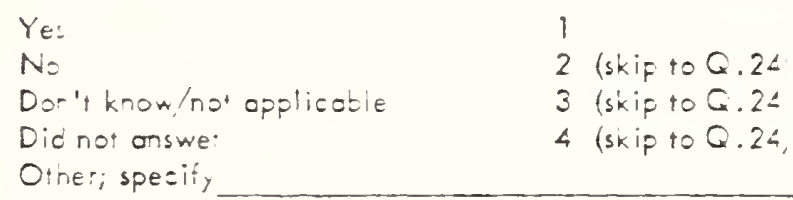

If "yes", please exploir.

23. Viere these woivers granted?

$\begin{array}{ll}\text { Yes } & 1 \\ \text { No } & 2 \\ \text { Dor't know/not opplicoble } & 3 \\ \text { Did not onswer } & 4\end{array}$

Other; specify

Please explain 
24. Viere any design changes required prior to approval?

$\begin{array}{ll}\text { Yes } & 1 \\ \text { No } & 2 \\ \text { Don't know/not applicable } & 3 \\ \text { Did not answer } & 4\end{array}$

Other; specify.

If "yes", please explcin

25. Viere syster approvals handled in the normal manner by regularory personnel or dio spesial considerations prevail? Pleose explain.

26. Vias special training needed for regulatory staff or field inspectors?

$\begin{array}{ll}\text { Yes } & 1 \\ \text { No } & 2 \\ \text { Don't know/not applicable } & 3 \\ \text { Did not answer } & 4 \\ \text { Orher; specify } \\ \text { If "yes", please explain }\end{array}$

27. Wiere jot inspections handled in a normal way or by special personnel? Please expiain. 
28. Were ony additional jot site inspections necessary?

Yes

1

No

Dor''l know/not opplicable

Did not answer

Other; specify

If "yes", please exploin

29. Did it take longer to piocess the sola: opplicatior thar it would have fo conventional properiy?

Yes

1

No

Don't know/not opplicable

Did not onswe:

Other; specify

2

3

Otheri specily

If "yes", pleose exploin

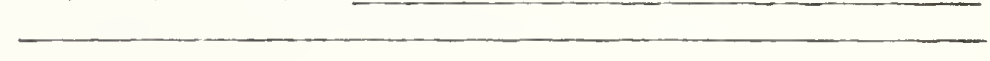

30. If the time foctor wos increased, would this hoid rive for future residentiol opplications using solc: energy systems?

Yes

No

Don's know/not opplicable

Did not answe?

Other; specify

Pleose exploin 
IV. SOLAR ENEPGY SYSTENSIMPACT ON BUILDIIVG CODE

31. Dses your cooe contcir provisions for solar systems instollotion?

Yes

1

No

Don't know/not opplicoble

Dio' not onswer

Other; specify

If "yes", please exploin these provisions. (Inieviewet ob: oin copies).

32. Hos your depatimen' studies the ovestion of the patentiol impart of solar energy systems on the building cose?

Yes

1

No

Don't know/nol opplicoble

Did not answer

2 (skip to Q.35)

Orher; spesify

3 skif to $Q .35$

4 (skip to Q.35

33. Winot were the conclusions of the study? (Interviewer try to obtoin copy of study).

34. As o result of this study, hove pracedures or regulations been madified or changed to focilitote the instollotion of solor energy systems in residentiol developments?

Yes

No

Don't knaw/not applicoble

Did not onswer

Other; specify

Pleose exploin
1 (skip to Q.36)

2 (skip to Q.36)

3 (skip to Q.36)

4 (skip to Q.36) 
35. Would such o study be useful?

$\begin{array}{ll}\text { Yes } & 1 \\ \text { No } & 2 \\ \text { Don't know/not opplicoble } & 3 \\ \text { Did not onswer } & 4\end{array}$

Other; specify

36. Are you seeking organizationa! certificatior (praduet opprovol) of e sola: energy system as a piereguisite to issuing o builoing permit?

Yes

1

No

2 skip to 0.38

Dor't know/nat opplicoble

Dió not answe

3 skip to Q.38

Other specity

4 sitip to G.3E

If "yes", please explair. whot type of opprova! wauld be nesessa"y":

37. To which orgatizotion(s) would you look fo prosust opprovo!?

3E. What kinds of soia energy systems would have probiems meeting coos requirements? Why? 
39. Dos this jurisdiction require compliance with FHA-MPS?

Yes

1

No

Don't know/not opplicoble

Did not answer

Other; specify

40. Wiould there by building cade problems in setrititing o solar system in an older structure?

$\begin{array}{ll}\text { Yes } & 1 \\ \text { No } & 2 \\ \text { Dor't know/not applicable } & 3 \\ \text { Didno: answer } & 4 \\ \text { Other; spezify } \\ \text { If "yes", please explain }\end{array}$

41. Apart from normal differences, woulc any unique considerations prevail for a multifamily vs. single-family solar residence?

$\begin{array}{ll}\text { Yes } & 1 \\ \text { No } & 2 \\ \text { Don't know/not applicable } & 3 \\ \text { Did not onswer } & 4\end{array}$

Other; specify

If "yes", please explain

42. About how long does it take to get a major building code change approved? Plecse exploin. 
43. Is enabling legislation nesessary in orde: 10 amend or madity the builaing code?

Yes

$N=$

Don't know/not opplicable

Did not answe?

Other; specify

If "yes", please exploin the nature of this legisiotion and the odministrative proces:

44. Aie there ocministrative rules ond regulations which coule irpeje tre widespread accep'ance of sois energy sysiems ir resideritia' develogne-"? Yes

No

Dor': know.'not applicable

Dió not answe?

Oner; specity

If "yes", piezse exploin 
45. Wrould you soy that the existing building coof tends to encourage or discourage energy conservation?

$\begin{array}{ll}\text { Encourage } & 1 \\ \text { Discourage } & 2 \\ \text { No impoet } & 3 \text { (skip to Q.4.7) } \\ \text { Don't know/no: applicable } & 4 \text { (s'kip to Q.47) }\end{array}$

46. In what way dses the code encourage (or discourage energy conservation?

47. Dos the building deparment hove ar estatlishez energy conservation program that it promotes among builaers in the area?

Yes

No

Dor't know/not applicable

Did not answer

Other; spesify

If "yes", please describe the progrom:

4E. Does on energy conservation procam exist within the city/county government?

Yes

No

Don'l know/not applicable

Did no: answer

1

2

3

Other; specify

If "yes", please describe the program and its relation to the building deportment: 


\section{V1. KNOWLEDGE AND ATIITUDES RE: SOLAP. ENEREY SYSTEMS}

49. How knouledpeable ore yau and the others in you department ogensy obout residentiol solct energy systems?

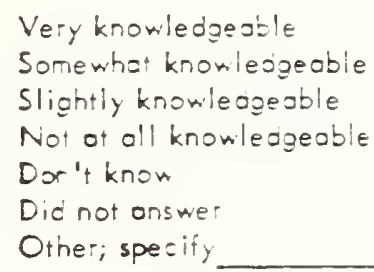

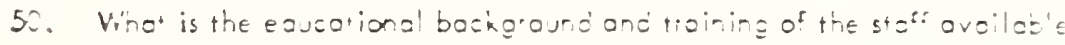
to prosess applications dealing with sola energy systerts ir residentic development?

51. Víhere did you leorn about solar energy systems?

Neurspoper

Popular mogezines

Trose publications

Professional journals

Television

Radio

Oiner; specify

52. In your position, what majar barriers do you see today regarding builaing codes which may impede the installation of solar energy systems in you? jurisdiction? 
53. What problems do you foresee regarding building codes for the future application o: residential sola energy systems in this jurisdiction?

54. Please identify specific aieas where assistance to the building officic might be required for solar opplicarions:

(Note to interviewe: cite these os examples)

\section{Chesk}

Training of Evcluators Inspestors

Mranuls of Accepied Proctice

Inspeztion Guigelines

Certificotion

Tezhnical Support/Aóditional Stait

Moje! Codes'Orjinances

Others; piease exploin

55. What specific kinds of information do you need to moke o better decisior regaroing solar systems opplicotions in resióntiol development? 
56. To which of the following sources would you normally look for building cade issues related to solo energy systems? Please rank them by orat: of importance.

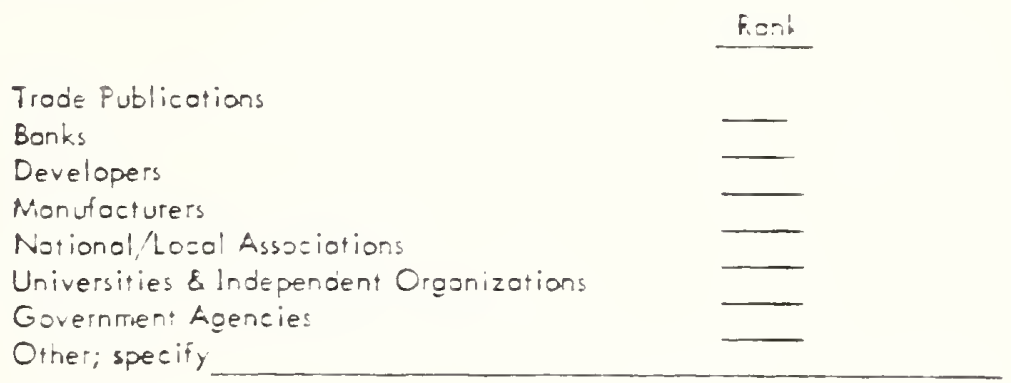

Note to Interviewer: Odtain copies of all building cooe regulations and reio:ez mane in: opp'icobie for solar energy systems ir resioential developme-:.

END OF INTERVIEW

Time elapses

Comments 
APPENDIX I

SECTION B

Selected Questions From AIA/RC Data Collection Instruments Relative to Codes and Standards

\section{Appendix \\ Reference}

I. BI

Building and Site Description

I. B2

Design Process Data

Page A-2

Page $\mathrm{C}-11$;

Question 19 
TYPE OF SOLAR SYSTEM INTEGFATION

.. The desion is:

( ) o new design

( ) on adopiation of an existing desio-

( la retrotit, original buileing completed, 19

REGULATORY CODES

- The apriicable codes are:

( ) stote

() local

( ) otner (specify)

NAME OF STATE OR LOCAL CODE/RECULATIO'.

- Buildins

- Nechonico

- Elestrico!

- Piumbirg

- Other

MODEL CODES WHICH ARE THE BASIS FOP REGULATIOI IS

NUTE: Use abbreviations from beisu

- Building

- Miechanicol

- Electrica!

- Plumbing

- Other (specify)

Abbreviotions

ICBO - Uniform

BOCA - Sosiz Building Code

SBCC - Southera Euilding Code

Alń - National Building Code

HUD - Minimum Property Stondards

NO.' - Nane

OTH-Other (specify)

\section{Edition (Yeo-)}

Edition (Yecr)

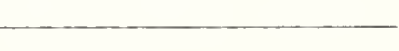




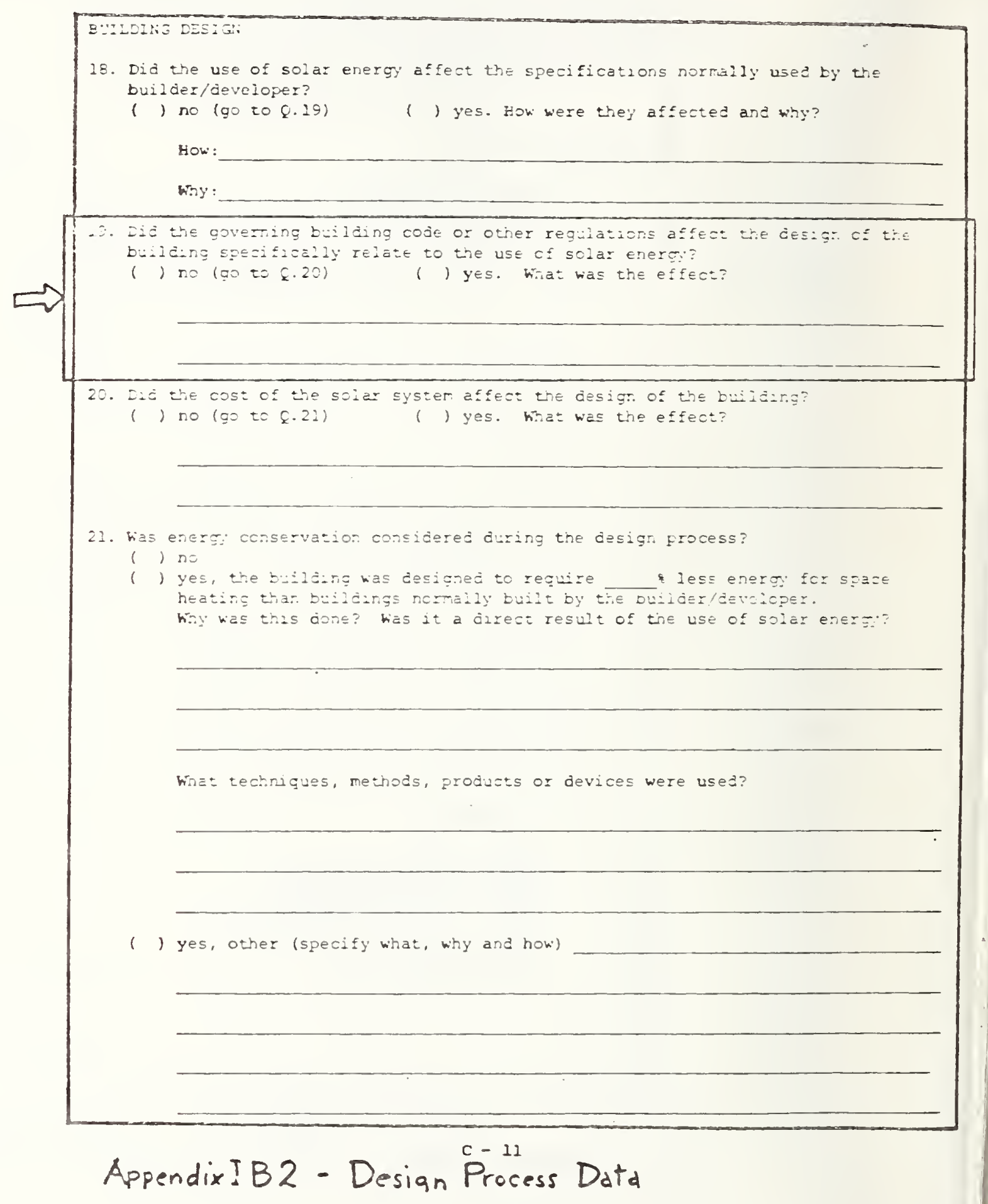


APPENIDX I

\section{SECTION C}

Selected Questions From HUD/Boeing Data Collection

Instruments Relative to Codes and Standards

Appendis

Reference

I. Cl Report No. 3, Construction Report

Page 3;

Question Qd 
Q o. Building Code:

1) Name of Local Building Code:

2) Is this code based on a National Model Code:

Yes () ; No $($ )

If "Yes", which Model Code:

E. Sack-uf Syster Energ:

1) Bach-up syster energy used. Wame \& Aadress of Utility company or suzzier

c. Gas ( )
b. Eieztric
c. Fue? Ci?
c. Other (

Idertify ivoe: (Prozarie, hooc, coai, etc

2: hate Structure requested

3) Fàte Siructure granied

4) Current cost of fuei 0il or other:

5) Experience (including problers, if any) in obtaining baci-ut energy:

\section{Appendix ICl - Report\#3. Construction Report}


Selected Questions Fror PRC Data Collection Instruments Relative to Codes and Standards

Appendix

Reference

I. D1

I. D $2 a$

I. $\quad D 2 b$

I. D3

I. D4a

I. D4b

I. D5a

I. D5b

\section{Series 10}

Building Description

Solar System Design Progress Report

Question 11

Question $\varepsilon$

Question 10

Series 20

Construction Progress Report

Question $\varepsilon$

\section{Series 30}

Demonstration Observation Report

Question $\varepsilon$

Question $9(-)$

\section{Series 40}

Owner/User Attitudinal Data

Question 3:

Question 1 ic 


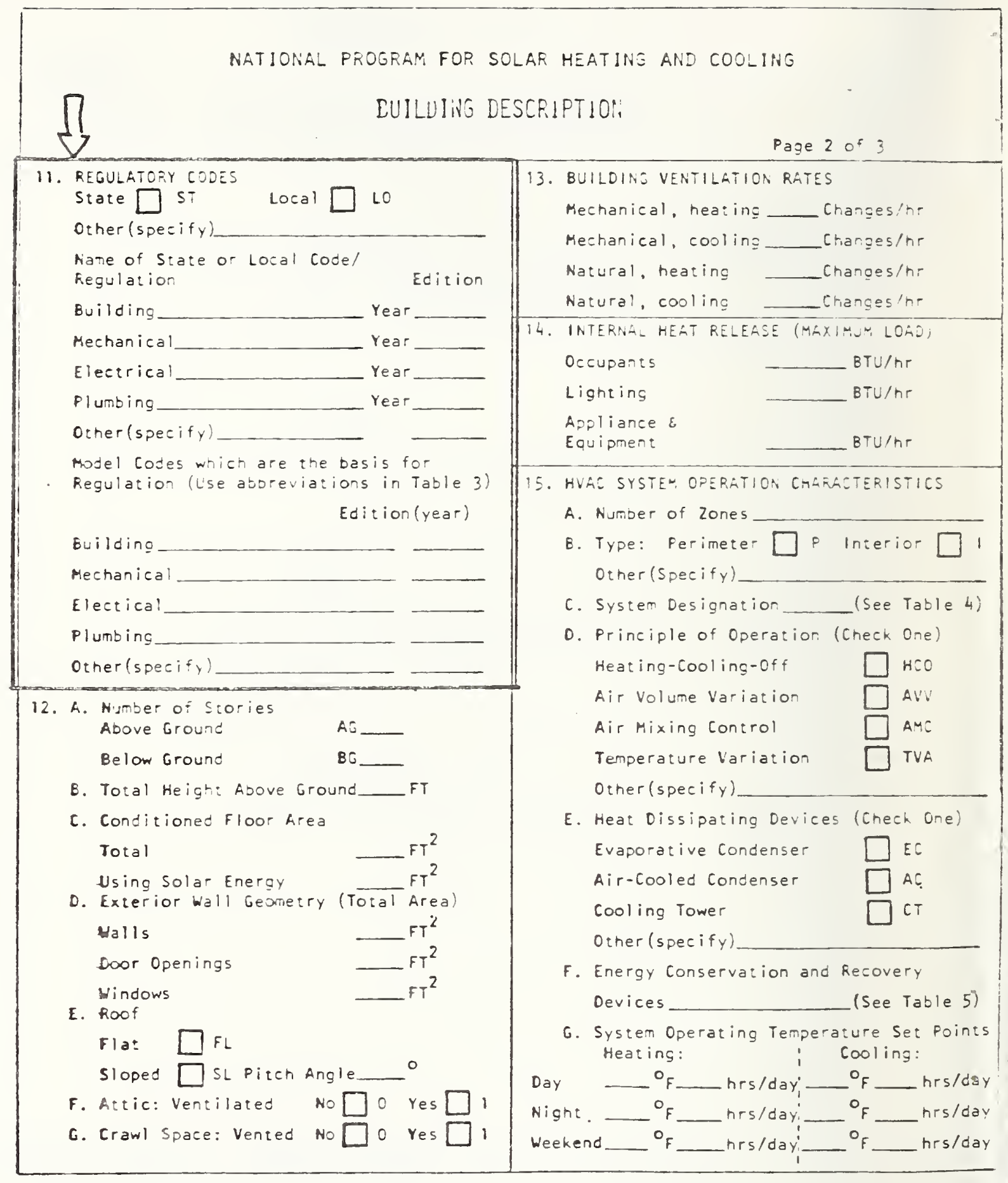

\section{Appendix -IDI}




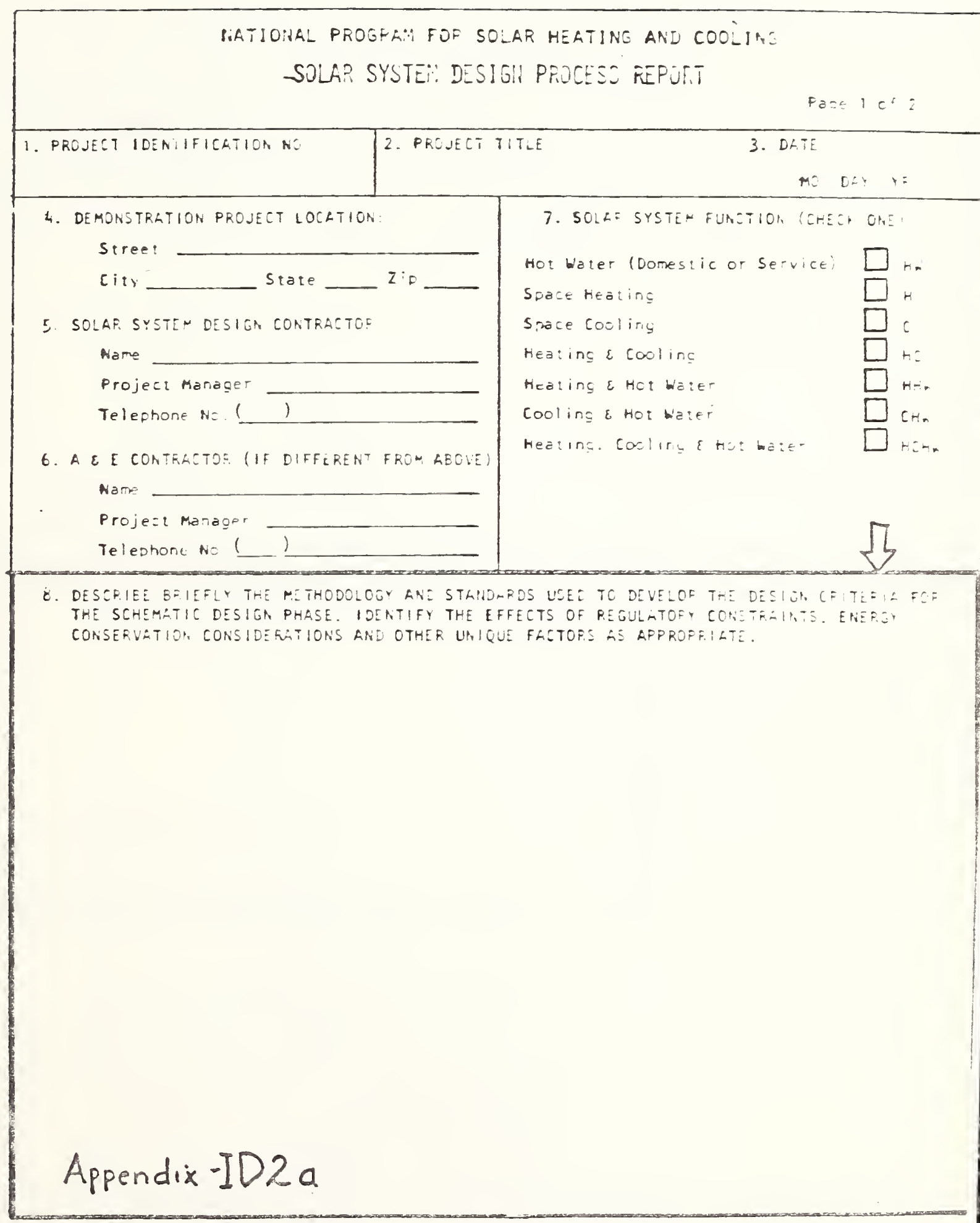




\section{NATIONAL PROGRAM FOR SOLAR REATING ANE COOLING}

SOLAR. SYSTEY: UESIGIV PROCESS REPOFT

Paçe 2 of 2

9. A. BFIEFLY DESCFIBE AIVY SYSTEM JUSTIFICATION ANO TRADE-OFF STUDIES UNDEFTAKEN IA THE SCHEMATIC DESICN PHASE AND/OR THE DESIGN DEVELOPMENT PHASE

B. IDENTIFY GOVERNIRU CODE

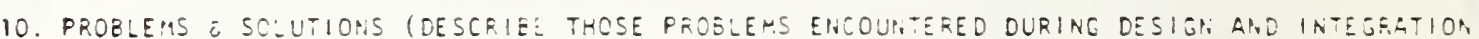
OF SOLAP SYSTEM ESPECIALLY IN THE FOLLOWINO AREAS: PEFFORMANEE STANDARDS. EULDINE CODES. LANO USE, ZOINA, SUN ACCESS. INSURANICE. AESTHETICS. ALSO DESCKIEE HOW THESE WERE ALLEVIATED)

11. SYSTEM SAVINES E PAYBACK PERIOD (ATTACH WORKSHEETS OF COMOUTATIONS)
A. Estimaied cost of Sular System E Auxiliar. System
B. Estinaled cost of Conventional Energy System
C. Incremental cosi of Solar sysiem
(C) $=(A)-(B)$
D. Estinated cost of Solar System Operation (including Auxiliary Enerayl
E. Estinated cost of Conventional System Operation
F. Energy cosi savings $(F)=(E)-(D)$
C. Simple Payback Period $(C) /(F)$

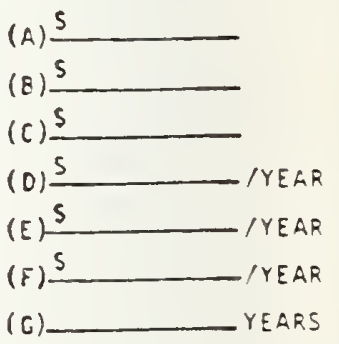

PREPARED BY

\section{Appendix -ID2b}




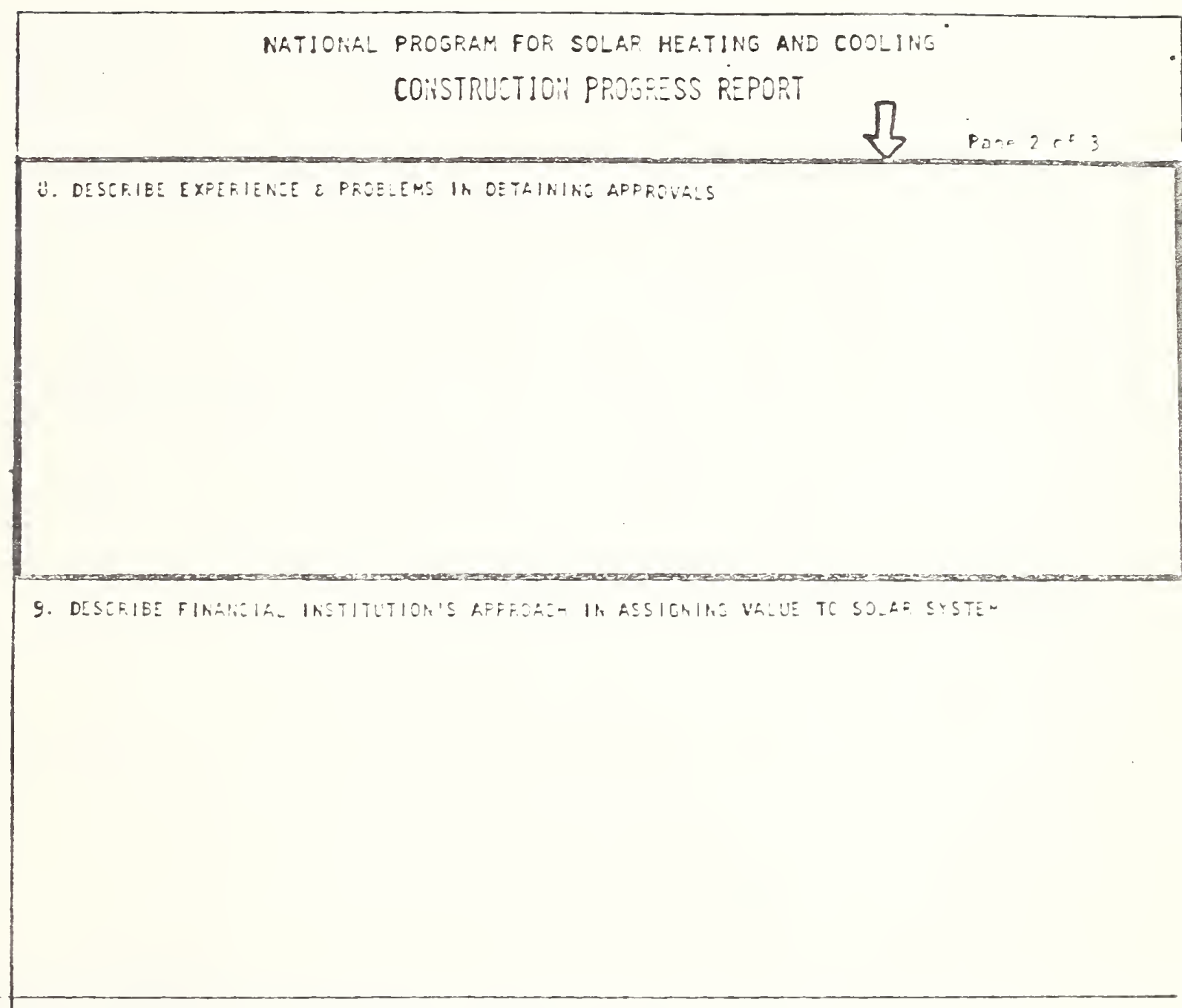

10. DESCRIBE SOLAP. SYSTEM RELATE CONSTRUETION/THSTALLATION PROELEN

\section{Appendix - IDJ}




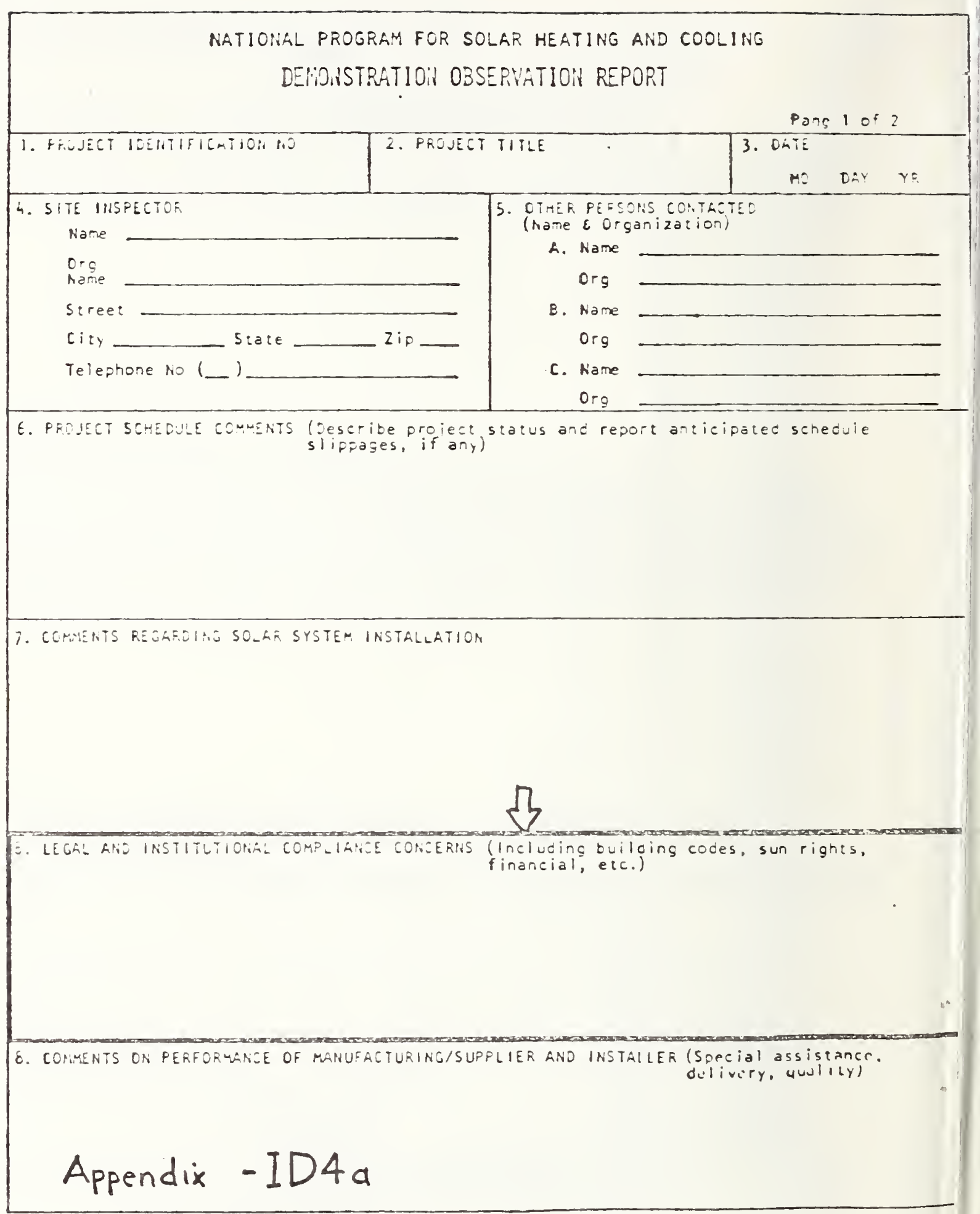




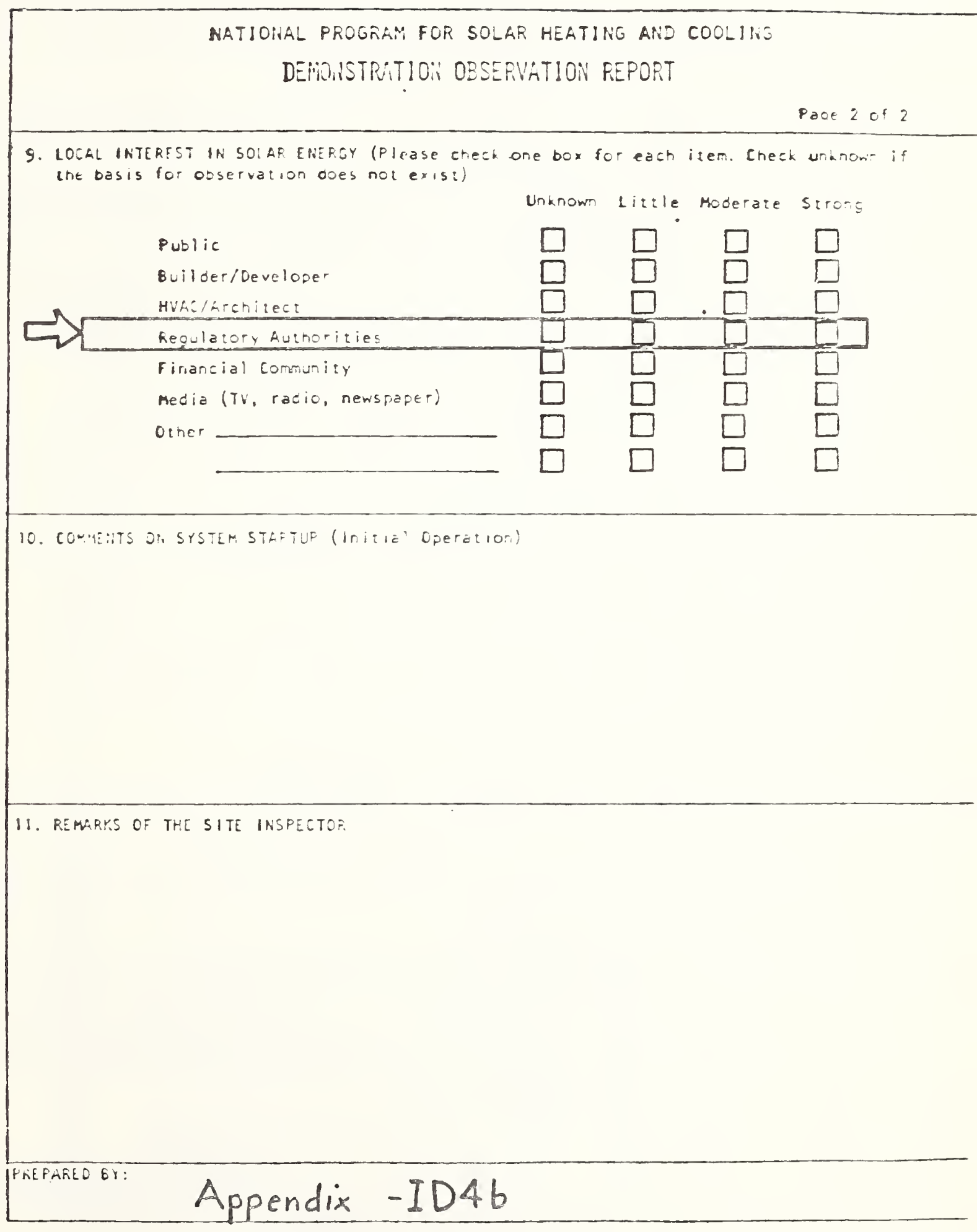




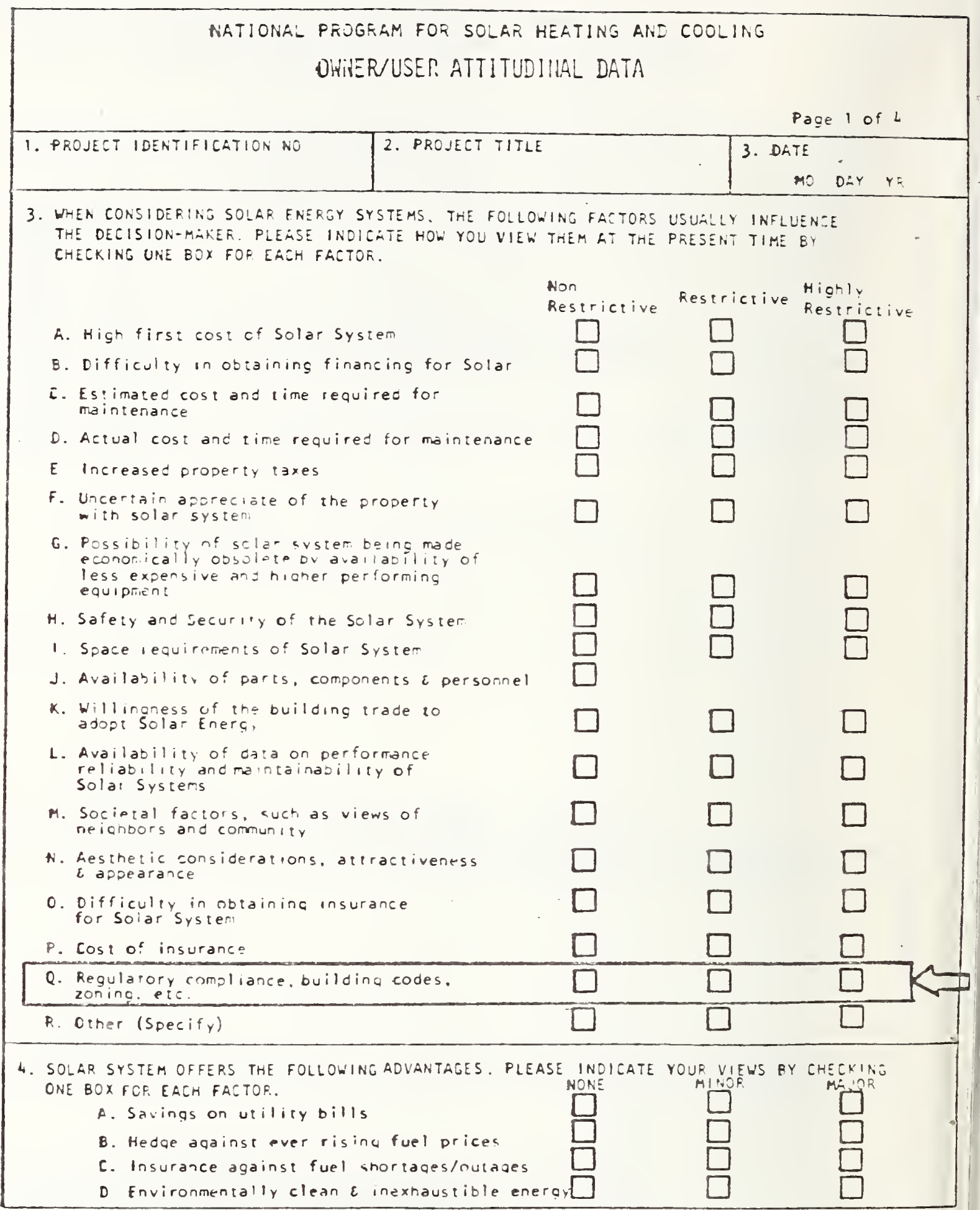

\section{Appendix-ID5a}




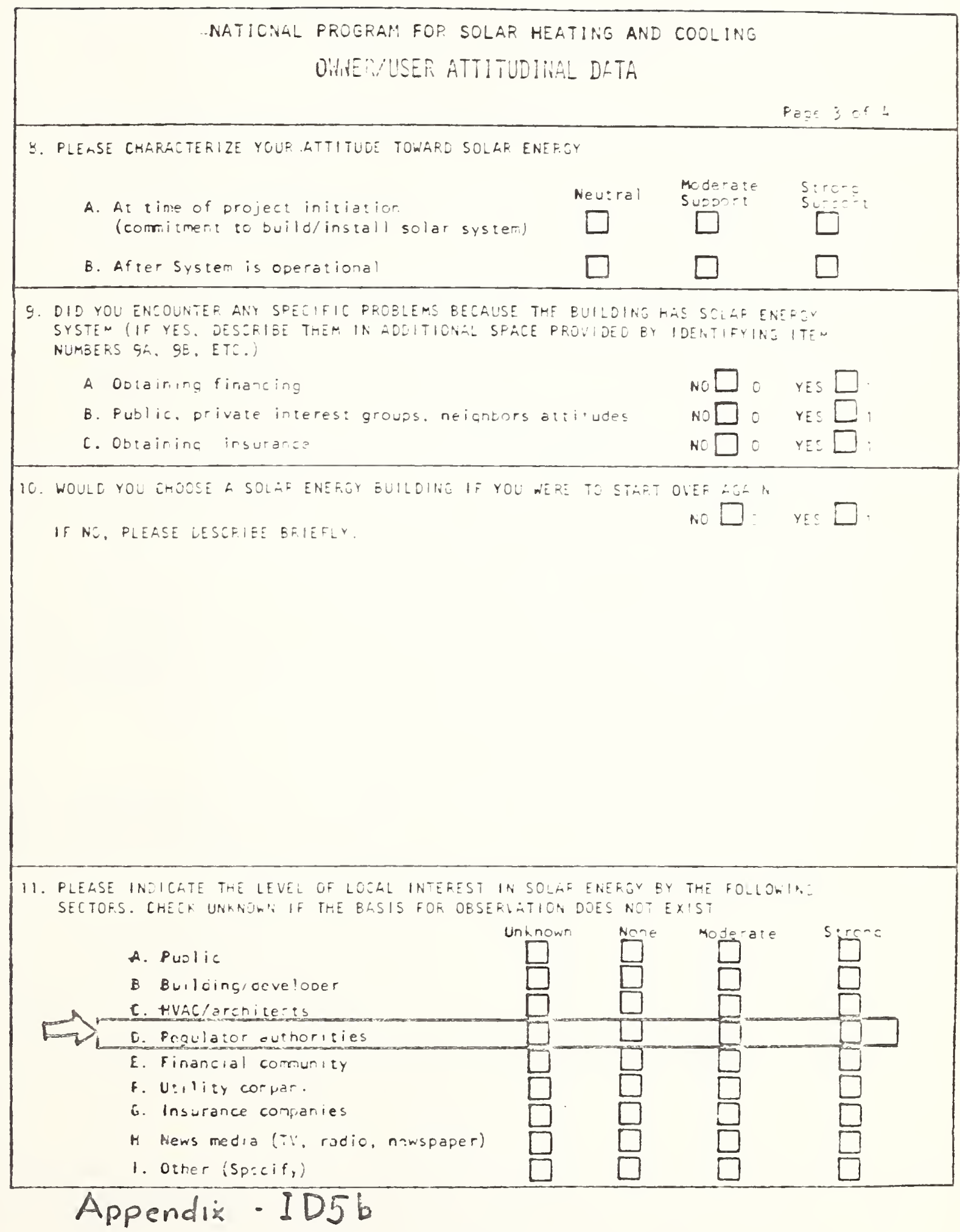




\section{IXTRODLCTION}

The purpose of this literature survey was to determine the perceived constraints identified as barriers to the installation and use of solar energy systems as contained in published reports, trade magazines, professional journals, newspapers, etc. The identification of barriers and constraints to acceptance of solar energy systems in residential development is one of the objectives of the HL'D Solar Demonstration Program ${ }^{1}$.

The publications surveyed do not specifically document constraints, but generally discuss problems which could inhibit the use of solar energy systems. Discussions are focused on the long-standing premise that prescriptive codes inhibit innovation and that the only reasonable solution to effective solar codes is the performance approach.

Another perceived difficulty is the lack of standards in the solar area, but this problem should be resolved as the solar industry matures with the development of́ a full range of standards, test procedures, accepted practices, etc.

Other perceived problems, although isolated and speculative at this time, should be confirmed or dismissed as data are collected and analyzed during the Solar Demonstration Program.

\section{PERFORMANCE STANDARDS}

The "Solar Heating and Cooling Demonstration Act of 1974" calls for the development of interim performance criteria for solar heating and combined solar heating and cooling components and systems to be used in residential

1 "Plan for Non-Technical Survey Research Activities for the HuD Residential Solar Heating and Cooling Demonstration Program" - Volume I, p. 9, Real Estate Research Corporation, January 1977. 
dwellings, and for interim performance criteria for the dwellings themselves. The key word in these.provisions is "performance."

Over the years, various public and private committees, commissions, task forces, etc., established to study the impacts of building standards and codes on innovative technologies have recommended that standards and codes be written to stress the performance approach rather than a specification approach; e.g., performance statements specify the intent, the quantifiable goal to be achieved through design solutions as contrasted with the specification (prescriptive) approach which specifies the design solution to be adopted.

Some such early reports are those of the National Commission on Lrban Problems ${ }^{2}$ and various committee reports of the National Conference of States on Building Codes and Standards, Inc. (NCSBCS). These reports cited a need for a system which unleashes our innovative and entrepreneurial genius and whereby standards of performance, based upon objectives and scienific methon, are set by bodies with high reputation and prestige. As the performance concept becomes incorporated in building construction regulations, the full potential of expanded research in building technology can be made generally available; and (standards) must be performance-oriented to the extent practical and where current knowledge is inadequate as a basis for performance criteria, research must be undertaken.

One of the major dificulties impeding utilization of solar technolog: was said by its early users to be a lack of usable and reliable performance information from solar product manufacturers and also the absence oi a set of user requirements to define how solar buildings should perform. The early users also believed that the development and adoption of a set of industry-wide performance standards and tests would help to facilitate widespread utilization.

2 "Building the American City," U.S. National Commission on Urban Problems (Douglas Commission), December 1968. 
A study conducted by the AIA Research Corporation ${ }^{3}$ notes that there are few building codes which directly affect use of solar energy; however, the possibility exists that they may develop into a barrier--either by being too prescriptive or by establishment of performance requirements which cannot reasonably be met.

Although dealing with energy conservation generally, and not solar energy in particular, a report prepared by the National Bureau of Standards for the Federal Energy Administration ${ }^{4}$ states that further problems with enforcing the performance-based type of standards may develop because of difficulties in making objective judgments in the field. This report also cites a need for assistance in the area of product and equipment acceptance.

In referring to a report ${ }^{5}$ developed by ERDA (now incorporated into the Department of Energy), the Energy Research Digest cites "the absence of nationally-recognized performance criteria" as one of six barriers to the introduction of new products. This report criticizes prescriptive standards as "antithetical to the development of new and innovative products."

A study done by TRli Systems Group ${ }^{6}$ cited as a result of its analysis one conclusion to be that performance-oriented rather than prescriptive codes will be required in the solar energy area, but that no major technical

3 "Early l'se of Solar Energy in Buildings. A Study of Barriers and Incentives to Widespread Use of Solar Heating and Cooling Systems. Summary Report to the National Science Foundation", May 1976.

4 :BSIR 77-1259, "Building Energy Conservation Program--A Preliminary Examination of Regulatory Activities at the State Level," Robert M. Eisenhard and Patrick W. Cooke, June 1977.

5 Energy Research Digest, April 25, 1977, pp. 5-6.

6 "Solar Heating and Cooling of Building" (Phase 0), pp. 2-8, 2-9, 7-55, 7-56, 11-3, 11-4, TRW Systems Group, May 1974. 
obstacles are foreseen. It states that codes do not provide incentives or opportunities, and the infrastructure problems relating to building codes will have to be identified and overcome. It continued with, "As pressure is brought to bear on code-writing authorities to improve the semantics of model codes...the better chance there is for entry of solar energy systems into the building construction market."

Solar energy programs, projects and performance criteria may be the first phase--the initial occurrence--of the development and/or revision of building standards and codes toward a more performance-oriented system.

\section{BLILDING SIANDARDS AND CODES}

With the enactment of the Solar Demonstration Act came numerous studies relative to the use of solar energy as a feasible alternative to fossil fuels. The majority of these studies cite present building standards and codes as barriers to solar energy utilization. Articles published in newspapers, trade journals, etc., also cite codes as barriers to new technolog: in gentral, and solar technology in particular. Excerpts from four such articles are:

1. Contractor Magazine of June 1, 1977 , noted that early results from a New England solar project, which installed solar heating systems in 100 residences, pointed to problems resulting from a lack of standards for installing solar equipment anc from a lack of standards for design and manufacturer of such equipment.

2. The Christian Science Monitor of August 27, 1976, reports the tangle of building codes and real estate tax law's needs sorting out to encourage domestic solar energy.

3. The Washington Post of April 3, 1977, in an article relative to solar technology, states that obstacles remain--such as some 30,000 independent building code jurisdictions in the U.S., all of which have their own rules about what can and cannot be used in construction. 
4. In an article of the Engineering News-Record of February 24, 1977 , entitled "Simmering solar heating market awaits cost-effective products", building codes are cited as a significant barrier to widespread use (of solar energy).

Prior to actual selection of the HUD residential and DoE commercial demonstration sites, various studies of building standards, building codes, zoning laws, etc., were conducted so as to identify any obvious problems which may affect the demonstration programs.

A study conducted by the American Institute of Architects Research Corporation ${ }^{\prime}$ under a vational Science Foundation grant was partially based on the assumption that the importance of potential barriers to the widespread use of solar energy can only be fully understood over time as they clearly emerge.

A survey of some 3,000 architects, although inconclusive because of insufficient response, revealed that architects believe one of the most formidable barriers to the adoption of solar technologies in design is building code restrictions. In speaking on the subject of innovation, this study 8 states that very few innovations really offer substantial economic advantage to the building project as a whole, and rarely does the stated advantages of an innovation overcome the increased sense of risk associated with it.

The second volume of a May 1976 study $^{9}$, analyzing personal contacts of on-site visits and telephone inquiries made of over 900 persons in some

7 "Early l'se of Solar Energy in Buildings. A Study of Barriers and Incentives to Widespread Use of Solar Heating and Cooling Systems, Summary Report to the National Science Foundation", May 1976.

8 solar Heating and Cooling of Buildings, Phase 0 , "Feasibility and Planning Study" - Final Report, General Electric Company, Nay 1974.

9 "A Location Matrix Plan for the Residential Solar Heating and Cooling Demonstration Program," Arthur D. Little, Inc., May 1976. 
way connected with the building community, revealed that a model code is used by about $3 / 4$ of the metropolitan areas in the United States and the code issue would be insignificant if solar systems were designed to minimize code problems and are coupled with an effort to make modifications, where necessary. However, a few areas were found where specific local code provisions would impede installation and use of solar systems.

The study suggested that more problems are apt to materialize in congested urban areas than in rapid growth areas, which are more open to innuvative technologies.

Although some areas of existing codes might be interpreted as applicable to solar HVAC equipment, one study ${ }^{10}$ suggests that ERDA should encourage the model codt organizations to establish regulations relating to solar, separate from the actual model code documents. These separate regulations will provide clear-cut building construction requirements. It suggests that much of the confusion associated with interpreting and judging existing codes, probably will be eased by the addition of such regulations to the model codes.

Although a Federally-funded solar demonstration program is mandated by the "Solar Heating and Cooling Act of 1974," the Energy Research and Development Administration stressed that participation by state and local government is important as these groups will be involved in revising the building codes to accommodate innovative technologies. 11

10 "General Electric Company Survey to Define Import of Statewide Building Codes on Solar HVAC Systems", Commercial Buildings Space Division, General Electric Company, July 1976.

- 11 ERDA report to Congress and the President--A National Plan for Energy' Research Development and Demonstration, "Creating Energy Choices for the Future," pp. l'II-3, ERDA - 48, Volume 1 and 2, June 28, 1975. 
A report prepared under a National Science Foundation Grant ${ }^{12}$, summarizes that a significant fraction of the U.S. energy budget can be provided by solar energy and that to encourage use of solar energy requires investigation and revision, if necessary, of land use, zoning restrictions and building codes. It further states that "Freedom is essential for further advancement in the field of solar energy utilization."

It states that traditionally, new code provisions or interpretations develop as an outgrowth of reactions either to unfavorable events or fear of unfavorable events.

\section{CODES AND PRODLCT APPROYALS}

A very comprehensive study previously referenced ${ }^{8}$ revealed that in spite of the recent upsurge in interest in solar technologies because of the energy crisis, experience suggests that the rapid commercial development, introduction, and diffusion of solar technologies within the construction industry will not be a simple matter. It also suggests that to the extent that innovation is not compatible with laws and regulations, professional practices, building department approval processes, etc., barriers to its use will appear.

In a study ${ }^{13}$ dealing with a specific product for use in a solar energy system, the building industry is referred to as fragmented, and made up of groups, some of which encourages and some of which discourages innovation. The product is cited as an innovation in the building industry which must be introduced to and accepted by it.

12 "Solar Heated Residence Annual Research Report," (Colorado Springs, Colorado); pp. 91, 92, 147, 153, July 1975, James D. Phillips.

13 "Phase Zero - Goal Study for the Technical and Economic Evaluation of the Compound PARABOLIC Concentration Concept Applied to Solar, Thermal and Photovoltaic Conditions," Bechtel Corporation, June 1975, pp. 7-6, 1-3. 
One study 14 states that a lack of proper regulation also may present a barrier to acceptance of solar technology. However, it adds that present building codes themselves will not prohibit the installation of solar systems.

The first volume of a previously mentioned report ${ }^{9}$, prepared for HLD relative to the demonstration program, cites standards and code constraints. However, this report reflects the attitude that builder support can overcome many of the obvious constraints. Obstacles presented by zoning and code authorities are often cited as the most significant factor in resisting the introduction of new products--this report disagrees with these statements. In the economic area, the report states "If the economic performance of solar systems is favorable, there will be an incentive for potential participants in the industry, from manufacturer to consumer, to overcome whatever constraints may exist."

The following quote from reference ${ }^{9}$ sums up the issue of building codes as the barrier or the constraint to utilization of solar energy:

"If the (solar) systems, through product testing, meet established specifications, are proven through experience to be reliable, and are compatible with current regulations, and if procedure modifications are pursued, the constraints should not be significant."

14 Inter-Technology Corporation Proposed System Level Plan for Solar Heating and Cooling Commercial Building, National Solar Demonstration Program, rolum I, Nay 1976 . 
1. BACKGROLND

A building code is a legal document which sets forth requirements to protect the public health, safety and general welfare as related to the construction and occupancy of buildings and structures. The building code development process in the United States is quite complex. Building codes are normally enacted into law by local governments exercising the police power of the state delegated to them for this purpose. One consequence oI this is a considerable diversity of substantive provisions among the thousands of locally-enacted codes. This is true even though three-quarters of locally-enacted codes are based on one of the nationally recognized model codes. Possible reasons for this diversity are:

local governments frequently alter provisions of the model codes;

local codes are infrequently updated;

the model codes are not uniform; and, some municipalities write their own codes.

Except for some of the largest cities, drafting of building codes in the Lnited States is accomplished by the model code organizations and allied groups.

The first model building code was published in 1905 by the National Board of Fire Underwriters (now the American Insurance Association - AInA) to guide municipalities concerned with reducing the fire hazard in and about buildings. This is now known as the National Building Code, which is drafted by engineers of AInA with assistance from many sources.

The first model code prepared by building officials was the Uniform Building Code developed in 1927 by the Pacific Coast Building Officials (now ICBO). This Code is currently used extensively on the west coast and in the Central Midwest. The Southern Building Code Congress International, Inc., recognizing the unique problem affecting construction in the South, prepared the Standard Building Code in 1945. This is the dominant building 
code in the Southern States. The Basic Building Code was first published in 1950 by the Building Officials and Code Administrators International, Inc. and is extensively used in the Upper Midwest, New England and the Middle Atlantic States.

BOCA, ICBO and SBCC consider annual code revisions and publish completely new code editions every three years. Generally, this allows the model codes to be up-to-date and permits the use of most new materials and new techniques in building construction. Two other important functions provided by these model code organizations are those of plan review and product approval. Product approval allow's a manufacturer to get a single approval, which can generally apply in all locations where the model code is used.

\section{BLILDING CODES AT STATE AND LOCAL LEVEIS}

Within the past several years, many states have assumed more active roles in writing, promulgating and enforcing building codes. A growing minority of states have withdrawn virtually all authority to enact building codes from their respective municipalities. They exercise their building code authority in various ways. Some states have mandatory statewide codes, but in several states their adoption by localities is voluntar: . The application of the codes also varies since they may include minimum requirements only or may include both maximum and minimum requirements. When a statewide minimum code is provided, the locality is free to adopt stricter requirements; however, for the minimum/maximum type, the locality must secure state approval of its proposed change on the basis of some unusual condition or special need.

Statewide code enforcement is usually delegated to the local authority with some supervision, training and assistance frum the state. Within single municipalities, the authority to enforce codes may be fragmented among different departments without coordinated supervision. These considerations cause quite a variation among localities in the interpretation of similar code requirements. 
NBS.114A (REV. (1.77)

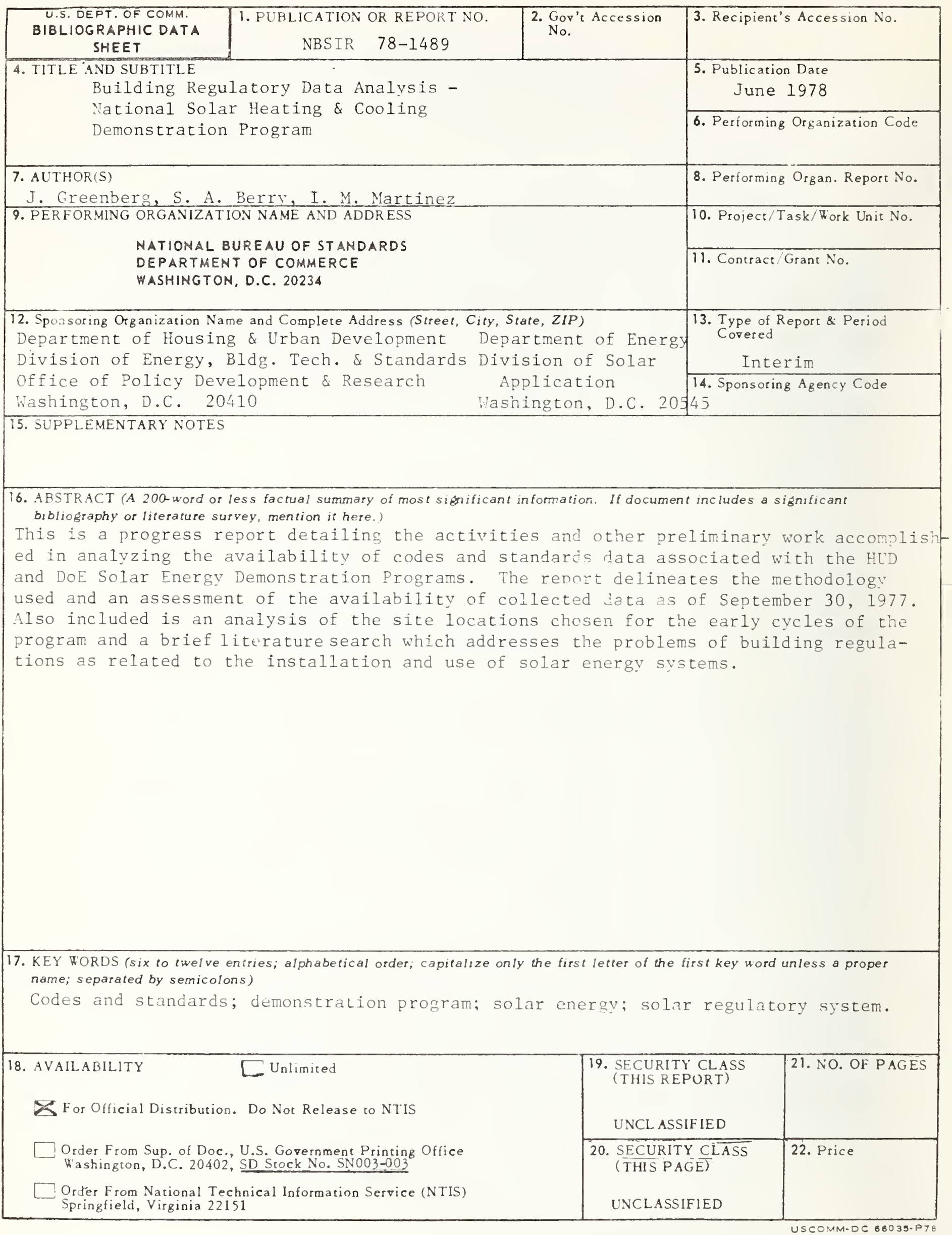


